Review Article

\title{
SAR and Computer-Aided Drug Design Approaches in the Discovery of Peroxisome Proliferator-Activated Receptor $\gamma$ Activators: A Perspective
}

\author{
Vaibhav A. Dixit and Prasad V. Bharatam \\ Department of Medicinal Chemistry, National Institute of Pharmaceutical Education and Research (NIPER), \\ S. A. S. Nagar, Punjab 160062, India \\ Correspondence should be addressed to Prasad V. Bharatam; pvbharatam@niper.ac.in
}

Received 28 November 2012; Accepted 28 January 2013

Academic Editor: Michele Migliore

Copyright (C) 2013 V. A. Dixit and P. V. Bharatam. This is an open access article distributed under the Creative Commons Attribution License, which permits unrestricted use, distribution, and reproduction in any medium, provided the original work is properly cited.

\begin{abstract}
Activators of PPAR $\gamma$, Troglitazone (TGZ), Rosiglitazone (RGZ), and Pioglitazone (PGZ) were introduced for treatment of Type 2 diabetes, but TGZ and RGZ have been withdrawn from the market along with other promising leads due cardiovascular side effects and hepatotoxicity. However, the continuously improving understanding of the structure/function of PPAR $\gamma$ and its interactions with potential ligands maintain the importance of PPAR $\gamma$ as an antidiabetic target. Extensive structure activity relationship (SAR) studies have thus been performed on a variety of structural scaffolds by various research groups. Computer-aided drug discovery (CADD) approaches have also played a vital role in the search and optimization of potential lead compounds. This paper focuses on these approaches adopted for the discovery of PPAR $\gamma$ ligands for the treatment of Type 2 diabetes. Key concepts employed during the discovery phase, classification based on agonistic character, applications of various QSAR, pharmacophore mapping, virtual screening, molecular docking, and molecular dynamics studies are highlighted. Molecular level analysis of the dynamic nature of ligand-receptor interaction is presented for the future design of ligands with better potency and safety profiles. Recently identified mechanism of inhibition of phosphorylation of PPAR $\gamma$ at SER273 by ligands is reviewed as a new strategy to identify novel drug candidates.
\end{abstract}

\section{Introduction to Diabetes}

Diabetes is a metabolic disorder caused mainly by insulin resistance and obesity. It is now recognized as a major health problem worldwide and affects adults of working age in developing countries. WHO estimates of global prevalence are expected to increase from 171 million in 2000 to 366 million in 2030 , and $21.7 \%$ (i.e., $~ 8$ crores) of these will be Indians [1]. The chronic nature of this disease leads to metabolic complications like kidney failure and cardiac problems. Early diagnosis and controlled diet combined with physical exercise of just thirty minutes have been shown to provide control in the progression of the disease.

Increasing technological advancements and decreasing proportion of physical activities in routine life are promoting sedentary lifestyle. Thus pharmacological intervention may remain the only choice in certain group of subjects. In addition lack of proper treatment and delayed diagnosis are the two major reasons for the increased economic burden and prevalence of diabetes in the developing countries.

Diabetes is generally classified into three classes: (1) Type 1-caused by complete lack of insulin production, (2) Type 2 -due to insulin resistance and ineffective downstream signaling in the cell, and (3) gestational diabetes-affects $4 \%$ of all pregnant women and is rarely fatal. Almost $90 \%$ of all cases of diabetes are Type 2 class. All these facts and figures have forced most of the governments and scientists world over to look for effective therapies, resulting in a mammoth of efforts in the discovery and development of novel drug candidates.

These efforts have been based on a variety of drug targets and have led to introduction of a few drugs in the market. These drugs and their targets are briefly mentioned in 
TABLE 1: Current treatment against Type 2 diabetes mellitus.*

\begin{tabular}{|c|c|c|c|}
\hline Compounds & Examples & Mechanism & Adverse effects \\
\hline $\begin{array}{l}\text { Secretagogues (sulfonylureas, } \\
\text { nonsulfonylureas) }\end{array}$ & Glibenclamide, meglitinide & Increase of insulin secretion & $\begin{array}{l}\text { Hypoglycaemia, } \\
\text { hyperinsulinaemia, weight gain, } \\
\text { and vomiting }\end{array}$ \\
\hline Biguanides & Metformin & $\begin{array}{l}\text { Decrease of hepatic } \\
\text { glucose output }\end{array}$ & $\begin{array}{l}\text { Diarrhoea, vomiting, and lactic } \\
\text { acidosis }\end{array}$ \\
\hline$\alpha$-Glucosidase inhibitors & Acarbose miglitol, voglibose & $\begin{array}{l}\text { Inhibition of carbohydrate } \\
\text { absorption }\end{array}$ & $\begin{array}{l}\text { Flatulence, diarrhoea, and } \\
\text { abdominal pain }\end{array}$ \\
\hline GLP1, GIP, and DPP IV & $\begin{array}{l}\text { Exenatide, LAF-237 } \\
\text { Liraglutide, CJ-1131, }\end{array}$ & $\begin{array}{l}\text { Incretin effect improvement of } \\
\beta \text {-cell function }\end{array}$ & Vomiting, nausea \\
\hline Thiazolidinediones & Pioglitazone, and Rosiglitazone & PPAR $\gamma$ activation & Weight gain, oedema \\
\hline
\end{tabular}

${ }^{*}$ Modified from [2].

Section 2. The focus of this paper is to highlight the major SAR and CADD studies performed on PPAR $\gamma$. Readers interested in other targets are suggested to consult some of the excellent recent and older reviews published on these topics [3-5]. A brief literature search shows that a large amount of work has been done for the identification and testing of novel scaffolds for antidiabetic drug discovery in the PPAR arena. A review on PPAR $\gamma$ ligands was published with focus on dual, pan, and SPPARMs based strategy in 2008 [6]. As discussed in the Section 3.2 a large number of crystal structure have been published for PPAR $\gamma$-ligand complexes, but a thorough understanding about the links between receptor-ligand interactions and antidiabetic benefits is far from complete. Thus an expert perspective and overall assessment of these efforts are urgently required to give proper direction to these attempts.

This paper begins with a brief introduction to current therapies for Type 2 diabetes followed by PPAR $\gamma$ localization, structure, and its ligands (natural and synthetic). This is followed by a brief classification of the ligands based on their agonistic character. Next, in an attempt to fill the gaps in the understanding of structure and function of PPAR $\gamma$ and its ligands, this review is divided into sections on (i) SAR studies performed in the past twelve years. An attempt has been made to present these studies in the chronological order, but some exceptions are allowed to maintain connectivity between selected studies. Majority of these studies involved classical medicinal chemistry approach to build SAR that is to modify the substituents on a structural scaffold using mostly biochemical intuition till the desired activity/affinity is observed. (ii) Rational drug design approaches using computational methods are then discussed. In this section also a chronological order has been followed, with some exceptions, and QSAR (2D, 3D, and higher-dimensional methods), pharmacophore mapping, molecular docking, and structure-based, ligand based, and de novo drug design approaches employed are discussed.

Despite the large number of SAR and CADD studies reported on PPAR $\gamma$ agonists, none of the molecules has made it to the clinic after the introduction of TZDs. Incomplete understanding of the dynamical nature of PPAR $\gamma$-ligand interactions and translation of these interactions into physiological response could be one of the major reasons for this failure. Molecular dynamics simulation studies coupled with other experimental techniques that have been utilized by some groups to bridge these gaps are discussed briefly. Role of recently identified implications of phosphorylation of $\operatorname{PPAR} \gamma$ residues and resulting nonagonistic/partial agonistic character of novel ligands is highlighted in the last section.

\section{Current Treatment Options for Type 2 Diabetes}

The cause of insulin resistance has been traced to defects in insulin receptor (IR) function, IR-signal transduction, glucose transport and phosphorylation, glycogen synthesis, glucose oxidation, and dysregulation of fatty acid metabolism [7]. Consequently these defects are targets of current pharmacological treatments as well as potential sites for new therapies.

Figure 1 shows the structures of currently marketed and a few withdrawn drugs which form the existing armor against Type 2 diabetes (see also Table 1). The biguanides, like metformin, reduce the hepatic glucose production and also enhance muscle insulin sensitivity. Acarbose decreases gastrointestinal absorption of carbohydrates by inhibiting $\alpha$ glucosidase. The sulfonylureas bind to specific receptors on the $\beta$ cells of pancreas resulting in inhibition of $\mathrm{K}^{+}$channels leading to depolarization of cell membrane followed by exocytosis of insulin. The dipeptidyl peptidase IV inhibitors exert their antidiabetic effects by inhibiting the metabolism of glucagon-like peptide-1 (GLP-1). GLP-1 mediates its effects through transmembrane GPC receptors leading to increased insulin secretion in response to feeding. It has also been shown to enhance the differentiation, survival, and maturation of the $\beta$ cells [8]. This has encouraged the development of GLP-1 analogs, also known as incretin mimetics, like exenatide, a 39-amino acid peptide with glucoregulatory properties.

Most of the above-mentioned drug molecules act as direct or indirect insulin secretagogues of moderate to low potencies. The major cause of Type 2 diabetes, a generalized insulin resistance in the body, is actually not addressed by these lines of therapy. Thiazolidinediones (TZD) were identified in 1995 to exert their antidiabetic actions by binding to PPAR $\gamma$ with high affinity [9]. This is the only class of molecules that decrease generalized insulin resistance in tissues like muscle 
<smiles>Cc1c(C)c2c(c(C)c1O)CCC(C)(COc1ccc(CC3SC(=O)NC3=O)cc1)O2</smiles>

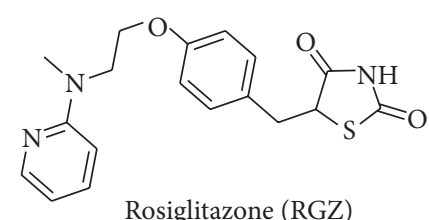
Withdrawn

Rosiglitazone (RGZ)<smiles>CCc1ccc(CCOc2ccc(CC3SC(=O)NC3=O)cc2)nc1</smiles>

Pioglitazone (PGZ)

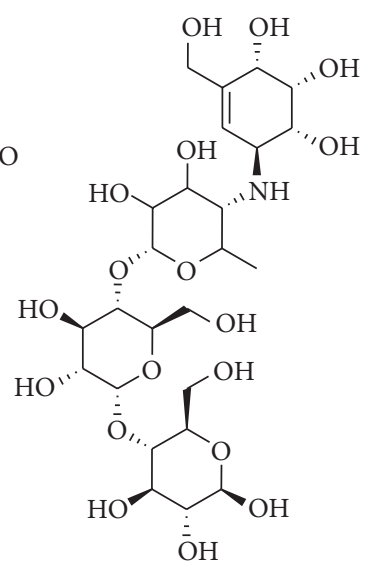

$\alpha$-glucosidase inhibitor
Sulfonylureas<smiles>CCCCNC(=O)NS(=O)(=O)c1ccc(C)cc1</smiles><smiles>CCC1=C(C)CN(C(=O)NCCc2ccc(S(=O)(=O)NC(=O)NC3CCC(C)CC3)cc2)C1=O</smiles><smiles>COc1ccc(Cl)cc1C(=O)NCCc1ccc(S(=O)(=O)NC(=O)NC2CCCCC2)cc1</smiles>

Dipeptidyl peptidase IV inhibitors<smiles>Cn1c(=O)cc(N2CCC[C@@H](N)C2)n(Cc2ccccc2C#N)c1=O</smiles>

Alogliptin

NDA submitted<smiles>C/C=C\CC(N)CC</smiles>

Vildagliptin

Approved in EU<smiles>C#C[C@H]1CCCN1C(=O)CNC1CC2CCC1C2O</smiles><smiles>Cc1cnc(C(=O)NCCc2ccc(S(=O)(=O)NC(=O)NC3CCCCC3)cc2)cn1</smiles>

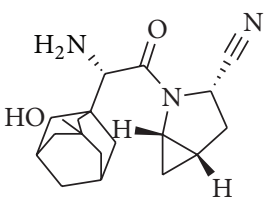

Saxagliptin Linagliptin phase III

phase III<smiles>N[C@@H](CC(=O)N1CCn2c(nnc2C(F)(F)F)C1)Cc1cc(F)c(F)cc1F</smiles>

GLP-1 Analog

H-His-Gly-Glu-Gly-Thr-Phe-Thr-Ser-Asp-Leu-Ser-Lys-GlnMet-Glu-Glu-Glu-Ala-Val-Arg-Leu-Phe-Ile-Glu-Trp-Leu-LysAsn-Gly-Gly-Pro-Ser-Ser-Gly-Ala-Pro-Pro-Pro-Ser-NH ${ }_{2}$ Exenatide Amylin Pharmaceuticals and Eli Lilly

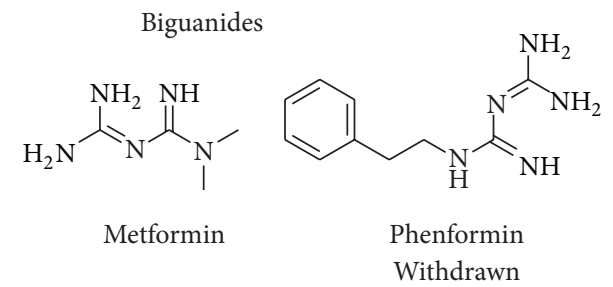

FIgURE 1: Currently marketed and a few withdrawn antidiabetic drugs. 
and adipose. Rosiglitazone (RGZ, Avandia) and Pioglitazone (PGZ, Actos) are the two most widely used drugs in the treatment of diabetes. Troglitazone (TGZ, Rezulin) was also in the market since 1997, until hepatotoxicity forced its withdrawal in 2000 [10,11]. TZDs are potent agonists of the peroxisome proliferator-activated receptor $\gamma(\operatorname{PPAR} \gamma)$, a ligand-activated transcription factor thought to be a master regulator of adipocyte differentiation and multiple adipocyte genes. AcylCoA synthase/oxidase, Apolipoprotein A/C, CPTI (carnitine palmitoyl transferase I), CYP4A1/P450 IV family, lipoprotein lipase, mitochondrial 3-hydroxy-3-methylglutaryl-CoA synthase, phosphoenolpyruvate carboxykinase (PEPCK), uncoupling protein 1 , and so forth are a few target proteins of PPAR $\gamma$ activation indicating its important role in carbohydrate and lipid metabolism. In addition to this, there is a complex feedback mechanism between the adipose tissue and insulin sensitivity. Adiponectin, a peptide hormone secreted by the adipocytes during differentiation, has been shown to decrease insulin resistance [12]. Although TZDs have been observed to increase the expression of adiponectin, it is not clear whether this is a direct result of PPAR activation or is caused by secondary effects.

\section{Peroxisome Proliferator-Activated Receptor $\gamma($ PPAR $\gamma)$}

3.1. PPAR Location and Organization. Peroxisome proliferator-activated receptors (PPARs) belong to a super family of nuclear receptors. Phylogenetic studies suggest that the ancestral genes associated with PPAR might have appeared more than 500 million years ago during the eukaryotic evolution [13]. They are present in the cytoplasm as monomers, but upon activation by the ligand they heterodimerize with retinoid $\mathrm{X}$ receptor $\alpha(\mathrm{RXR} \alpha)$ and enter the nucleus to regulate transcription of a wide variety of receptors and enzymes. Three isotypes (PPAR $\alpha, \gamma$, and $\beta / \delta$ ) have been identified, and the human-PPAR $\gamma($ hPPAR $\gamma$ ) has been located on chromosome 3 at position $3 \mathrm{p} 25$ close to retinoid $\mathrm{X}$ receptor $\beta$ $(\operatorname{RXR} \beta)$ and Thyroid hormone receptor $\beta(\operatorname{TR} \beta)$ [14], while $\operatorname{PPAR} \alpha$ and PPAR $\beta / \delta$ have been assigned to chromosomes 22 and 6, respectively. For hPPAR $\gamma$ three isoforms have been identified (PPAR $\gamma 1, \operatorname{PPAR} \gamma 2$, and PPAR $\gamma 3$ ) based on the differential use of three promoters and alternative splicing of the three $5^{\prime}$-exons $\mathrm{A} 1, \mathrm{~A} 2$, and $\mathrm{B} 1$ [15]. Amino acid sequences and various regions in the receptor are depicted in Figure 2.

In PPARs two main functional domains have been identified, namely, (i) DNA-binding domain (DBD) and (ii) ligand-binding domain (LBD). The DNA-binding domain is the hallmark of nuclear receptor superfamily and is formed by highly conserved two zinc finger-like motifs folded in a tertiary structure that can recognize DNA target sequences of six nucleotides. It is specific for direct repeat of two core recognition motifs, AGGTCA, spaced by one nucleotide hence called DR1. These nucleotide sequences are also known as PPAR response elements (PPREs). For CYP4A6 an extended consensus sequence for PPRE has been identified ( $5^{\prime}$-AACTAGGNCAAAGGTCA-3'). These distinguishing features of PPRE contribute to PPAR-RXR heterodimer specificity and differential regulation of transcription.
3.2. PPAR 3 3D Structure. PPAR $\gamma$ consists of $13 \alpha$ helices and four $\beta$-sheets. The overall structure is very similar to other nuclear receptors from helix $\mathrm{H}-3$ to $\mathrm{C}$ terminus and has one extra small helix $\mathrm{H}-2^{\prime}$. Helices $\mathrm{H}-3, \mathrm{H}-7, \mathrm{H}-10$, and $\mathrm{H}-12$ along with the $\beta$-sheets arranged in antiparallel orientation constitute a large-ligand binding pocket of this nuclear receptor (Figure 3) [16]. In the crystal structure with PDB code: 2PRG, the RGZ molecule is found to straddle helix $\mathrm{H}-3$ and interacts with four residues SER289, HIS323, HIS449, and TYR473 strongly. This set of interactions is generally considered as the molecular recognition interaction, and any ligand showing this set of interactions is considered as an effective agonist (though many exceptions are found). RGZ takes a U shape in this Y-shaped active site (Figure 3). Table 2 shows active site shapes and volumes of some representative cocrystal structures of important ligands with PPAR $\gamma$. A search in the PDB database retrieved a large number of crystal structures (112) for $\operatorname{PPAR} \gamma$, (13) for $\operatorname{PPAR} \alpha$, and (22) for $\operatorname{PPAR} \beta / \delta$ (search performed on 23/11/2012). PDB codes, resolution of the crystal structures, and citation are shown in Table 3. In most of the crystal structures, agonists are bound with the LBD of PPAR $\gamma$. A closer inspection and analysis of the crystal structures reveal that the active site shape and important interactions in the active site are similar for most of the agonists. The active site consists of Y-shaped binding pocket, in which the acidic head groups of the ligands interact with the H-12 helix by forming hydrogen-bonding interactions with HIS323, HIS449, and TYR473 amino acid residues.

Figure 4 shows the general pharmacophoric features present in PPAR $\gamma$ agonists as exemplified for RGZ. In Figure 5(a) RGZ is seen to bind in a $U$ shape in the Y-shaped active site by forming strong hydrogen-bonding interactions with mainly polar residues (PDB code: $2 \mathrm{PRG}$ ). The other two arms of the active site are relatively nonpolar consisting of mainly hydrophobic residues. Induced fit conformational changes in the active site shape have also been seen to accommodate larger ligands like Farglitazar leading to the formation of additional subpocket in the active site giving it an almost $\mu$ shape (PDB code: 1FM9, see Figure 5(e)). Partial agonists can bind near the H-12 helix (e.g., clofibric acid analogue, Figure 5(f)) or near the $\beta$-sheet region (e.g., BVT.13, Figure 5(g)). Endogenous ligand 15d-PGJ2 takes an almost $\mathrm{Y}$ shape in the active site of PPAR $\gamma$ (PDB code: 2ZVT, 2ZK1, and 2ZK2), thus highlighting the importance of the interactions in all the three arms of the receptor for physiological response.

Three 3D structures of DNA-RXR $\alpha$-PPAR $\gamma$ tertiary complex were reported by Chandra et al. in 2008 [19]. The DBD and LBD of PPAR $\gamma$ have overall topology similar to those reported in other monomer and dimer crystal structures of PPAR $\gamma$. Structures of terminal helices known to bind to the DNA were clearly seen in these heterodimer structures. Analysis of LBD of PPAR $\gamma$ in this heterodimer shows that it interacts with the PPRE more closely than RXR $\alpha$. PPAR $\gamma$ resides upstream of RXR $\alpha$ giving a polar arrangement of these nuclear receptors on the PPRE. Helices H-7, H-9, and $\mathrm{H}-10$ of each receptor form DNA-dependent contacts and 


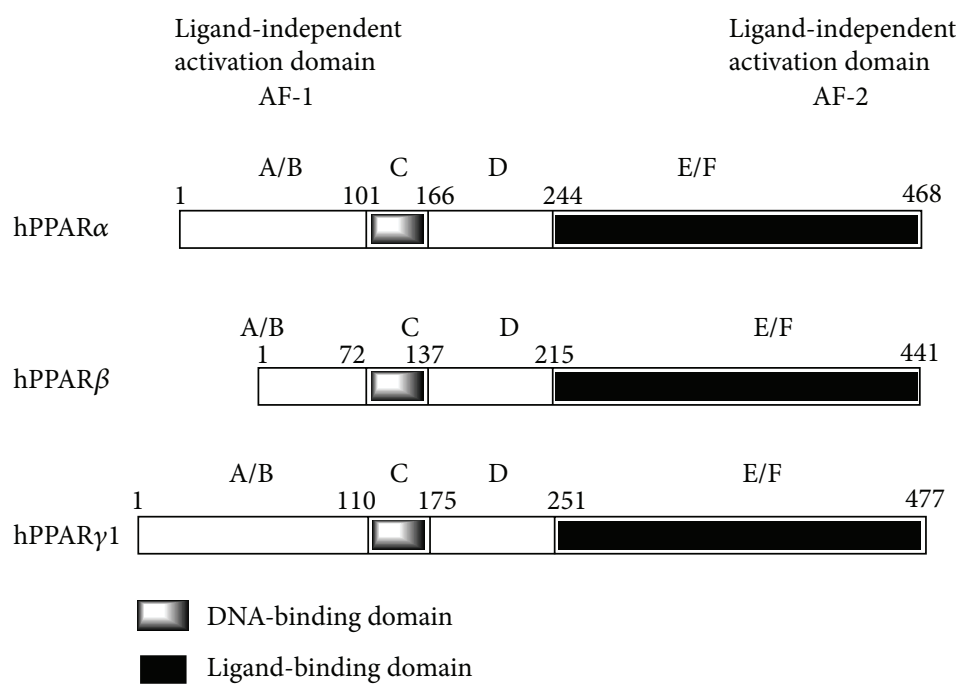

FIGURE 2: Functional domains of the PPAR family are represented schematically. Ligand-dependent activation domain (AF-1) consists of domains A/B, DNA-binding domain (C), and domain D. Ligand-dependent activation function (AF-2) consists of domains E/F and forms the ligand binding site with important molecular recognition interactions in the receptor. hPPAR $\gamma 1$ is the largest isoform (477 AAs). (Modified from [15]).

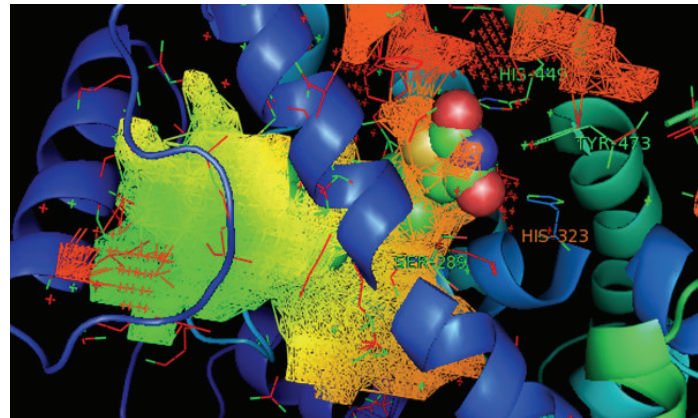

FIGURE 3: Rosiglitazone (RGZ) takes U shape in the Y-shaped active site of PPAR $\gamma$ (PDB code: $2 \mathrm{PRG}$ ). The TZD ring forms hydrogenbonding interactions with HIS323, HIS449, and TYR473 in the active site. Figure is generated using LigSite [17] and PyMol [18].

TABLE 2: Active site shape and volume for PPAR $\gamma$ agonists (see Figure 5).

\begin{tabular}{lccc}
\hline PDB & Ligand & $\begin{array}{c}\text { Active site } \\
\text { shape }\end{array}$ & $\begin{array}{c}\text { Active site } \\
\text { volume }\end{array}$ \\
\hline 2PRG & RGZ (A) & Y & $1703 \AA^{3}$ \\
2PRG & PGZ (B) & Y & $1703 \AA^{3}$ \\
2PRG & Barbituric acid analogue (C) & Y & $1703 \AA^{3}$ \\
2Q59 & MRL20 (D) & L & $1407 \AA^{3}$ \\
1FM9 & Farglitazar (E) & $\mu$ & $1815 \AA^{3}$ \\
3CDP & Clofibric acid analogue (F) & $\mu$ & $1598 \AA^{3}$ \\
2Q5P & MRL24 (G) & L & $1218 \AA^{3}$ \\
2Q6S & BVT.13 (H) & L & $1568 \AA^{3}$ \\
\hline
\end{tabular}

lead to DBD (PPAR $\gamma)$-DBD $(\mathrm{RXR} \alpha)$ interaction of approximately 2,160 $\AA^{2}$ solvent accessible surface area (Figure 6). The structure shows that PPAR $\gamma$ LBD interacts with DBD and
LBD of the RXR $\alpha$ and DNA. Three well understood ligands Rosiglitazone (RGZ), GW9662, and BVT.13 gave rise to a "Yshaped" pocket. This suggests that Y-shaped ligands may fit better in the active site with higher affinity.

\subsection{PPAR $\gamma$ Ligands}

3.3.1. Natural (Endogenous) Ligands. Polyunsaturated fatty acids like linolenic acid, eicosapentaenoic acid, 9-hydroxy10,12-octadecadienoic acid (9-HODE), 13-hydroxy-9,11octadecadienoic acid (13-HODE), and 15-deoxy- $\Delta^{12,14}$ prostaglandin J2 (15d-PGJ2) are important endogenous ligands of PPAR $\gamma$ (Figure 7). They bind with lower $\left(K_{\mathrm{D}} \sim\right.$ $2-50 \mu \mathrm{M})$ affinity to $\operatorname{PPAR} \gamma$. Through interaction with these fatty acids, PPAR $\gamma$ is thought to monitor the lipid concentrations and maintain homeostasis in the cytoplasm. The oxidized forms of prostaglandins induce adipocyte differentiation at low micromolar levels.

3.3.2. Synthetic Ligands. Since the discovery of Ciglitazone (CGZ), as effective insulin-sensitizing agent by Shoda et al., [20] many synthetic ligands of PPAR $\gamma$ have been identified. They have shown a wide variety of activation profiles based on receptor-binding affinity and transactivation assays. Thus, based on the dose-response curves they cac acid analogues, BVT.13 and MRL24, and so forth, (iii) dual PPAR $\gamma / \alpha$ agonists, (iv) selective PPAR $\gamma$ modulators (SPPARMs), and the least studied (v) antagonists. A recent review has reported classification based on the agonistic activity as well as chemical group [21]. The classification based on agonistic activity is more useful for understanding the activity profiles and resulting antidiabetic effects and hence is given in the following.

Full Agonists. Full agonists like RGZ, PGZ, TGZ, and MRL20 lead to complete activation of PPAR $\gamma$ as shown by doseresponse curves generated using transactivation assays. 


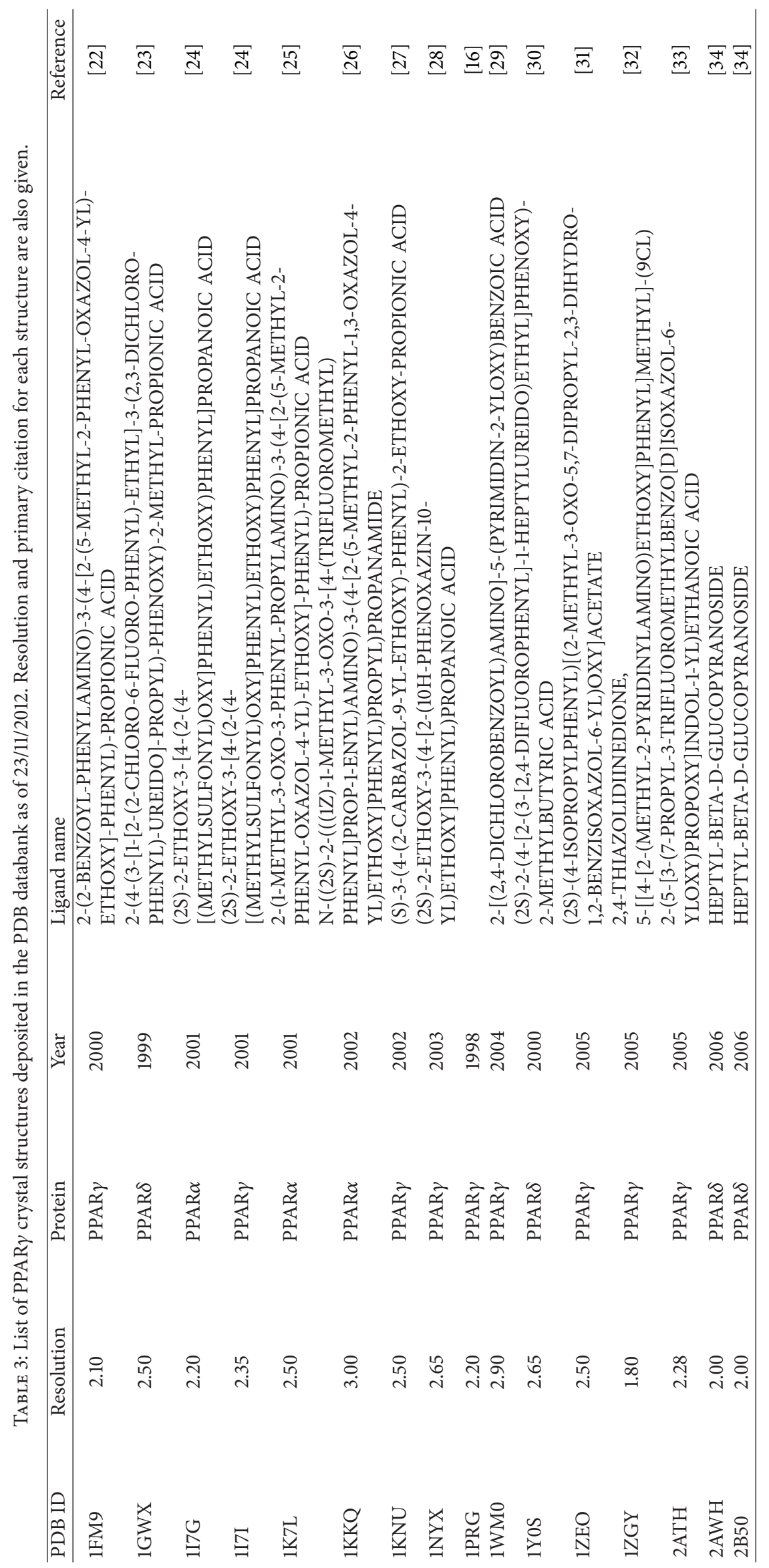




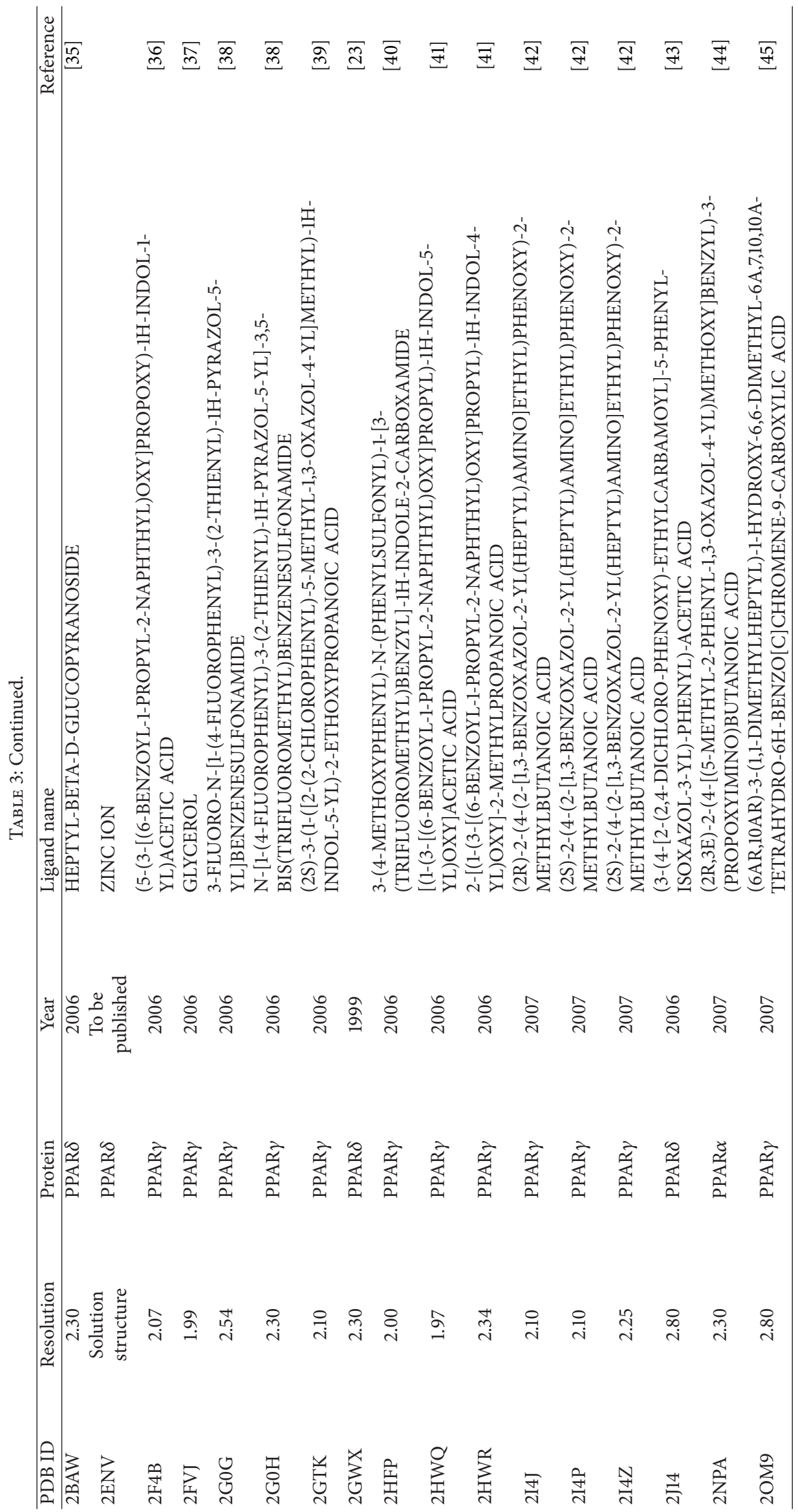




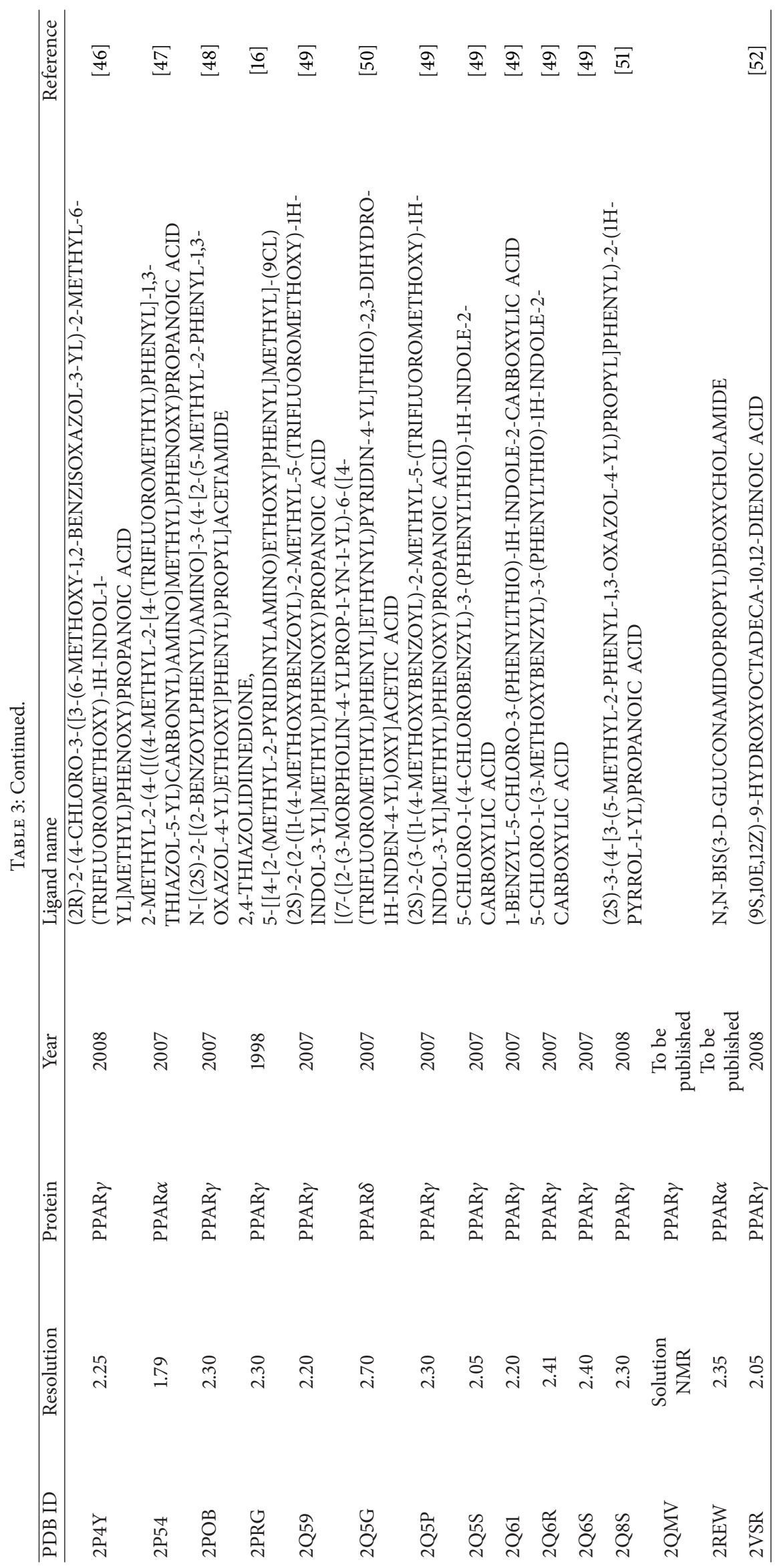




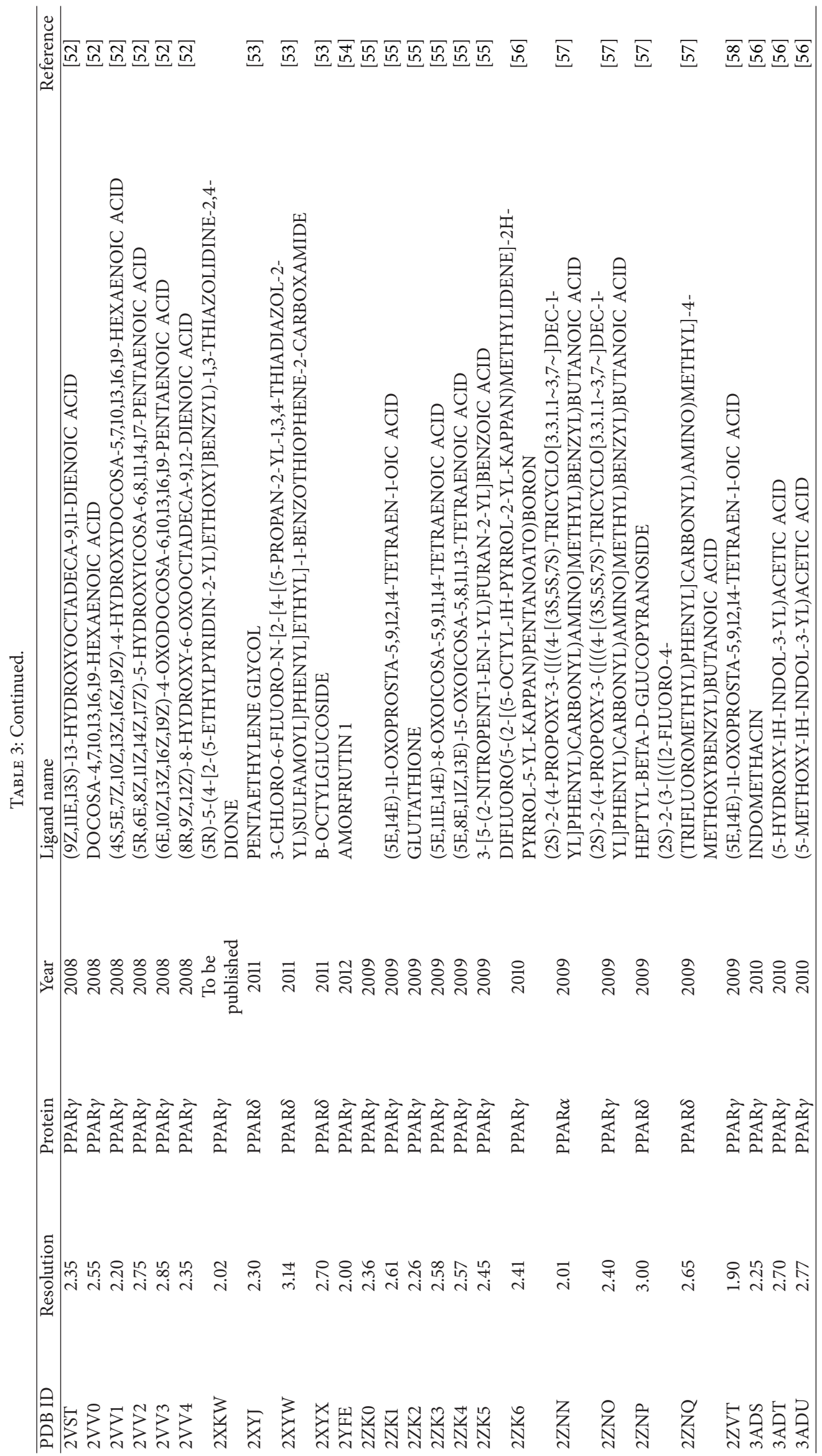




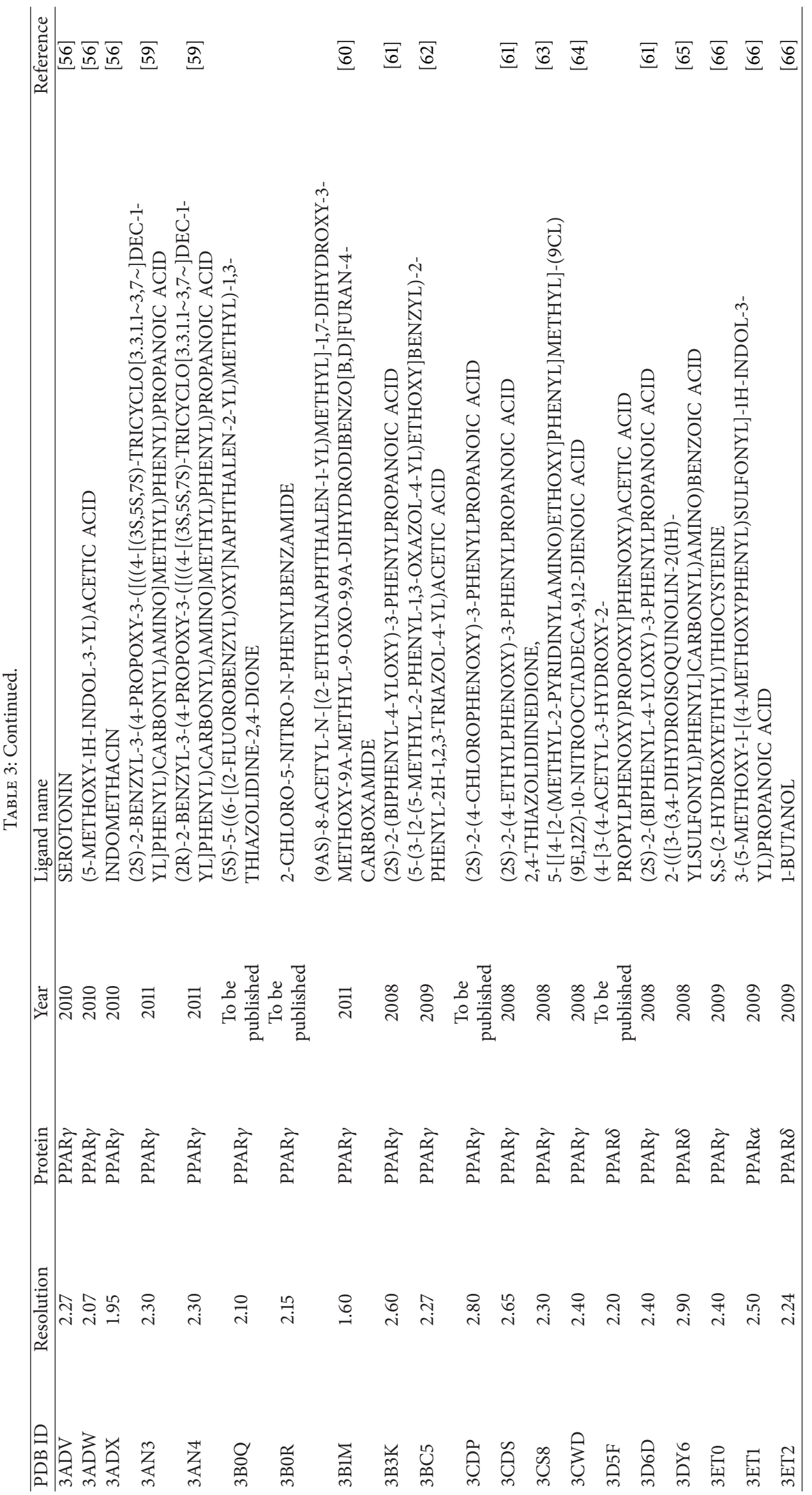




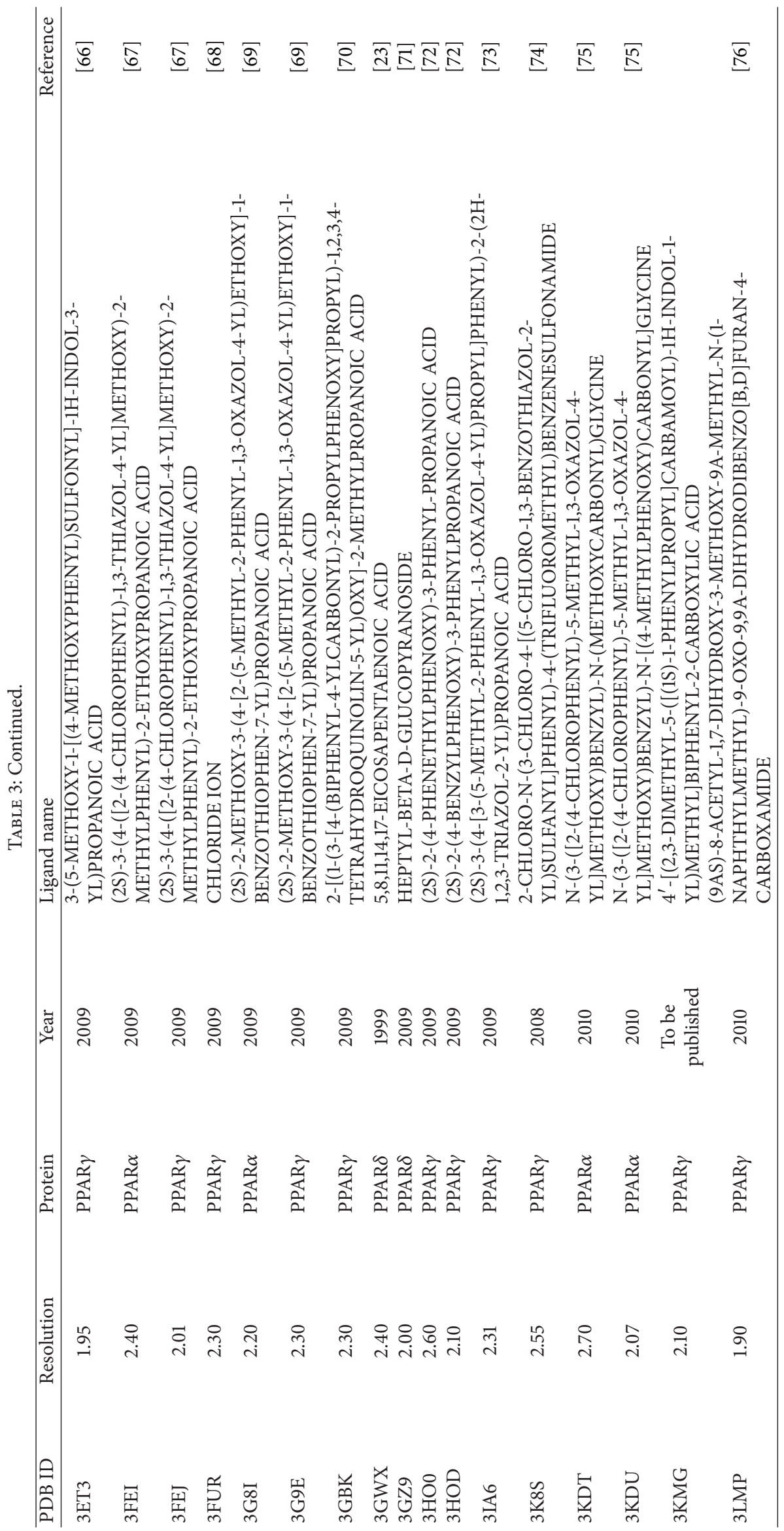




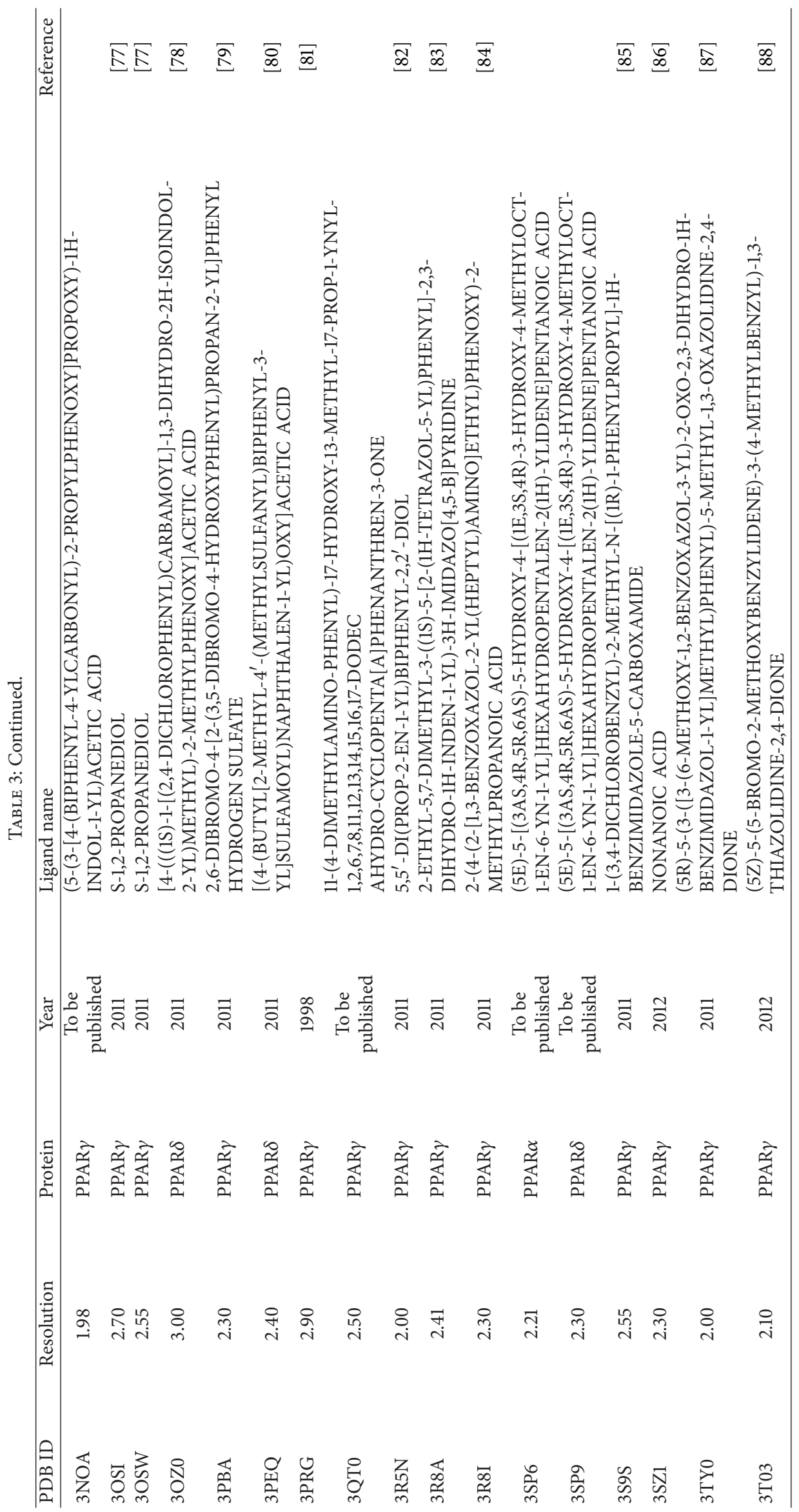




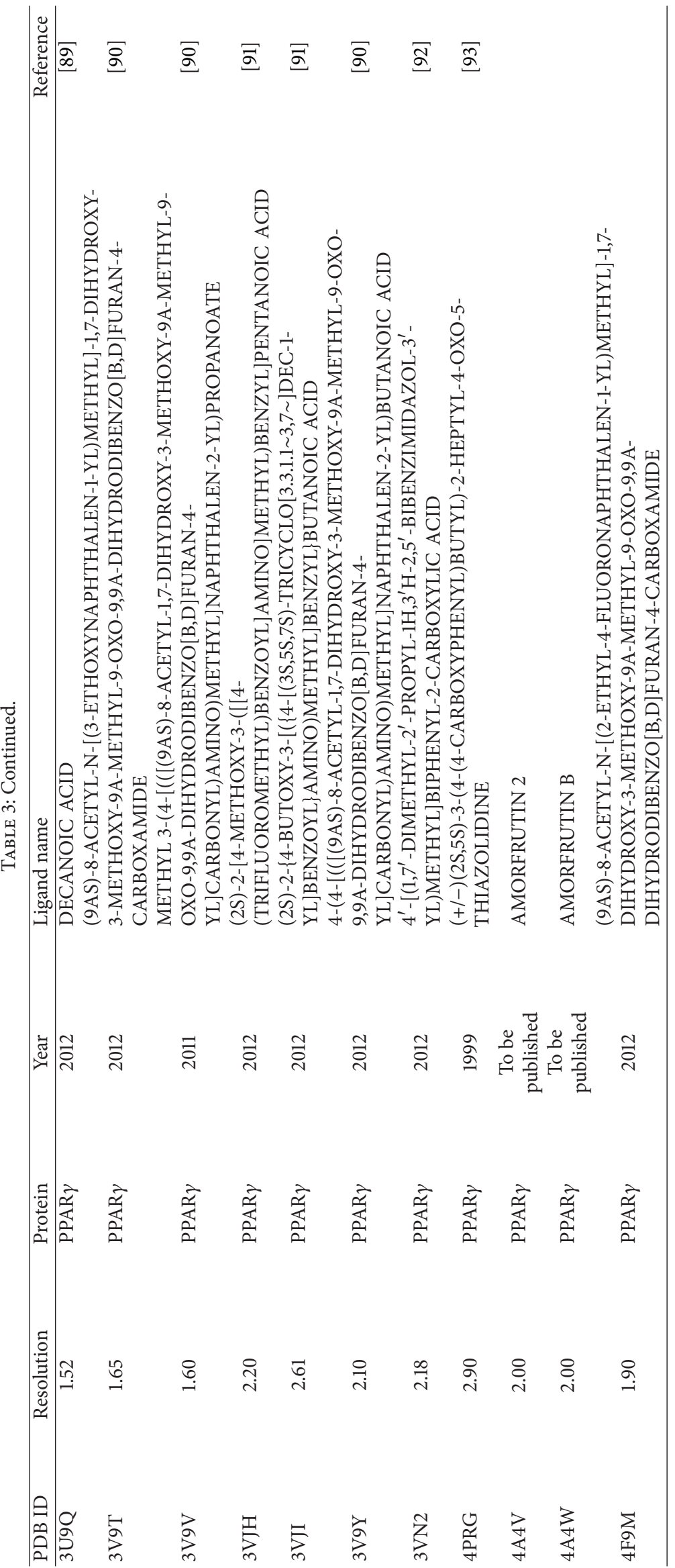




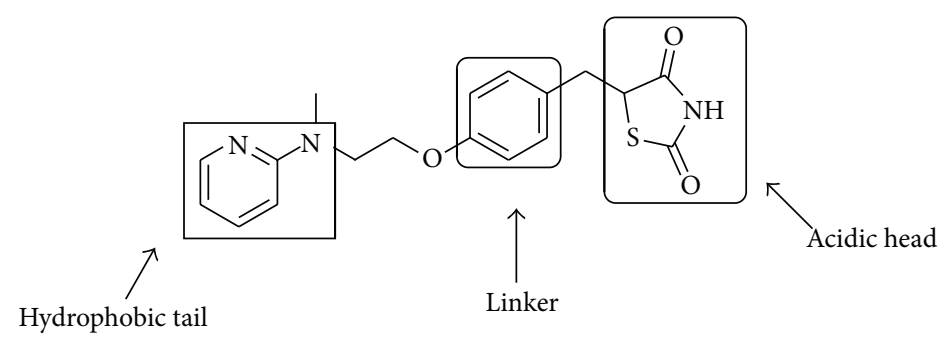

FIGURE 4: Pharmacophoric features in a PPAR $\gamma$ agonist Rosiglitazone (RGZ).

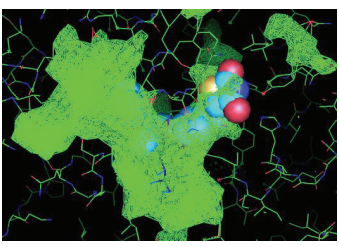

(a)

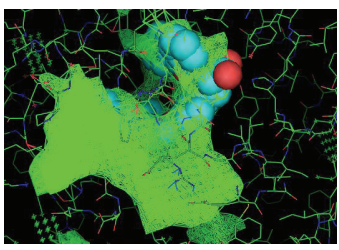

(e)

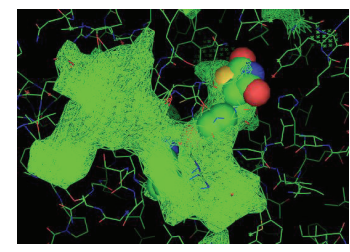

(b)

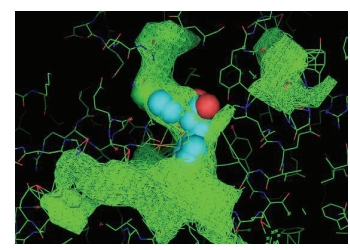

(f)

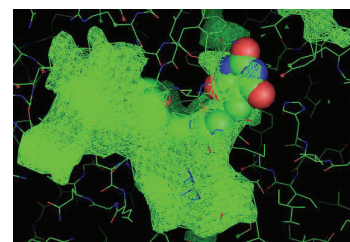

(c)

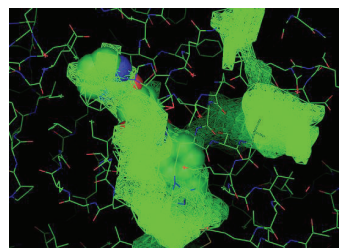

(g)

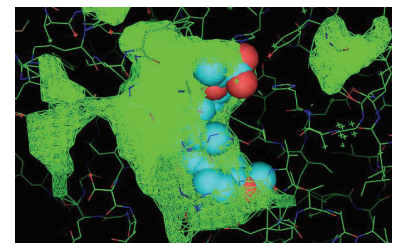

(d)

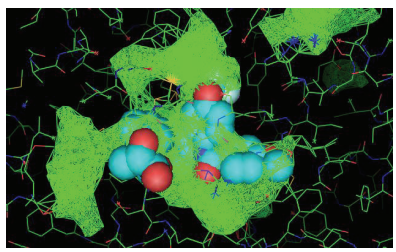

(h)

FIGURE 5: Active site shape and volumes occupied by PPAR $\gamma$ ligands. First row shows PPAR $\gamma$ full agonists: RGZ (a), PGZ (b), Barbituric acid derivative (c), and moderate agonist MRL20 (d). Second row shows PPAR $\gamma$ partial agonists: Farglitazar (e), clofibric acid analogue (f), BVT.13 (g), and MRL24 (h). Docked poses were used for active site analysis for PGZ and barbituric acid analogue. Calculations were performed using PocketFinder which is a modification of LigSite [17].

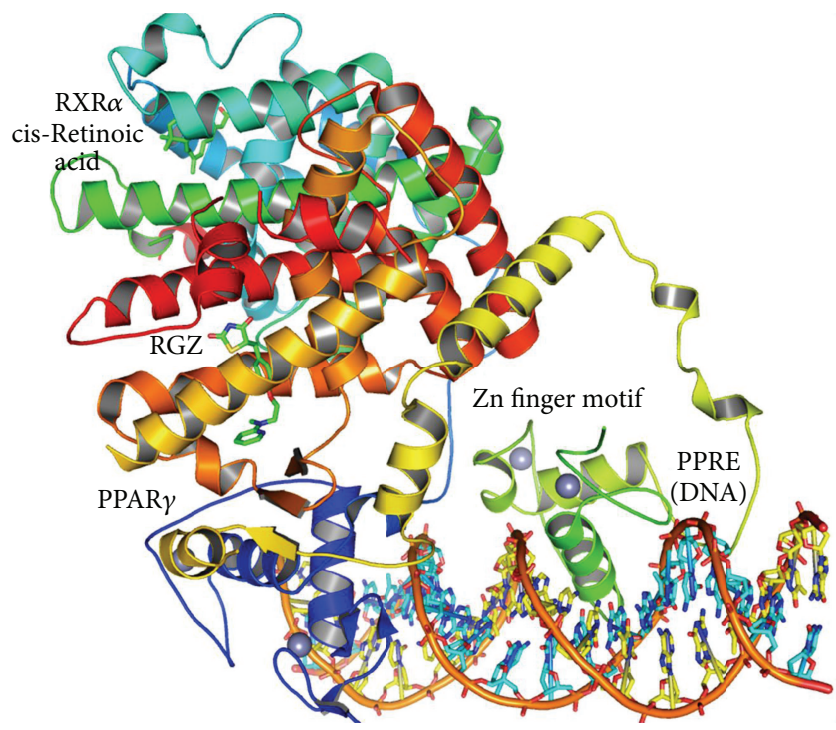

FIGURE 6: PPAR $\gamma$-RXR $\alpha$-DNA cocomplex crystal structure obtained with RGZ and cis-Retinoic acid bound in the active site (PDB code: 3DZY). Proximity of PPAR $\gamma$ LBD with RXR $\alpha$ LBD and PPRE (DNA) is clear. Interaction of C-terminal helices in the major grove of the DNA and $\mathrm{Zn}$ finger motif provides clues for graded activation of different genes by different ligands. This figure has been generated using PyMol [18].
While compounds like endogenous fatty acids and their nitrated derivatives, BVT.13, Farglitazar, MRL24, and nTZDpa do not lead to complete activation of the receptor and thus can be classified as partial agonists. Any ligand showing more than $60 \%$ of the transactivational activity shown by RGZ is classified as a full agonist. Ligands with transactivational activity near $60 \%$ are moderate agonists, but sometimes are referred as full agonists (e.g., MRL20). Partial agonists generally have less than $50 \%$ transactivational activity compared to RGZ [24, 49, 94]. Although this is a reasonably correct definition, any two ligands should be compared only when similar or identical transactivational assays have been utilized in obtaining the dose-response curves. This is due to the dependence of the observed transactivational activity on the many factors like cell type (adipose, muscle, kidney, or liver used), presence/absence of coactivators/corepressors, PPRE used, and so forth [95]. Figure 8 shows 2D structures of some full agonists. Crystallographic $[16,19]$ and mutation studies [46] have established the role of H-12 helix and TYR473 in the activity of full agonists.

The tyrosine amino acid residue (TYR473) present in the $\mathrm{H}-12$ helix of AF-2 function forms strong hydrogen-bonding interactions with acidic head groups of full agonists as seen in Figure 3. This pocket of the active site consists of mostly polar residues (SER289, HIS323, HIS449, and TYR473), thus 
<smiles>CC/C=C\C/C=C\C/C=C\CCCCCCCC(=O)O</smiles>

Linolenic acid (1)<smiles>CCCCC/C=C/C=C/C(O)CCCCCCCC(=O)O</smiles>

9-Hydroxy-10,12-octadecadienoic acid (9-HODE, 3)

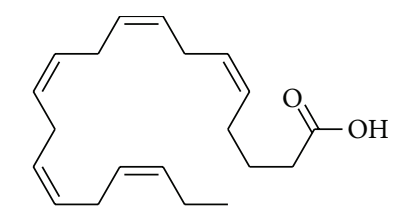

5,8,11,14,17-Icosapentaenoic acid (eicosapentaenoic acid,2)

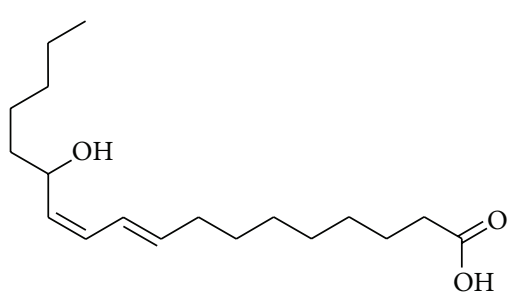

13-Hydroxy-9,11-octadecadienoic acid (13-HODE, 4)<smiles>CCCCC/C=C\C=C1\C(=O)C=C[C@@H]1C/C=C/CCCC(=O)O</smiles>

(Z)-7-[(1S,5E)-5-[(E)-oct-2-enylidene]-4-oxocyclopent-2-en-1-yl] hept-5-enoic acid 15 -deoxy- $\Delta^{12,14}$-prostaglandin J2 (15d-PGJ2, 5)

FIGURE 7: PPAR $\gamma$ endogenous ligands are mostly polyunsaturated fatty acids and their oxidized derivatives.<smiles>CN(CCOc1ccc(CC2SC(=O)NC2=O)cc1)c1ccccn1</smiles>

Rosiglitazone (RGZ) (6)<smiles>Cc1c(C)c2c(c(C)c1O)CCC(C)(COc1ccc(CC3SC(=O)NC3=O)cc1)O2</smiles>

Troglitazone (TGZ) (8)<smiles>COc1ccc(C(=O)n2c(C)c(Cc3ccccc3O[C@@H](C)C(=O)O)c3cc(OC(F)(F)F)ccc32)cc1</smiles>

MRL20 (10)<smiles>CCc1ccc(CCOc2ccc(CC3SC(=O)NC3=O)cc2)nc1</smiles>

Pioglitazone (PGZ) (7)<smiles>CC1(COc2ccc(CC3SC(=O)NC3=O)cc2)CCCCC1</smiles>

Ciglitazone (CGZ) (9)<smiles>O=C1NC(=O)C(=Cc2ccc(OCc3ccccc3)cc2)C(=O)N1</smiles>

FIgURE 8: PPAR $\gamma$ full agonists have polar acidic head groups essential for interaction with the TYR473 of H-12 helix. 
interactions of full agonists with the receptor are mostly electrostatic in nature $[96,97]$.

Such interactions lead to significant stabilization in the fluctuations of the H-12 helix, thus stabilizing the active conformation of the receptor promoting its interaction with the coactivators and RXR $\alpha$ leading to gene transcription. Thus, the full agonists have polar acidic head groups and a hydrophobic tail separated by an aromatic or aliphatic linker. These three fragments constitute the pharamcophore essential for PPAR $\gamma$ agonistic activity (Figure 4). Endogenous ligands also have structures satisfying these pharmacophoric criteria.

Partial Agonists. Bruning et al. suggested that partial agonists (see Figure 9), in contrast to the full agonists, interact with the receptor with mostly hydrophobic interactions leading to PPAR activation that is $\mathrm{H}-12$ helix independent [49]. This is evident from their radio-ligand and transactivationalbinding assays. Farglitazar is known to interact with mostly hydrophobic interaction in the active site and has larger binding affinity due to the presence of extra substituent (benzophenone) that interacts in the additional subpocket near the $\mathrm{H}-12$ helix.

Balaglitazone (BGZ, 12), a partial agonist, discovered by Henriksen et al. showed lesser hemodynamic effects of fluid retention and weight gain compared to PGZ in a Phase III clinical trial [98]. PAT5A (13), a molecule with exocyclic double bond in the TZD ring, is a partial agonist. Treatment of PAT5A in rodents with Type 2 diabetes resulted in dosedependent reduction in plasma glucose levels similar to RGZ along with reduced weight gain [99]. The partial agonistic character of BGZ and PAT5A points to the fact that agonistic character is not dependent on the groups present in ligands but is a function of the dynamical behavior of the $\mathrm{H}-12$ helix when the ligand is bound. Thus, understanding the dynamical behavior of the AF-2 function in PPAR $\gamma$ is vital for future drug discovery efforts to find ligands with better pharmacological and safety profiles. Other partial agonists so far discovered generally either bind near the $\beta$-sheet region or have very weak interactions with the H-12 helix $[21,49]$. These differences in the interaction features lead to recruitment of different coactivators and thus different gene expression patterns in comparison to the full agonists. For example, TZD class of compounds showed an increase in the expression of chemokine monocyte Chemoattractant protein-1 (MCP-1), whereas 15d-PGJ2 had little effect in a model of experimental glomerulonephritis (GN) in rats. TZD class of compounds also showed augmented activator protein-1 (AP-1) binding but had little effect on NF- $\kappa$ B, while the 15d-PGJ2 showed decrease in NF- $\kappa$ B without affecting AP-1 levels [95].

Dual PPAR $\gamma / \alpha$ Agonists. PPAR $\gamma$ and PPAR $\alpha$ show complementary effects of insulin sensitization in the adipocytes/ muscles and correction of atherogenic dyslipidemia. Thus a dual agonist, combining the beneficial effects of both full and partial agonists while avoiding the side effects of weight gain, has been sought by various research groups (see Figure 10) [6, $21,100-103]$. Aleglitazar, novel $\alpha$-alkoxy- $\beta$-arylpropionic acid derivative derived from SAR studies [69], has shown balanced effects on the glucose and lipid metabolism in primate models of metabolic syndrome [104]. Acidic head group of Aleglitazar forms important hydrogen-bonding interactions with H-12 helix in both PPAR $\gamma$ (HIS323, HIS449, and TYR473) and PPAR $\alpha$ (SER280, TYR314, and HIS440). It is currently in Phase III clinical trials (January 2012, NCT01042769: a study with Aleglitazar in patients with a recent acute coronary syndrome and type 2 diabetes mellitus). Aryloxy$\alpha$-methylhydrocinnamic acid derivative, LYS10929, with a thiophene tail showed insulin-sensitizing effects, decreased hyperglycemia, and improved overall lipid profiles [103]. Tesaglitazar, an $\alpha$-alkoxy-propionic acid derivative, showed promise as a dual agonist [105] but was later withdrawn from a phase III clinical study due to increased serum ceratinine and decrease in glomerular filtration rates [106]. Although dual agonists demonstrated beneficial impact over selective PPAR agonists by improving both lipid and glucose homeostases, safety has been a critical issue and has led to the discontinuation of their development because of adverse toxicity profiles [101]. Molecules like Tesaglitazar and Ragaglitazar have been suspended in Phase III, and Muraglitazar has failed to get a continued FDA approval.

Selective PPAR $\gamma$ Modulators (SPPARMs). Selective PPAR $\gamma$ modulators (SPPARMs) are defined as ligands, which induce agonistic or antagonistic responses depending on the cellular context and lead to expression of specific target genes [107]. A SPPARM is different from partial agonist because the doseresponse relationships for various activities are uncoupled from each other. This can be understood as resulting from tissue/organ specific responses which are not directly related to each other [21, 107]. Efforts in this direction resulted in the identification of Fmoc-L-leucine as SPPARM with most characteristics like a partial agonist [108]. Figure 11 shows 2D structures of selected SPPARMs. Metaglidasen, an enantiomer of halofenate, was found efficient at reducing glucose levels and having beneficial effects on lipid profiles. This drug candidate, a prodrug, is hydrolyzed by nonselective esterases in the plasma and converted to active metabolite. Due to uricosuric properties, this molecule was repositioned in the treatment of gout by Metabolex Inc [109]. FK-614 was found to be a structurally novel SPPARM with insulin sensitizing activities. But due to adipocyte hypertrophy its further development was halted [110]. Telmisartan, used in the treatment of hypertension, was rediscovered as a SPPARM which binds to PPAR $\gamma$ in a conformation different from TZDs [111]. Insulin-sensitizing effects of Telmisartan fueled its development as a combination therapy in patients with diabetes and cardiovascular complications [112]. It is currently used in the trade name MICARDIS $(80 \mathrm{mg}$ ) for treating hypertension.

Antagonists of PPAR $\gamma$. Both covalent and noncovalent antagonists of PPAR $\gamma$ have been identified (see Figure 12). Antagonists of PPAR $\gamma$ have similar insulin-sensitizing activities, but further studies are required to confirm their clinical applications. Compound GW9962 forms a covalent bond with the cysteine located on helix H-3. It has shown potent antagonistic activity against $\operatorname{PPAR} \gamma$ in cell-based assays 
<smiles>Cn1c(COc2ccc(CC3SC(=O)NC3=O)cc2)nc2ccccc2c1=O</smiles>

Balaglitazone (BGZ) (12)<smiles>COc1ccc(Cc2ncc(CN3CCC(c4ccccc4OC)CC3)c3cc(OC)c(OC)cc23)cc1OC</smiles>

PA-082 (14)<smiles>O=C1NC(=O)/C(=C/c2ccc(OCC3CCCN3c3ccccn3)cc2)S1</smiles><smiles>O=C(Nc1ccc(Oc2ncccn2)cc1C(=O)O)c1ccc(Cl)cc1Cl</smiles>

BVT.13 (15)<smiles>O=S(=O)(Nc1ccc(Sc2nc3cc(Cl)ccc3s2)c(Cl)c1)c1ccc(C(F)(F)F)cc1Cl</smiles>

T2384 (16)<smiles>Cc1oc(-c2ccccc2)nc1CCOc1ccc(C[C@H](Nc2ccccc2C(=O)c2ccccc2)C(=O)O)cc1</smiles>

Farglitazar (17)

FIgURE 9: 2D structures of some representative PPAR $\gamma$ partial agonists, which interact with PPAR mostly by hydrophobic interactions and also have vital pharmacophoric features of PPAR agonists (Figure 4).<smiles></smiles>

Aleglitazar (18)<smiles>CCOC(Cc1ccc(OCCN2c3ccccc3Oc3ccccc32)cc1)C(=O)O</smiles>

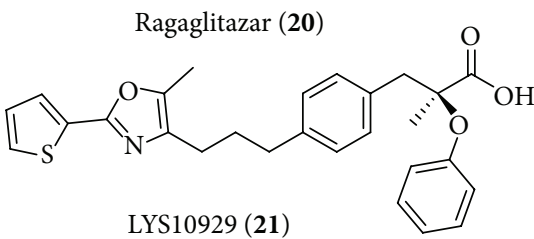<smiles>CCOC(Cc1ccc(OCCc2ccc(OS(C)(=O)=O)cc2)cc1)C(=O)O</smiles>

Tesaglitazar (19)<smiles>COc1ccc(OC(=O)N(CC(=O)O)Cc2ccc(OCCc3nc(-c4ccccc4)oc3C)cc2)cc1</smiles>

Muraglitazar (22)

FIGURE 10: PPAR $\alpha / \gamma$ dual and partial agonists. 


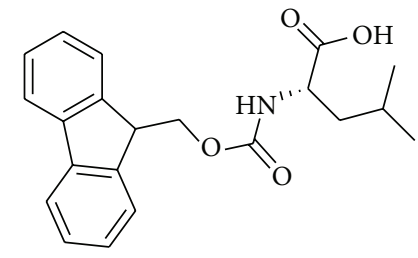

Fmoc-L-leucine (23)

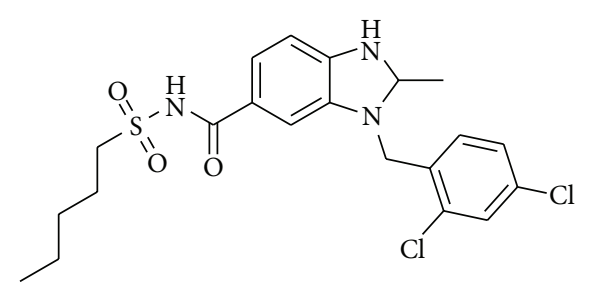

FK614 (25)<smiles>CC(=O)NCCOC(=O)C(Oc1cccc(C(F)(F)F)c1)c1ccc(Cl)cc1</smiles>

Metaglidasen (24)

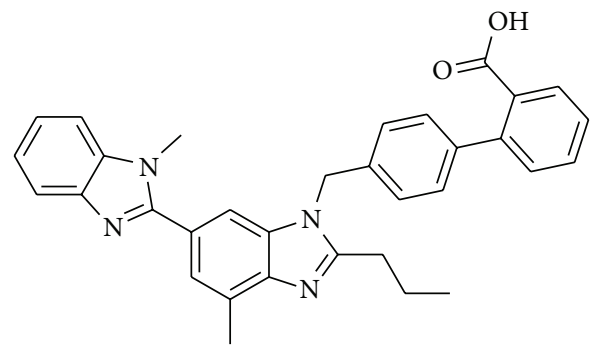

Telmisartan (26)

FIGURE 11: Selective PPAR $\gamma$ modulators (SPPARMs).

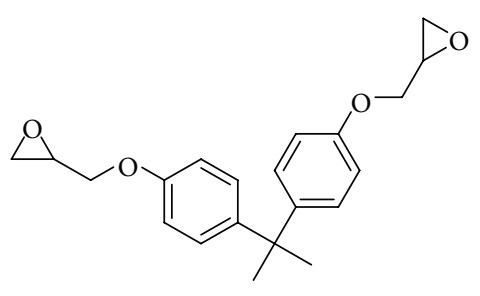

BADGE (27)

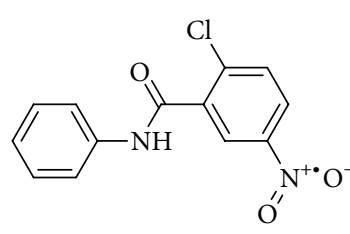

GW9662 (28)
FIGURE 12: PPAR $\gamma$ antagonists.

[113]. Polycarbonate-based diglycidyl ether (BADGE) is an antagonist with micromolar potency [114].

\section{Structure Activity Relationship (SAR) Studies for PPAR $\gamma$ Ligands}

With the discovery of TZDs as the potent synthetic agonists, fatty acids and their derivatives as natural ligands of PPAR $\gamma$, structure activity relationship (SAR) studies were performed by many groups to understand the nature of interactions between the PPAR $\gamma$ and its ligands. These important SAR studies are discussed briefly in this section.

SAR between PPAR $\gamma$ binding affinity and antihyperglycemic effects was reported first time by Willson et al. in 1996 [115]. In vitro PPAR $\gamma$ agonistic activity correlated accurately with the in vivo ability of the molecules to cause antihyperglycemic effect. Difference in the in vivo activity profiles of compounds belonging to same chemical class having similar pharmacokinetic profiles would have most likely arisen from their differences in pharmacodynamics and thus form the intrinsic potency of the molecules. Thus results from this and similar in vitro analysis could logically be used to screen large libraries of molecules with confidence. This in vitro SAR study also established the correlation between the antidiabetic effect of TZD class of compounds and PPAR $\gamma$ binding affinity.
Reddy et al. reported benzyloxy derivatives of TGZ to have better euglycemic and hypolipidemic activity (see Figure 13) [116]. Introduction of ethanolamine linker and benzyl protection at the hydroxyl group of TGZ resulted in compounds with better in vivo glucose lowering effect in $\mathrm{db} / \mathrm{db}$ mice and Wistar rats. In vivo analysis showed that the unsaturated analogues of TGZ are more effective in lowering the glucose levels. Transactivation assays on the other hand showed that the saturated TGZ derivatives lead to greater activation of PPAR $\gamma$. Such contrasting findings in the in vitro and in vivo data were attributed to the differences in pharmacokinetic profiles and use of different salt forms of the individual drug candidates. TGZ showed toxic effects in some patients, but mechanisms of toxicity were not completely understood at that time [117]. But involvement of the hydroxyl group from the metabolic profile was becoming clear and these lead Reddy et al. to design of compounds with hydroxyl group protected by benzyl groups (29) [118]. In a subsequent paper Reddy et al. reported the modification of a $\operatorname{PPAR} \alpha$ selective agent leading to the synthesis of PPAR $\alpha / \gamma$ dual agonist DRF2725 (31) [119]. The (-)-isomer of this compound was found to be potent in transactivation assays and showed better antidiabetic and hypolipidemic activity profile in vivo.

Brooks et al. reported the synthesis and dual agonistic activity of an oxazole containing phenoxypropionic acid derivative [120]. Substitution of methyl groups at $\alpha$ position was found to be necessary for activity. The biphenyl substitution also increased dual activation profile and gave very potent compound (32) as a dual PPAR $\alpha / \gamma$ agonist.

Racemization in the TZD class of compounds has been well established by both experimental [121] and theoretical studies [122]. Bharatam and Khanna performed theoretical studies and proposed the importance of S-oxidation in the rapid racemization of TZD class of drugs [122]. Thus, due to this racemization administration of a pure enantiomer was not considered for this class of drugs. Haigh et al. studied 
<smiles>Cc1c(C)c2c(c(C)c1OCc1ccccc1)CCC(C)(CN1CCC[C@H]1COc1ccc(/C=C3\SC(=O)NC3=O)cc1)O2</smiles>

O-benzyl substituted TGZ derivative (29)

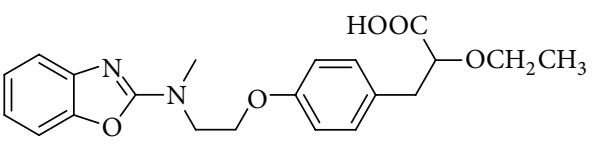

A PPAR $\alpha$ selective ligand (30)

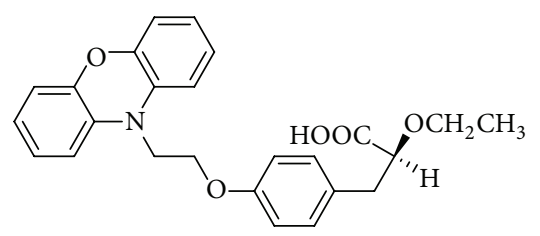

Dual PPAR $\alpha / \gamma$ ligand DRF2725 (31)

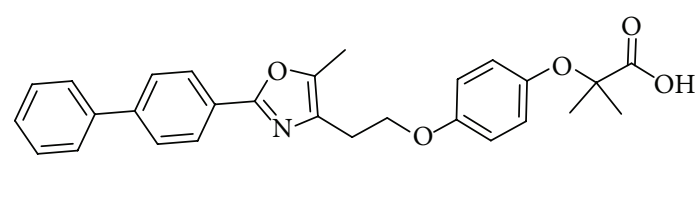

A oxazole phenylpropionic acid dervivatives (dual agonist, 32)

FIGURE 13: Benzyl protected TGZ derivatives, oxazole containing phenoxypropionic acid derivative, and DRF2725.

the effect of stereochemistry on the potency of $\alpha$-methoxy$\beta$-phenylpropanoic acids and found enzymatic racemization of $\mathrm{R}$ enantiomer to the $\mathrm{S}$ enantiomer responsible for the observed in vivo and in vitro equipotency of the two enantiomers [123].

Oguchi et al. performed molecular design, synthesis, and hypoglycemic activity studies on the imidazopyridine derivatives of TZDs [124]. In this study they developed molecules by cyclizing the $\mathrm{N}$-methylaminopyridine side chain of RGZ resulting in imidazopyridine nucleus (see Figure 14). Initial design, synthesis, and biological testing in this series gave compound, 33. This compound showed potent in vivo hypoglycemic activity but with side effects of cardiac hypertrophy. Linkers larger than methylene showed lower activity. Substitution at the 5th-position of the imidazopyridine nucleus showed an increase in the activity with chloro, methoxy, ethoxy, benzyloxy and phenylthio groups. Especially, the methoxy substituted compound (Rivoglitazone, 34) was found to be more potent than RGZ and showed reduced side effects compared to (33). Phase 3 clinical trials on Rivoglitazone were discontinued, but its applications in xerophthalmia are being considered in a Phase 2 study [21].

Yanagisawa et al., on similar lines, developed oxime containing TZD analogues (Figure 14) [125]. The biphenyl derivative (35) was more potent than RGZ both in vitro and in vivo assays. The authors highlighted that introduction of aromatic groups, methyl group on the oxime nitrogen, and ethylene linker are key components leading to increased activity in this series of compounds.

Novel pyrimidinone containing TZD derivatives were reported by Madhavan et al. [126]. These were derived from the modification of DRF2189 (36) side chain which had emerged in an earlier study by the modification of RGZ side chain [127]. PMT13 (38) derived from this study has shown potent antihyperglycemic activity devoid of any adverse effects in a 28-day in vivo study on Wistar rats (see Figure 15). The 2,4-dimethyl substituted derivative showed lower potency than PMT13. Benzyl substitution in place of the ethyl group also reduced the antihyperglycemic activity.
Analogues with 1,2,4-oxadiazolidine-3,5-dione framework in place of TZD ring were found to be less effective in producing antihyperglycemic activity.

Compound (37) with (2-furyl)-5-methyl substitution and 2,4-oxazolidinedione head group showed better antidiabetic effects in genetically obese and diabetic animal models $\left(\mathrm{KKA}^{\mathrm{y}}\right.$ mice and Wistar fatty rats) [128]. Compounds with 3 -arylpropyl and ethoxy spacer with para substitution were found to be more potent than PGZ. From this study the requirement of the spatial configuration of the three rings (oxazole, central benzene, and oxazolidinedione rings) connected with two alkyl spacers emerged (see Figure 15). Only $\mathrm{R}$ enantiomer of the oxazolidinedione derivatives was found to be potent activator of PPAR $\gamma$. No racemization was observed under in vivo conditions in contrast to the TZD class of compounds; this is attributed to the oxygen atom in place of sulfur at the chiral center resulting in less stable corresponding carbanion. Asymmetric $O$-acetylation of the corresponding $\alpha$-hydroxyvalerate with immobilized lipase was an important step in the synthesis of these compounds.

Novel 5-aryl TZD dual PPAR $\alpha / \gamma$ agonists were discovered by Desai et al. in 2003 [129]. They identified that a change in the position of the substitution at the central phenyl ring converts a PPAR $\gamma$ selective agonist (39) into a dual PPAR $\alpha / \gamma$ agonist (40).

An ethylene linker along with the para substitution was found to be necessary for potent PPAR $\gamma$ activity. Substitution of lipophilic groups on the terminal phenyl group reduced the activity, while chloro and fluoro substituents gave moderately potent dual agonists. The dual agonist, shown in Figure 16, also showed better pharmacokinetic (PK) parameters. Kim and Lee et al. reported novel pyridine and purine containing TZDs for their hypoglycemic and hypolipidemic activity in $\mathrm{KKA}^{\mathrm{y}}$ mice in vivo $[130,131]$. Substitution at the 5 th position of the pyridine ring resulted in compounds more potent than RGZ. Purine substituted analogues were found to be less potent than RGZ (see Figure 17).

Due to the proposed benefits, mentioned previously, with dual agonists many groups are actively developing 


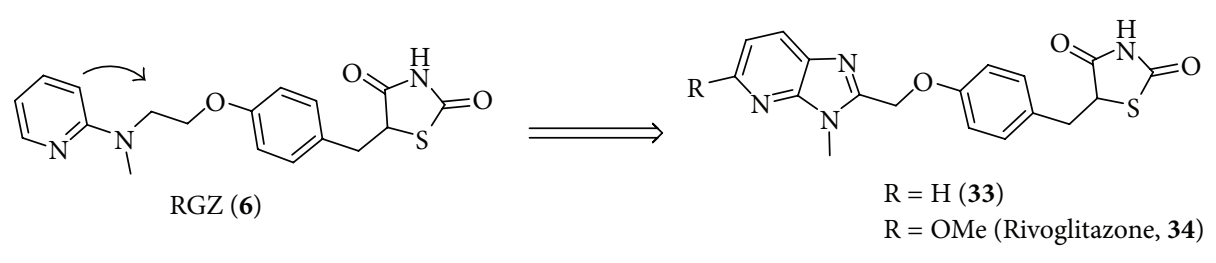

Imidazopyridine deriatives

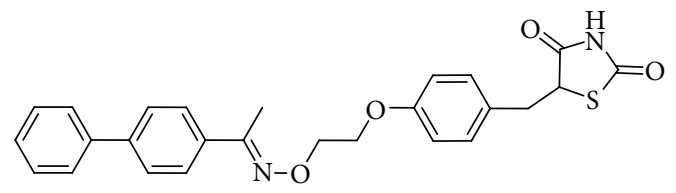

Oxime derivative (35)

FIGURE 14: Cyclization of RGZ side chain leads to the design of imidazopyridine derivatives with hypoglycemic activity and oxime derivatives.

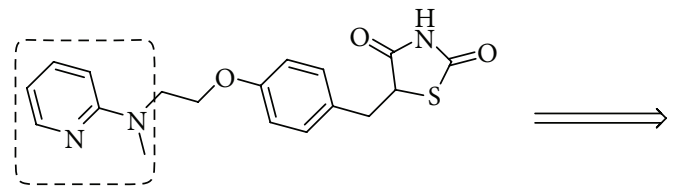

RGZ (6)<smiles>COc1cc(CCCC2OC(=O)NC2=O)ccc1OCc1nc(-c2ccco2)oc1C</smiles>

Furyl-substituted oxazolidinedione derivative (37)<smiles>O=C1NC(=O)C(Cc2ccc(OCCn3ccc4ccccc43)cc2)S1</smiles>

DRF2189 (36)<smiles>C=C=C=C</smiles>

PMT13 (38)

FIGURE 15: Design of pyrimidinone derivatives from RGZ and oxazolidinedione derivatives.

SAR studies for the design of dual agonists. Liu et al. combined the isobutyric acid head group of fenofibric acid (46), a PPAR $\alpha$ agonist, with the lipophilic aryloxy moiety of 47 (see Figure 18) [132]. This dual ligand (48) was found to be more selective for $\operatorname{PPAR} \alpha$ and inactive at other nuclear receptors. In vivo the dual agonist showed significant lowering of glucose levels and had dose-dependent hypolipidemic effect. Analogues with different substitution pattern at the $\alpha$ position were thus prepared. Transactivation and binding studies revealed that bis-substitution at the aromatic ring was essential for dual activation. Extending the linker between the carboxylic acid, and the phenyl ring reduced the activity drastically. Methoxy analogue and replacement of the isoxazole ring did not significantly affect the dual activation profile.

Knowledge of the clofibric acid, aryloxyacetic acid and naphthalene containing TZDs activities leads to the design of two series of $\alpha$-aryloxypropanoic acid derivatives and an $\beta$-aryl- $\alpha$-oxysubstituted propanoic acid [133]. Both $\mathrm{R}$ and $\mathrm{S}$ enantiomers of the compounds were studied by transactivation assay, and only $\mathrm{S}$-isomers were found to be effective in activation both PPAR $\alpha$ and PPAR $\gamma$. Substitution of the $p$ chloro substituent with more lipophilic aromatic moiety (51) improved both potency and efficacy leading to compounds with full agonistic character towards PPAR $\alpha$ and considerable activity against the PPAR $\gamma$ (see Figure 19). This compound was found be less effective in inducing adipocyte differentiation in vitro assays. Aliphatic groups lead to an increase in activity, while introduction of polar groups on the aliphatic chain reduced the activity considerably. Molecular docking analysis on the previously mentioned two compounds showed that they bind in mostly U-shaped conformation and form hydrogen bonds with key amino acids in the AF2 function.

SAR studies on the indoleacetic acid derivatives lead to the design of dual agonists with reversed substitution pattern (see Figure 20) [41]. Initially, a PAN agonist (52) was converted into a PPAR $\alpha$ selective agonist (53) by inverting the substitution pattern on the indoleacetic acid derivative. Adding dimethyl substitution and moving the acidic head group to the 4 th or 5 th position on the indole ring resulted in a PPAR $\alpha / \gamma$ dual agonists (54 and 55). The dimethyl substitution was found to be important for PPAR $\gamma$ activation, as it brought the acidic head group closer to the H-12 helix leading to the formation of strong hydrogen-bonding 


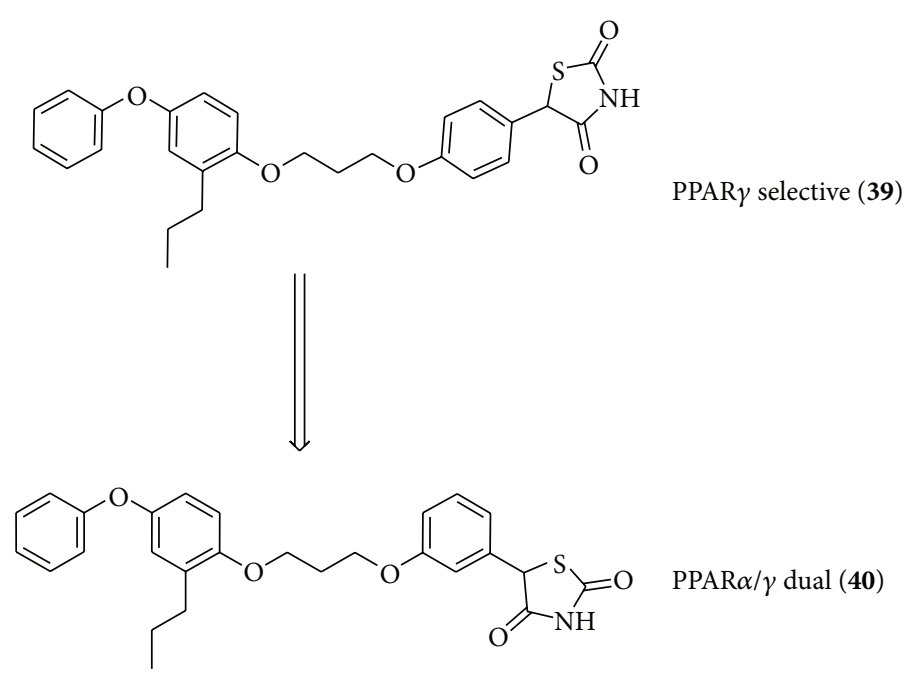

FIgURE 16: Converting a PPAR $\gamma$ selective ligand to PPAR $\gamma / \alpha$ dual agonist.<smiles>Cc1ccc(-c2ccc(N(C)CCOc3ccc(CC4SC(=O)NC4=O)cc3)nc2)o1</smiles>

5-Furanylpyridine TZD derivative (41)<smiles>CN(CCOc1ccc(Cc2ccc(-c3ccccc3)cn2)cc1)C1SC(=O)NC1=O</smiles><smiles>[R]n1cnc2c(N(C)CCOc3ccc(CC4SC(=O)NC4=O)cc3)ncnc2ncnc1N1C=CC=C[R]1[H]</smiles>
5-Phenylpyridine TZD derivative (42)

9-Substituted-9H-purine TZD derivatives (45)

FIgURE 17: Pyridine and purine TZD derivatives derived from RGZ.

interactions with SER289, HIS323, HIS449, and TYR473 as confirmed by crystal structure analysis.

Kim et al. reported SAR studies on novel benzyl thiocarbamates as dual PPAR $\alpha / \gamma$ agonists [134]. An initial study confirmed that thiocarbamates (56) are more potent than carbamates (57) (Figure 21). Aromatic terminal rings, like benzyl, gave potent compounds. Any increase or decrease in the chain length of this linker leads to decrease in activity. But bulkier substituents lead to an increase in PPAR $\gamma$ agonistic activity. S-isomer was found to be more active than the Risomer towards $\operatorname{PPAR} \alpha$, while both were found equally active at $\operatorname{PPAR} \gamma$. This is due to slightly larger active site volume in PPAR $\gamma$ in comparison to PPAR $\alpha$, thus both R- and S-isomers find space inside the active site of PPAR $\gamma$. But in the case of PPAR $\alpha$ the lipophilic region in the molecule is forced to enter in hydrophilic cavity giving a lower score as confirmed by docking analysis. The presence of thiocarbamate moiety was found to be essential for dual activity as confirmed by the PPAR $\gamma$ selectivity of the corresponding alcohol (58).

Casimiro-Garcia et al. reported the effect of substitution at the $\alpha$-position of phenylpropanoic acids on the dual $\operatorname{PPAR} \alpha / \gamma$ activation (see Figure 22) [51]. Replacement of ether moiety with acetylene, ethylene, propyl, or heteroatombased linker lead to significant changes in the affinity and transactivation profiles. In the series with methyl group in the oxazole ring and pyrrole ring as the $\alpha$-substituent, acetylene 


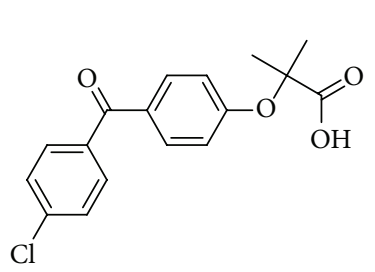<smiles>CCCc1cc2c(C(F)(F)F)noc2c(CCC)c1OC(C(=O)O)c1ccccc1</smiles>

Fenofibric acid

2-Aryloxypropanoic acid derivative

$\operatorname{PPAR} \alpha$ selective (46) $\operatorname{PPAR} \gamma$ selective (47)<smiles>CCCc1cc2c(C(F)(F)F)noc2c(CCC)c1OC(C)(C)C(=O)O</smiles>

A potent dual agonist

(48)

2-(5,7-dipropyl-3-(trifluoromethyl) benzo[d] isoxazol-6-yloxy)2-methylpropanoic acid

FIGURE 18: Design of a dual PPAR $\alpha / \gamma$ agonist from fenofibric acid and 2-aryloxypropanoic acid derivative.<smiles>CCCC(Oc1ccc2ccccc2c1)C(=O)O</smiles>

Naphthyl derivative of clofibric acid (49)<smiles>CCCC(OCc1ccc(-c2ccc(Cl)cc2)cc1)C(=O)O</smiles>

Biphenyl derivative (50)<smiles>O=C(O)C(Cc1ccccc1)Oc1ccc(Cl)cc1</smiles>

P-chlorophenoxy derivative (51)

FIGURE 19: Dual PPAR $\alpha / \gamma$ fibric acid derivatives.

linker gave nonselective ligand, while substitution with ethylene and propyl groups gave PPAR $\gamma$ selective compounds. These compounds showed less activation of PPAR $\gamma$ as compared to the pyrrole-containing compound reported earlier by GlaxoSmithKline [135]. S-isomers were found more active than the R-isomers as reported earlier for other tyrosine based compounds (59 and 60) $[135,136]$. Substituents like 3-pyridinyl, 4-biphenyl, 3-biphenyl, or phenyl in place of pyrrole drastically reduced the activity at both receptors. Molecule (61) showed lower PPAR $\alpha$ activation and was specifically selective for PPAR $\gamma$. This was understood to arise due to steric interaction with TYR314 in the PPAR $\alpha$ active site. Replacement of the ether oxygen by a nitrogen reduced $\operatorname{PPAR} \gamma$ activation.
Takamura et al. have performed synthesis and biological testing on $\alpha$-substituted $\beta$-phenylpropionic acid derivatives with pridin-2-ylphenyl moiety for PPAR activation and antihyperglycemic activity [137]. Oxime or amide linkers were kept in the molecules based on their earlier reported compound (37) [125]. Propyl group at $\alpha$ position showed potent glucose lowering activity compared to other groups like isopropyl, butyl, and phenylisopropyl (62 and 63 in Figure 23). Methylthio substitution at $\alpha$ position showed good dual agonistic activity. PPAR $\gamma$ agonistic activity could not be correlated in every molecule to its glucose lowering activity. As reported by many groups earlier, S-isomer was found to be more active in all compounds studied. The authors pointed out the fact that these compounds may be selective 


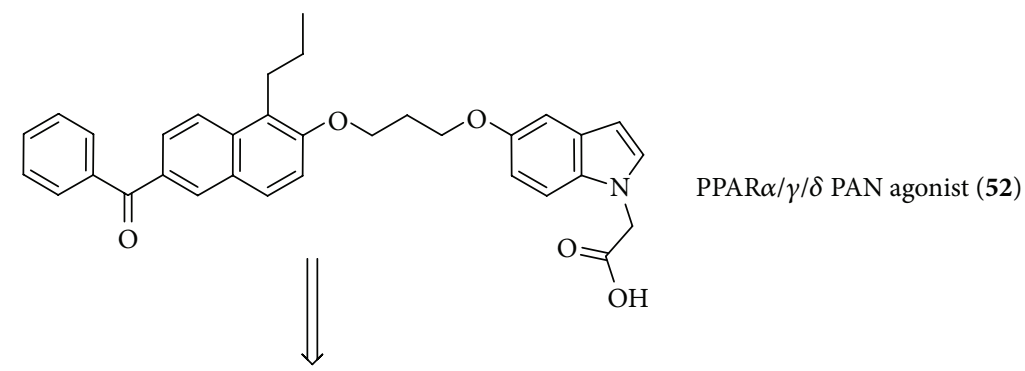

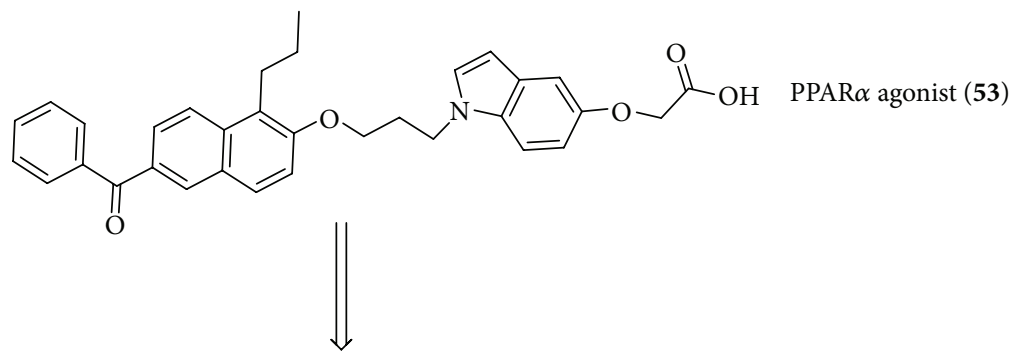<smiles>CCCc1c(OCCCn2ccc3c(C)c(OC(C)(C)C(=O)O)ccc32)ccc2cc(C(=O)c3ccccc3)ccc12</smiles>

FIGURE 20: Reversal of substitution pattern in indoleacetic acid gives PPAR $\alpha / \gamma$ dual agonist.<smiles>[X]C(NCc1ccccc1)OC(CCc1ccc(CC(OCC)C(=O)O)cc1)c1ccccc1</smiles>

$\mathrm{X}=\mathrm{S}$ thiocarbamate $(\mathbf{5 6})$

$\mathrm{X}=\mathrm{O}$ carbamate $(\mathbf{5 7})$<smiles>CCOC(Cc1ccc(CCC(O)c2ccccc2)cc1)C(=O)O</smiles>

Alcohol derivative (58)

FIgURE 21: Novel benzyl thiocarbamates based Dual PPAR $\alpha / \gamma$ agonists.

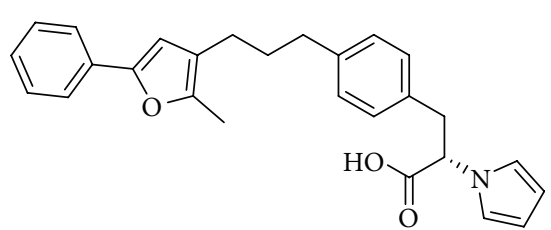

Pyrrole-based propanoic acid derivative (59)

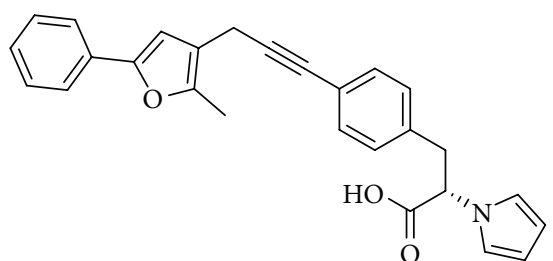

Propylene linker derivative (60)<smiles>Cc1oc(-c2ccccc2)cc1CCNc1ccc(C[C@H](C(=O)O)n2cccc2)cc1</smiles>

Ethylamine linker derivative (61)

FIgURE 22: Pyrrole-based L-tyrosine derivatives with different linkers. 


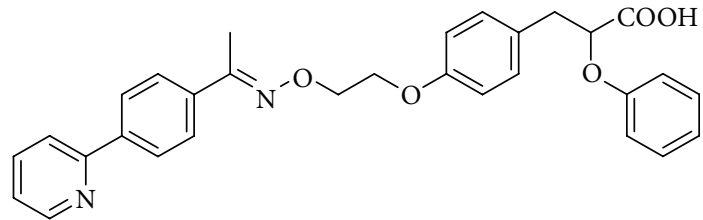

$\alpha$-phenoxy oxime derivative (62)

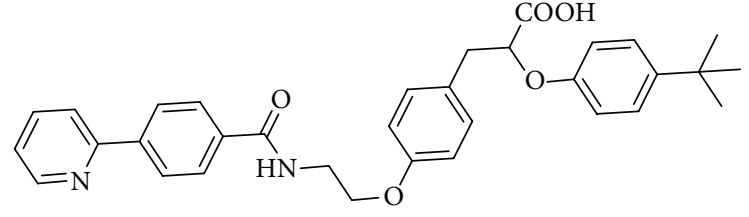

$\alpha-{ }^{t} \mathrm{Bu}$-phenoxy oxime derivative (63)

FIGURE 23: $\alpha$-substituted $\beta$-phenylpropionic acid derivatives with dual agonistic profiles.

$\operatorname{PPAR} \gamma$ modulators or might activate fatty acid receptors on the pancreatic cells (GPR40/FFAR) [138]. Recently, due to the failure of PPAR agonists to reach market, the pharmaceutical industry, and academicians started looking at other targets. GPR40, a GPCR found on islet $\beta$ cell membranes, is one such target known to mediate the insulin secretary effect of fatty acids [139-142].

Chromane 2-carboxylic acid derivatives were developed by Koyama et al. for discovery of novel dual PPAR $\alpha / \gamma$ agonists [143]. Cyclization of fibrates was envisioned as the synthetic route leading to the compounds with chromane nucleus. Substitution at the 6 th position of the chromane ring resulted in inactive compounds, while the compounds with substitution at the 7 th position were found to be active dual agonists. Compounds with propyl liker were found more potent than with ethyl and methyl linkers. Propyl, hydrogen, and halogen substituents resulted in potent PPAR $\gamma$ activators with moderate PPAR $\alpha$ activation. In vitro: binding and transactivation for affinity, in vivo: db/db mouse studies for antihyperglycemic, Hamster and Dog models for pharmacokinetic studies were utilized to select compound (64) for further studies (see Figure 24).

Parmenon et al. reported synthesis and biological evaluation of tetrahydroxyquinone derivatives for dual PPAR $\alpha / \gamma$ agonistic activity $[144,145]$. Di-ester- and ether-ester-based tetrahydroquinone derivatives were identified from these studies. No direct correlation between the $\mathrm{EC}_{50}$ (from transactivation assays) and $\mathrm{IC}_{50}$ values from receptor-binding studies was observed. This could be due to different binding site or interactions for the compounds under consideration and the standard (RGZ). The observed in vitro activity, unfortunately, did not translate into in vivo activity for this class of compounds.

Ohashi et al. have recently analyzed the effect of stereochemistry at the $\alpha$ position of the phenylpropanoic acid derivatives [146]. A reversal of enantiomeric activity was observed when a branched carbon atom is present at the $\beta$ position with respect to the carbonyl group. $\mathrm{R}$ enantiomer was found to be more active in both phenethyl and cyclohexyl substituents, while S enantiomer was more active in the ethyl substituted compound (Figure 25). Thus authors concluded that branched or unbranched nature of the substituents determine the enantiomer selectivity. Glide docking studies were performed to support the conclusions. But further crystallographic and molecular modeling studies are required to validate these findings.

In an effort to identify CNS penetrating PPAR $\gamma$ agonists Virley et al. at GlaxoSmithKline have discovered

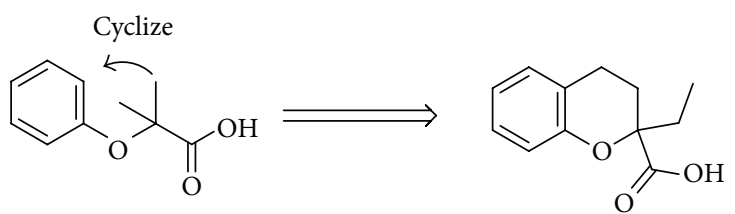

Fibrates $\operatorname{PPAR} \alpha$ pharmacophore

Chromane nucleus<smiles>CCC1(C(=O)O)CCc2ccc(OCCCOc3ccc(Oc4ccc(F)cc4)cc3Cl)cc2O1</smiles>

2-Ethylchromane-2-carboxylic acid derivative (64)

FIgURE 24: Chromane carboxylic acid derivatives developed for $\operatorname{PPAR} \alpha / \gamma$ dual activation.

GSK19971328B, a novel partial agonist. In the crystal structure benzylamide group in this molecule was found to bind in AF2 region where TZD ring of RGZ is known to have stabilizing interactions. A series of SAR studies were performed to understand the importance of substituents on each fragment in the molecule. Thus, ethyl substituent on the benzylamide group, presence of unsubstituted C2 position in benzimidazole central ring, and fluoro substitution gave compound with most desirable pharmacological and pharmacokinetic profile.

Majority of the SAR studies discussed previously have focused on one scaffold or another while attempting to increase the potency and efficacy towards the desired receptor subtype. The activity profiles observed in the SAR studies based on in vitro binding studies are not always reflected as similar profiles in the in vivo studies due to the involvement of many factors during the absorption, distribution, and metabolism (ADME) that is the pharmacokinetics/pharmacodynamics (PK/PD) of the drug candidates. These PK/PD factors and the corresponding tissue specific (muscle and adipose) responses lead to large variability in the patient's response to the drug. The in vitro and in vivo studies provide vital information about the overall profile of the drug candidates, but they cannot provide atomic and molecular level understanding of the interactions between the drug and the macromolecular protein targets which are at the heart of the final biologically observed response. Such electronic, atomic, and molecular level information on the interaction between the drug candidate and the target macromolecule can be obtained from structure-based and computer-aided drug discovery methodologies. A review of these efforts for 
<smiles>CCCOc1ccc(C[C@@H](CC)C(=O)O)cc1CNC(=O)c1ccc(C23CC4CC(CC(C4)C2)C3)cc1</smiles>

$\alpha$-ethyl substituted phenylpropanoic acid derivative $(S)$ enantiomer more active

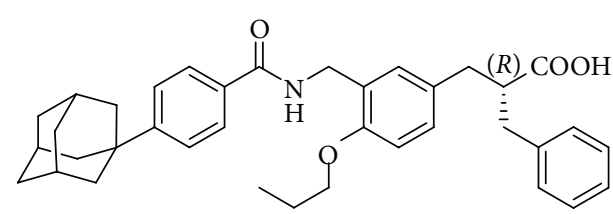

$\alpha$-phenethyl substituted phenylpropanoic acid derivative $(R)$ enantiomer more active

(a)

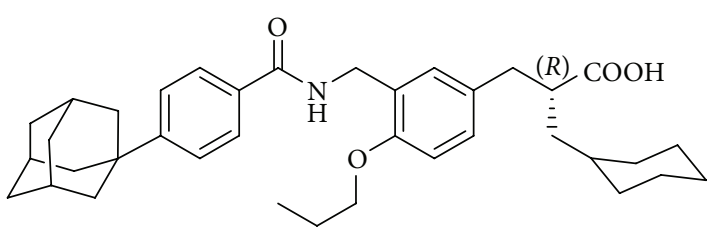

$\alpha$-cyclohexyl substituted phenylpropanoic acid derivative $(R)$ enantiomer more active

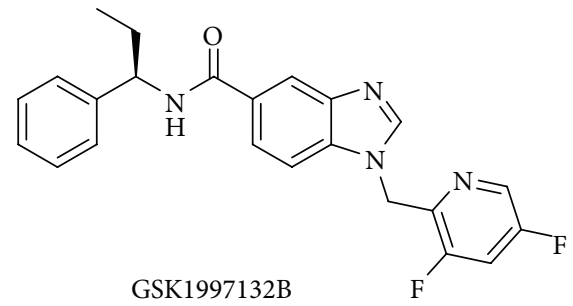

GSK1997132B

(b)

FIGURE 25: (a) Stereochemistry-activity relationship in a series of substituted phenylpropanoic acid derivatives. (b) A CNS penetrating benzimidazole derivative.

the discovery of PPAR $\gamma$ ligands is presented in the next section.

\section{Computational Approaches for the Discovery of PPAR $\gamma$ Ligands}

Drug discovery and development is a very time and resource demanding process in which a continuous exchange of information and knowledge takes place at the design and developmental stages. This generally involves a period of 10 to 15 years and 1.0 to 1.5 \$billion (these figures tend to vary depending on the therapeutic area, but a general increase is seen with time). Thus, computational predictive tools available in the physical, chemical, and biological scientific community are extensively utilized for making quick as well as well-thought strategic decisions. In the late phases of drug discovery, for example, clinical trials, statistical tools are more often utilized to understand the hidden trends in the data. On the other end of the spectrum, where target identification, validation, molecular design, and interactions of drug candidates with targets are to be understood, computer-aided drug design (CADD) approaches are often employed [147].

CADD methods generally employ a combination of the following methodologies: (1) two-dimensional quantitative structure activity relationship (2D QSAR), (2) 3D and higherdimensional QSAR methods, (3) pharmacophore mapping and virtual screening, (4) molecular docking in protein crystal structures (or homology models), (5) receptor-based QSAR methods, (6) receptor-based pharmacophore mapping and virtual screening, (7) de novo drug design, (8) molecular dynamics simulations, and (9) quantum chemical methods.
Reports making used of one or more such methodologies are described in the following.

QSAR methods based on 2D information are employed when the data set contains large variation in the chemical structures of the ligands under consideration as in the case for $\operatorname{PPAR} \gamma[148-150]$. Rücker et al. reported a 2D QSAR analysis of PPAR $\gamma$ ligands employing a set of molecular descriptors supplied in the program MOE. The descriptors like, atom and bond counts, connectivity indices, partial charge descriptors, pharmacophoric feature descriptors, calculated physical property descriptors and MACCS keys were used in the analysis. Data selection was based on the type of assay to derive meaningful correlation models. The receptor binding studies $\left(\mathrm{p} K_{i}\right)$ from the scintillation proximity assay and transactivation data from transient cotransfection assay were employed in the generation of models. Compounds were randomly partitioned into a training set $(90 \%)$ and test set (10\%). Four 2D QSAR equations were generated and thoroughly validated: (i) multiple linear regression (MLR), (ii) genetic algorithm variable selection module of $\mathrm{MOE}$ for receptor binding, (iii) MLR equation for gene transactivation, and (iv) activity-activity (receptor binding versus transactivation data) relationship. The authors concluded that variation in the central part of the ligand seemed to have minor importance in comparison to the other pharmacophoric features (acidic head group and hydrophobic tail). Utilizing only $2 \mathrm{D}$ structural features of the ligands although can allow molecules of diverse nature to be included in the analysis, it potentially leads to oversimplifications about the structure activity relationships. Thus, more robust 3D structural information about molecules can be considered while developing 
structure activity relationships. Efforts in this direction are presented in the following paragraphs.

QSAR methods like comparative molecular moment analysis (CoMMA) [151], comparative molecular field analysis (CoMFA) [152], molecular similarity indices in a comparative analysis (CoMSIA) [153], and adaptation of fields for molecular comparison (AFMoC) [154] make use of the 3D structural information of ligands to build correlations with biological activity. Khanna et al. have utilized a novel concept, of additivity of molecular fields using the CoMFA approach, to develop dual models for PPAR $\alpha$ and PPAR $\gamma$ dual activation [100]. In this study the authors reported individual models for $\operatorname{PPAR} \alpha$ and PPAR $\gamma$ activities and a dual model by summing the in vitro activity data, thus generating the dual model. This dual model was shown to be superior to individual PPAR $\alpha$ and PPAR $\gamma$ models in predicting the dual activation. General structure for the data set is shown in Figure 26. Individual models retained their ability to make reasonable individual activity predictions. These models were able to predict dual and selective activation for both receptors. Utility of these models in the drug design was shown by confirming the predictions of the model using molecular docking analysis and analyzing important $\mathrm{H}$-bonding interactions in the active site. The authors highlighted the importance of using dual model in combination with the individual models to avoid misleading conclusions. This is because the sum of activities for two molecules can be identical in spite of having very different individual activities.

A modified, receptor-based, QSAR study on the same set of molecules was reported by Lather et al. later [155]. Volume in the active site occupied by the ligands $\left(V_{\text {site }}\right)$ was shown as an important parameter in developing the QSAR equations. Utilizing the same dataset as used by Khanna et al. [100] they developed selective and dual models with the addition of $V_{\text {site }}$. Molecular descriptors like constitutional, topological (Zagreb and Balaban-type index), geometrical, electrostatic, and quantum chemical (CODESSA) were employed in this study. Balaban-type index performed better in comparison to the Zagreb index. The three models pointed out the differences in structural characteristics of PPAR $\alpha$ and PPAR $\gamma$ ligands. For PPAR $\alpha$ activity size and hydrophobicity of the ligands play a major role, while electrostatic and $\mathrm{H}$-bonding interactions were found to contribute more to the PPAR $\gamma$ activation. The authors claimed that limitations arising from the CoMFA requirements, namely, prior alignment of 3D structures could be avoided by using their method of QSAR. The PPAR $\gamma$ model of Lather et al. showed that with an increase in the number of double bonds there is a decrease in the activity. This corroborates with lower activity of the endogenous PPAR $\gamma$ ligands which have polyunsaturated framework (Figure 26).

In the quest to find novel insulin sensitizing molecules that can avoid toxicities associated with TZD class of drugs many research groups have looked towards other chemical class with similar pharmacophoric features. A few 3D QSAR studies have been reported on such compounds. Rathi et al. have employed Apex-3D software to determine primary and secondary binding characteristics in L-tyrosine analogues necessary for PPAR $\gamma$ activation (Figure 26) [156].
Brown et al. have used the concept of biased chemical libraries for screening of compounds for PPAR activation [157]. A library of 480 compounds was made using a combination of three phenoxyisobutyric acid derivatives along with different amines and isocyanate derivatives to generate urea analogues. The library was screened using cell-based reporter gene assay for PPAR-GAL4 chimeric receptors. A PPAR $\delta$ specific compound (GW2433, Figure 26) was identified during the screening. PPAR $\alpha$ showed most promiscuous nature among the three receptors by binding to more than $50 \%$ of the compounds screened, while PPAR $\gamma$ and PPAR $\delta$ showed larger selectivity profiles. The authors interpreted this result as PPAR $\alpha$ having a special physiological role in maintaining lipid metabolism due to its presence in the liver.

A structure-based drug design strategy was employed by Kuhn et al. to identify dual PPAR $\alpha / \gamma$ activators [39]. The indole-based scaffold (Figure 26) was selected from the in-house database with the hydrophobic central protein environment as a constraint while maintaining synthetic accessibility and drug-like properties. In the SAR study, effect of various structural features like position of the propionic acid chain attached to the indole scaffold, length of the linker between the indole and the oxazole ring, influence of various substituents on the activity were investigated. An increase in the size of the terminal substituents leads to an increase in the PPAR $\alpha$ affinity, while it decreased the PPAR $\gamma$ affinity. These findings can be used to fine-tune the selectivity of PPAR ligands.

Scarsi et al. performed in vitro binding and transactivation studies on sulfonylurea class of drug molecules for potential PPAR $\gamma$ activation [158]. Gliquidone, Glipizide, and Nateglinide activated PPAR $\gamma$ at physiologically relevant concentrations. Common pharmacophoric features based on $\mathrm{p} K_{a}$ values were suggested as the basis for PPAR $\gamma$ activation (see Figure 27). Based on these findings and molecular docking studies the authors suggested novel molecules (e.g., 70) by removing noninteracting nitrogen atom of the sulfonylurea group for further investigations.

Markt et al. performed pharmacophore mapping and virtual screening study on PPAR ligands [159]. Structure-based pharmacophore models (based on the active site differences) were reported for PPAR $\alpha$ and PPAR $\delta$, while a ligand-based pharmacophore model was reported for PPAR $\gamma$. Structurebased model was found less effective for PPAR $\gamma$ due to the small number of receptor complexes in comparison to the number of known ligands for this receptor subtype at that time. With larger number of crystal structures available now, a better receptor based pharmacophore model can be developed. Models specific for PPAR $\alpha$ agonists, PPAR $\gamma$ agonists, PPAR $\gamma$ partial agonists, and PPAR $\delta$ agonists were developed using 18, 21, 5, and 7 compounds, respectively. These models were validated using a set of 357 structurally diverse sets of PPAR ligands divided into 321 actives and 36 inactives. For the PPAR $\alpha$ and PPAR $\delta$ the structure-based models were refined using the ligand-based pharmacophore models. This was done by the removal of extra hydrophobic feature form the structure based models. In the next step the authors used an in-house pharmacophore database "Inte:Ligand database" consisting of 1537 structure-based 
<smiles></smiles>

$\mathrm{X}=\mathrm{S}: 5$-aryl thiazolidinedione $(\mathbf{6 5})$ $\mathrm{X}=$ O:oxazolidinedione $(66)$<smiles>CC(C)(Oc1ccc(CCCN(CCc2c(F)cccc2Cl)C(=O)Nc2cccc(Cl)c2Cl)cc1)C(=O)O</smiles>

GW2433<smiles>[R]NC(Cc1ccc(OCc2ccccc2)cc1)C([X])=O</smiles>

$\mathrm{N}$-(2-benzoylphenyl)-L-tyrosine derivatives<smiles>CCOC(Cc1ccc2c(ccn2Cc2nc(-c3ccccc3Cl)oc2C)c1)C(=O)O</smiles>

Indole propionic acids derivative

FIGURE 26: Molecules used to develop 3D CoMFA models of PPAR activity and novel PPAR $\gamma$ agonists discovered using QSAR and virtual screening approaches.<smiles>COc1ccc2c(c1)C(=O)N(CCc1ccc(S(=O)(=O)NC(=O)O)cc1)C(=O)C2(C)C</smiles>

Nateglinide (68)<smiles>[X]C(=O)NS(=O)(=O)c1ccc(CCNC(=O)N2CC(C)=C(C)C2=O)cc1</smiles>

$\mathrm{X}=\mathrm{NH}$ (glimepiride, 69)

$\mathrm{X}=\mathrm{C}(\mathrm{C}$-glimepiride, 70$)$

(a)

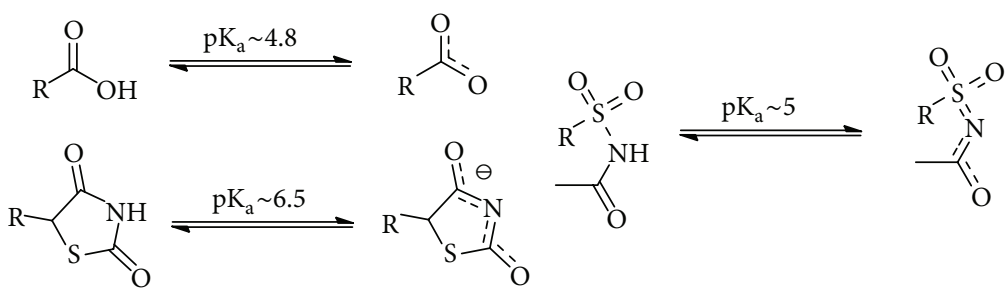

(b)

FIGURE 27: (a) Sulfonylureas, glinides, and N-sulfonyl carboxamides as potential PPAR $\gamma$ activators. (b) Pharmacophoric features common in carboxylic acids, TZDs, and sulfonamides.

models for 181 pharmacological targets for parallel screening study. Using a perl script and the target score, numbers of targets hit by the same set of ligands were identified. For one-third of the PPAR ligands PPARs were identified as the first target, while for $26 \%$ of the ligands P450 2C9 was the first target. Other protein targets identified were HRV coat protein and only $\operatorname{RXR} \beta$ from the rest of the nuclear receptor family. Thus, this study has proven the utility of parallel screening for determining the correct target for a set of compounds.

Giaginis et al. have analyzed correlations between lipophilic properties and the activities of PPAR $\gamma$ ligands [160]. A potential PPAR $\gamma$ ligand targeted for therapy should have, 
in addition to the pharmacophoric features, a right balance between lipophilic and hydrophilic group dispositions in the molecule. TZD and L-tyrosine class of compounds had an optimum $\log \mathrm{P}$ and $\log \mathrm{D}$ values in the range $0-2$. They highlighted the fact that although natural ligands of PPAR $\gamma$ are lipophilic long-chain carboxylic acids, there is no statistical correlation between $\mathrm{pEC}_{50} / \mathrm{pIC}_{50}$ and $\log \mathrm{P} / \log \mathrm{D}$ values.

Structure-based de novo design approach was employed by Dong et al. to identify PPAR $\gamma$ ligands. Ragaglitazar crystal structure was used to build the receptor-based model. Multiple copy simultaneous search (MCSS) and LeapFrog de novo design programs were employed to find the favorable orientation of indole-based derivatives in the active site. Two out of ten molecules thus identified compound (71) showed receptor-binding affinities similar to RGZ (see Figure 28).

Structure-based virtual screening approach was employed by Salam et al. for identifying PPAR $\gamma$ agonists. Induced fit docking protocol was utilized for this purpose. This lead to the discovery of $\psi$-baptigenin (72) (Figure 28) and other flavonoids as potent PPAR $\gamma$ agonists [161]. Similarly, pharmacophore-based virtual screening methodology was employed for the identification of natural-product-derived $\operatorname{PPAR} \gamma$ ligands by Tanrikulu et al. [162] Crystal structures for RGZ, Ragaglitazar, and Tesaglitazar were used in the study to develop receptor-based model using software LIQUID [163]. In vitro binding assays confirmed the validity of such screening approach where $\mathbf{7 3}$ (Figure 28) was identified as potent PPAR $\gamma$ activator.

A combination of pharmacophore mapping and QSAR model development was utilized by Al-Najjar et al. for the discovery of a new nanomolar PPAR $\gamma$ activator [164]. Ligand-based methods using CATALYST-HYPOGEN [165] were employed for generating pharmacophoric maps. The pharmacophoric space was explored by applying structural boundaries. Final analysis gave 104 models which were subsequently used in QSAR modeling. The QSAR equation consisted of 4 pharmacophore hypotheses, molecular fractional polar surface area (FPSA), number of rotatable bonds, and hydrogen bond donor (HBD). Comparison with crystallographic complexes (2Q59, 2G0G, and $2 \mathrm{P} 4 \mathrm{Y})$ was performed to validate the models. NCI database was screened using CATALYST, Lipniski's rule of five and Verber's rule were applied to filter the resulting hits. In vitro transactivation assay confirmed 3 molecules to be potent PPAR $\gamma$ activators. Figure 28 shows one of them (74).

Sundriyal et al. have performed virtual screening using CATALYST program for the identification of novel PPAR $\gamma$ ligands [166]. Crystal structure (2PRG) with RGZ cocomplexed with PPAR $\gamma$ ligand-binding domain was employed to generate query structure. Three pharmacophoric features, characteristic of PPAR $\gamma$ ligands, (i) two hydrogen bond acceptor, (ii) hydrophobic aromatic feature assigned to the central ring, and (iii) hydrophobic aromatic feature assigned to the side chain, were employed along with the query structure to screen the NCI and Maybridge databases. Out of the 46 and 13 hits obtained from the NCI and Maybridge databases, barbituric acid derivatives (11, see Figure 29) perfectly mapped on the query and pharmacophoric features.
These results were further validated using FlexX molecular docking study. In vitro and in vivo studies [167] have confirmed the PPAR $\gamma$ binding and antidiabetic/antiobesity effects of this class of compounds. Using a closely related replacement of acidic head group of Farglitazar, Sundriyal et al. identified novel PPAR $\gamma$ activators. Molecular docking using FlexX and receptor-binding affinity studies were employed to confirm the PPAR $\gamma$ binding. 2-Hydroxy-1,4naphthoquinone derivatives (Figure 29) were identified as potent PPAR $\gamma$ activators from this study. Phenyl, nitrile, and fluoro substituted derivatives showed significant binding affinity compared to PGZ [168].

Important pharmacophoric features for pan agonists were analyzed by Sundriyal and Bharatam using HipHop program [169]. Seven pharmacophoric features were used to generate a hypothesis "hypo-1." This hypothesis predicted pan agonistic character with $91.3 \%$ success rate for highly active compounds. The success rates for corresponding active and moderately active compounds were lower. Hydrogen bond acceptor feature (HBA) was found to be most critical for the discrimination of actives from inactives. Virtual screening with hypo-1 gave hits with large molecular weight. Thus, the authors modified this hypothesis by deleting less important features one at a time, leading to hits with more drug-like properties. Molecular docking was employed to understand the interaction profiles for these hits.

The "sum of activities" concept was extended by Sundriyal and Bharatam to pan PPAR agonists [170]. In this study the authors developed CoMFA based $\alpha, \gamma$, and $\delta$ and sum models using a data set of 39 compounds divided into training set of 28 and test set of 11 compounds. The sum model had molecular fields similar to $\alpha$ and $\gamma$ models. The sum model was used to design novel molecules with better predicted "overall activity" and docking scores.

Ligand and receptor centric 3D shape methods of virtual screening were combined by Choi et al. to identify 1,3-diphenyl-1H-pyrazole and ( $\beta$-carboxyethyl)-rhodanine derivatives as novel PPAR $\gamma$ agonists [171]. Four partial agonists and three full agonists were used to build the ligands based 3D queries which were used to screen a library of 1000 compounds. Receiver-operating characteristic (ROCS) combo score was employed for the screening. In the receptor centric method shape-based distributed docking in the cognate PPAR $\gamma$ crystal structure of the class representing ligand was performed. Fluorescent protein (FP) transactivation assay and receptor-binding studies were performed on 50 virtually selected compounds. SP3300 (75) and SP1818 (76) were identified as a novel partial and full agonists from these studies (Figure 28). A CoMFA study based on the docking pose of the most potent compound was performed to understand QSAR in this series and to design new compounds.

A de novo/rational approach was utilized in the identification of isoxazolyl-serine-based PPAR agonists [172]. Using the already existing SAR for PPAR ligands these agonists were developed. Some of the weak agonists of PPAR $\gamma$ were observed to stimulate cardiomyocyte differentiation from murine ES cells. PPAR $\alpha$ agonists fenofibrate, Wy-14643, and PPAR $\gamma$ as well as PPAR $\delta$ agonists RGZ, GW1929, and GW501516 were found inactive in this assay. Thus the authors 
<smiles>O=C(NC(Cc1c[nH]c2cc(OCc3ccccc3)ccc12)C(=O)O)c1ccc(Cl)cc1</smiles>

Indole-based PPAR $\gamma$ agonist (71)

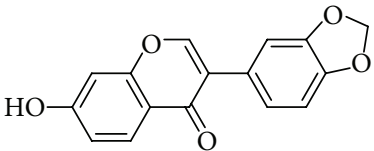

$\psi$-baptigenin (72)<smiles>CCCOc1cc(C)c2c(c1C)C[C@H](C(C)C(=O)O)CC2</smiles>

(73)<smiles>Cc1ccc(COc2ccccc2/C=C2\SC(=S)N(CCC(=O)O)C2=O)cc1</smiles>

SP1818 (76)

FIGURE 28: Indole-based (de novo design), pyrazole-based, rhodanine derivatives, and natural-product-derived PPAR $\gamma$ agonists.

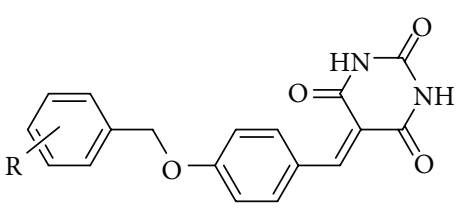

Barbituric acid derivatives

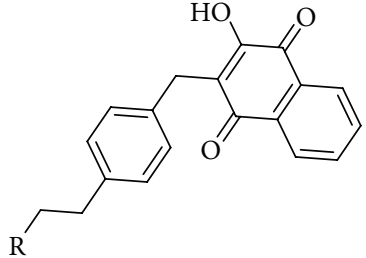

2-hydroxy-1,4-naphthoquinone derivatives

FIGURE 29: Barbituric acid and 2-hydroxy-1,4-naphthoquinone derivatives discovered as PPAR $\gamma$ agonists using a combination CADD approaches.

concluded that PPAR activation is not the primary target for the ligand-induced cardiomyocyte differentiation. This points to the fact that ligands with PPAR activation but lacking cardiotoxic profiles could be developed.

Molecular docking studies using GOLD software were performed by Kaya et al. to develop a screening approach for the identification of phthalate monoester-based PPAR $\gamma$ activators [173]. Initial docking experiments confirmed that near native conformations were predicted for PPAR $\gamma$ ligands with 6-8 rotatable bonds (RGZ, Ragaglitazar, Tesaglitazar, Farglitazar, and GW409544), but for ligands with larger number of rotatable bonds (partial agonist: GW0072) many conformational clusters were generated by the docking program. Strong correlation $\left(R^{2}: 0.62\right.$ and 0.82$)$ between $\mathrm{EC}_{50}$ and the docking score/rescored CHARMM/ACE energies was obtained. But the authors emphasized the fact that this is due to restricting to a small dataset and highlighted the fact that correlations between binding affinity, transactivational activity. and binding score are not seen in larger and diverse datasets. For example, GW0072 has larger activity than RGZ, but based on more decisive, transactivational data and in vivo, the former is partial agonist and the later a full agonist. These anomalies and lacunae in the understanding of PPAR activation result from the neglect of dynamic state of the receptor-ligand interactions, associated energetics, and the role of H-12 helix dynamics in the function of PPARs.
Considering the fact that most of the natural ligands of PPARs are fatty acids, Maltarollo and Honorio have calculated molecular properties of different fatty acids and made an attempt to correlate them with PPAR activity [174]. Optimum ranges for molecular properties like molecular weight (250-310), molecular volume (950-1200 $\left.\AA^{3}\right), \log \mathrm{P}$ (5.0-6.5), number of carbon atoms (16-20), and hydration energies $(<-1.0 \mathrm{kcal} / \mathrm{mol})$ were found for PPAR activation. Unsaturation increased activity in molecules with similar number of carbon atoms. Authors suggested the use of these parameters while considering novel ligand development.

Recently a combination of core hopping approach, molecular docking, and molecular dynamics has been utilized by $\mathrm{Ma}$ et al. for the design novel dual agonists [175]. Structure of GW409544 was divided into three core substructures. Five different fragments for each core were selected from the ZINC database by utilizing the "protocore preparation" module in Schrodinger 2009. Then a core hopping approach was utilized to generate $1 \times 5 \times 5=25$ different compounds. Crystal structures of PPAR $\alpha(1 \mathrm{~K} 7 \mathrm{~L})$ and PPAR $\gamma(1 \mathrm{~K} 74)$ were utilized for performing glide docking of these novel compounds. Based on the docking score comp 1 and comp\#8 (Figure 30) were selected for molecular dynamics studies. Complex of $\operatorname{PPAR} \alpha$ and PPAR $\gamma$ with comp 1 showed significant stabilization of the backbone RMSD and AF-2 function, while complex of comp\#8 showed significant RMSD fluctuations in 

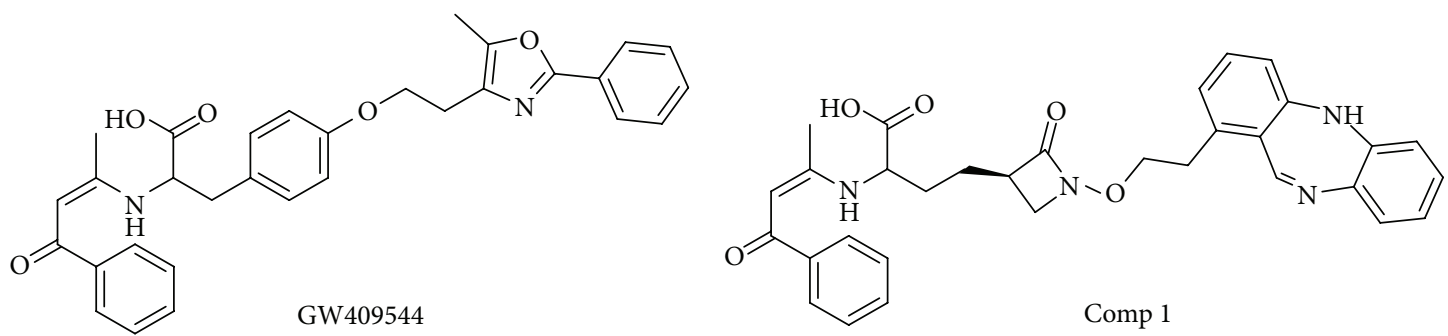

FIgURE 30: Dual agonist comp 1 identified from GW409544 using core hopping, docking, and MD approach.

both regions. These results agreed with the relative binding affinity predicted by docking.

To summarize, in the past decade a large number of structural scaffolds have been identified to show selective activation of the PPAR class of receptors. Many of the leads thus recognized have shown promising pharmacological profiles. But long-term safety and in vivo efficacy have remained the major challenging aspects in the development of novel molecules for the treatment of diabetes. Thus, in addition to having a deeper understanding of SAR and QSAR of novel class of molecules, focus must be equally placed on optimizing drug-like properties, pharmacodynamic/pharmacokinetic parameters of drug candidates, and clinical end points in the diabetic patients.

\section{Dynamics of PPAR $\gamma$ and Its Relation to Activation and Antidiabetic Effects}

The ligand-binding domain (LBD) of PPAR $\gamma$ consists of 270 amino acids, and as discussed in Section 3.2 and shown in Table 2/Figure 5, PPAR $\gamma$ has a large Y-shaped active site. Except the region around the AF-2 (H-12 helix) most of the interactions within the active site are hydrophobic in nature [16]. This causes the receptor to be very dynamic, and large variations in the active site volume can be seen in the crystal structures published (Tables 2 and 3 ). A comparison of the apo and ligand (RGZ) bound PPAR $\gamma$ crystal structures reveals the fact that the $\mathrm{H}-12$ helix in the activation function (AF-2) can take two conformations "open" and "closed" [16]. Backbone RMS value of $1.45 \AA$ was found between the two structures. Small RMS values for the backbone alignment suggest that the overall structural fold is maintained in the bound and unbound structures. While the RMS value for backbone atoms of the H-12 helix (residues 466-476) between the two structures was found to be $4.77 \AA$. Thus, significant differences are seen in the disposition of the $\mathrm{H}-12$ helix in the various states accessible to the receptor. In the apo state the H-12 helix can take two positions "open" and "closed", while in the presence of agonist the closed conformation of the H-12 helix is stabilized significantly (Figure 31). This characteristic is a common feature of most of the nuclear receptors [49]. In the closed state the significant interactions of $\mathrm{H}-12$ helix with the $\mathrm{H}-3$ and $\mathrm{H}-10$ helices are observed giving additional stability to the conformation $[16,19]$. Presence of charge clamp interactions between residues in the H-12 (GLU471) and H3 (LYS301) helices with residues in the coactivators gives further stabilization in the closed conformation.

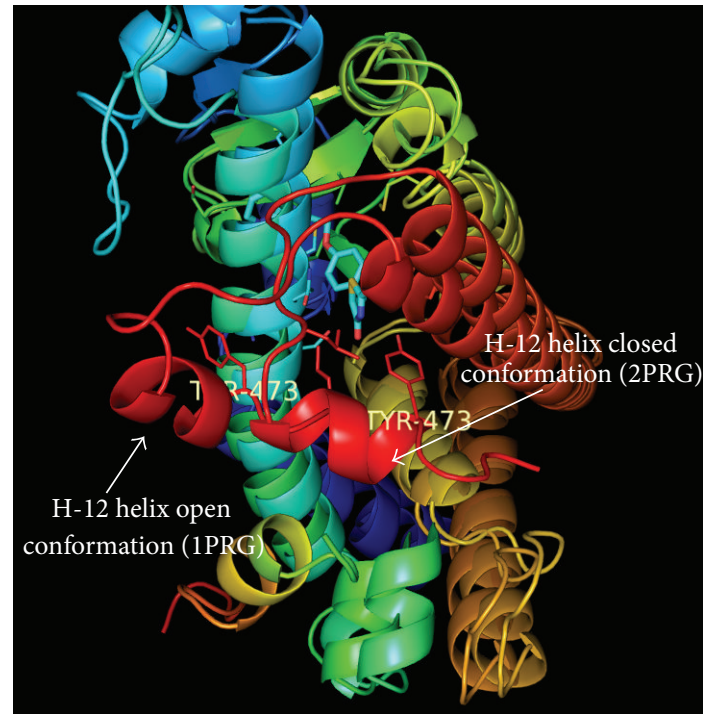

FIGURE 31: Apo (1PRG) and RGZ (2PRG) bound crystal structures of PPAR $\gamma$ overlaid (RMS backbone atoms $=1.45 \AA$ ). $\mathrm{H}-12$ helix in the apo structure takes the open conformation, while in the RGZ bound structure (2PRG) the H-12 helix is in closed state. RMS for $\mathrm{H}-12$ helix backbone atoms is $4.77 \AA$.

Due to these characteristic interactions full or partial agonistic behavior of various ligands was explained earlier based on H-12 helix dynamics and led to the design and synthesis of large number of structural scaffolds (Section 5) $[21,25,42,49,176]$. Ligands interacting with the H-12 helix and polar amino acids in the AF-2 region showed full agonistic character, while ligands with weaker or no interactions with the $\mathrm{H}-12$ helix showed moderate to partial agonistic behavior. Earlier Willson et al. have correlated the binding affinity of ligands with the antihyperglycemic activity [115]. But this agonistic nature of the ligands do not always correlated with antidiabetic activity quantitatively $[177,178]$. Thus the exact mechanism of activation of PPAR $\gamma$ and its relation to antidiabetic effects remains to be unclear.

Failure of the dual, SPPARMs and other molecules to reach the market calls for a fresh look at the molecular mechanism by which different endogenous/synthetic ligands and corepressors/coactivators of different PPAR receptors function to give a myriad of responses under different physiological conditions. It has been postulated that different ligands interact with the PPAR receptors resulting in ligand specific conformational changes. These differences translate 
into selective recruitment of cofactors (corepressors and coactivators) giving ligand specific gene expression patterns. Molecular dynamics (MD) simulations, which are used to follow the properties of a system as a function of time, coupled with rigid and flexible docking methods can really bridge this gap between the structurally diverse set of known ligands and a broad range of in vitro and in vivo activity profiles.

Considering the dynamic behavior of PPAR $\gamma$ and flexibility in its natural ligands it becomes important to find the conformational space and freedom that the natural ligands have in the active site of PPAR $\gamma$. Thus, it can be suggested that any ligand, which is expected to have similar effects, should have the conformational landscape similar to these natural ligands for optimal activity. In the family of nuclear receptors role of the $\mathrm{H}-12$ helix in the activation of the receptor is generally recognized. Full agonists are known to bind with the $\mathrm{H}-12$ helix leading to the complete activation of the receptor. Partial agonists, on the other hand, are proposed to activate the receptor partially by binding in other end of the active site and have minimal interaction with the H-12 helix. Similar, hypotheses have been made in the literature regarding the activation of PPAR $\gamma$ by full and partial agonists. But the crystal structure data (see Table 3) available for PPAR $\gamma$ suggests that the distinction is not so simple: as many partial agonists bind to or near the $\mathrm{H}-12$ helix and have important hydrogen-bonding interactions with the amino acids in/near H-12 helix. Hence, a clear understanding of the agonistic character of ligands based on the interactions within the active site is missing or obscure in the literature.

MD simulations were performed by Jyrkkarinne et al. recently to understand the agonistic and inverse agonistic behavior of constitutive androstane receptor (CAR) ligands [179]. Genest et al. have performed MD simulations on peroxisome proliferator-activated receptor $\gamma(\operatorname{PPAR} \gamma)$, a nuclear receptor, in order to elucidate the ligand escape trajectories from the bound state [180]. They also showed that the ligands like GW0072 make use of the intrinsic flexibility in the protein structure to maneuver in the active site. Another report on ligand specificity, molecular switch, and interactions with regulators has tried to reassess the importance of various interactions of ligands (using MD studies) with PPAR and reiterated the fact that the interactions of acidic groups, although are important for efficient activity, are not the sole factor in determining the partial or full agonistic nature of the ligands [181]. Other important interactions in the Y-shaped cavity of PPAR $\gamma$ are hydrophobic and $\pi$ stacking interactions. Similarly, MD simulation studies by Michalik et al. have reanalyzed the role of the AF-2 region and other amino acids in the active site of PPAR $\alpha$ [176]. In another study, MD simulations were performed with two ureidofibrate-like enantiomers and confirmed stabilization of the H-12 helix by the more active S-isomer [182]. Ji and Zhang highlighted the importance of protein polarization and electrostatic interactions in the AF-2 functional domain [97]. All these reports have substantiated the fact that full potential of the interactions in the active site have not been explored for this very important antidiabetic target and MD simulations can give useful insights into the receptor-ligand interactions and agonistic character of a ligand.
Choi et al. have alternatively suggested that the inhibition of phosphorylation of PPAR $\gamma$ at SER273 by cyclin-dependent kinase (Cdk5) could be mediating the beneficial antidiabetic effects of PPAR $\gamma$ agonists like RGZ and MRL24 [177]. SER273 (SER274 in 2PRG structure) is located in a loop between the helices $\mathrm{H} 3$ and $\mathrm{H} 4$ and occupies the surface opposite to the AF-2 region in the PPAR $\gamma$ active site $[16,19]$. MRL24, a partial agonist, reduced the dynamic nature of the $\mathrm{H} 3$ helix (AAs 309-315), $\beta$-sheet region (369-379), and SER273. RGZ was found to have less effect on the dynamics of these regions but reduced the dynamics of $\mathrm{H}-12, \mathrm{H}-11$ helix, and $\mathrm{AF}-2$ region significantly.

Based on these results Choi et al. have suggested the development of novel ligand with three important characteristics, namely, (1) high affinity for PPAR $\gamma$, (2) blocking of Cdk5-mediated PPAR $\gamma$ phosphorylation, and (3) lack of classical agonism [178]. A novel indole-containing benzoic acid derivative (SR1664) was developed which stabilized the $\mathrm{H}-3$ and $\beta$-sheet regions of the receptor while increasing the dynamical nature of the H-11 helix. This ligand shows minimal effect on the dynamics of $\mathrm{H}-12$ helix. As expected from the dynamical nature of the H-12 helix, SR1664 did not show any classical agonistic character. Gene expression patterns of SR1664 overlapped only partially with that of RGZ, directing towards beneficial and harmful genes expression patterns. Genes like aP2, Adipsin, Cd24a, and so forth were expressed at higher level with SR1664 than with RGZ, while genes like Pdk4, Hsdl2, and so forth showed opposite expression levels. On the other hand RGZ and SR1664 showed similar effects on the expression of genes like Adiponectin, Nr1d2, Ddx17, and so forth. Further studies are thus required to fully understand the implications of these results for understanding PPAR biology and to drug discovery efforts.

Recently Amato et al. have reported, 5-(5-bromo-2methoxy-benzylidene)-3-(4-methyl-benzyl)-thiazolidine-

2,4-dione, (GQ-16) as a novel partial agonist promoting insulin sensitization without the side effects of weight gain [88]. Crystallographic studies showed that this compound binds near the $\beta$-sheet region like MRL24 and BVT.13. Inhibition of Cdk5-mediated phosphorylation of SER273 was observed and proposed as a possible explanation for its partial PPAR $\gamma$ activation and antidiabetic activity.

\section{Conclusions and Future Directions on Developing Novel Ligands}

More than a decade has passed since the introduction of TZD class of drugs in the market, but still a guided development of a novel drug with ideal balance of controlling glucose levels and simultaneously avoiding the side effects related to cardiovascular system and toxicity remains a challenging task. This is a combined effect of incomplete understanding of biology of the PPAR $\gamma$, its in vitro and in vivo interactions with potential drug candidates, and correlation of these factors with clinically beneficial effects.

Nevertheless both SAR and CADD approaches have played a vital role in the identification of novel scaffolds with improved PPAR activation profiles. Glitazars, new TZD 
derivatives, L-tyrosine-based analogues, sulfonamide derivatives, sulfonylureas, barbituric acid derivatives, 2-hydroxynaphthoquinones, indoleacetic acid derivatives, propionic acid derivatives, oxazolidindiones, and $\alpha$-substituted propanoic acid derivatives represent the remarkable success achieved so far in this area. Both ligand and receptor-based methods have contributed to this success.

Novel virtual screening techniques, pharmacophore models coupled with recent QSAR approaches, better methods of estimating binding affinities, and advances in understanding the dynamics of PPAR $\gamma$-ligand interaction by employing molecular dynamics simulations have raised new hopes towards finding ligands with better pharmacological profiles.

Recently discovered alternate mechanisms of antidiabetic actions of PPAR $\gamma$ ligands, via inhibition of Cdk5mediated phosphorylation, have given new impetus to efforts for the discovery of novel PPAR $\gamma$ ligands as antidiabetic agents. Overlap in the gene expression patterns (Section 4) of classical agonists (RGZ) and ligands (SR1664) inhibiting phosphorylation (but lacking classical agonism) suggests that partial agonists with inhibitory effects on phosphorylation could prove more effective. Thus retaining partial agonistic character with specific gene expression patterns could prove beneficial. These beneficial genes could be clustered from expression patterns of the already known ligands. A number of recent studies have begun to identify and cluster such gene sets $[177,178,183,184]$. This suggests that ligands with following characteristic should be developed: (1) partial agonist of PPAR $\gamma$, (2) potent inhibitor of Cdk-5-mediated phosphorylation at SER273 of PPAR $\gamma$, and (3) high-binding affinity for PPAR $\gamma$.

\section{Abbreviations}

$(\operatorname{PPAR} \gamma): \quad$ Peroxisome proliferator-activated receptor $\gamma$

$(\operatorname{PPAR} \alpha):$ Peroxisome proliferator-activated receptor $\alpha$

$(\operatorname{PPAR} \delta): \quad$ Peroxisome proliferator-activated receptor $\delta$

(TZD): Thiazolidinedione

(RGZ): Rosiglitazone

(PGZ): Pioglitazone

(TGZ): Troglitazone

(SPPARM): Selective PPAR modulators

(SAR): $\quad$ Structure activity relationship

(QSAR): Quantitative structure activity relationship

(CADD): Computer-aided drug discovery

GOLD: (Genetic algorithm optimized ligand docking)

(ROCS): Receiver-operating characteristic

(GLP-1): Glucagon like peptide-1

(MCP-1): Monocyte chemoattractant protein-1.

\section{Conflict of Interests}

Authors declare that they have no conflict of interests.

\section{Acknowledgments}

Authors are thankful to the Council of Scientific and Industrial Research (CSIR), New Delhi, India, for financial support.

\section{References}

[1] S. Wild, G. Roglic, A. Green, R. Sicree, and H. King, "Global prevalence of diabetes: estimates for the year 2000 and projections for 2030," Diabetes Care, vol. 27, no. 5, pp. 1047-1053, 2004.

[2] B. Pourcet, J. C. Fruchart, B. Staels, and C. Glineur, "Selective PPAR modulators, dual and pan PPAR agonists: multimodal drugs for the treatment of type 2 diabetes and atherosclerosis," Expert Opinion on Emerging Drugs, vol. 11, no. 3, pp. 379-401, 2006.

[3] R. H. van Huijsduijnen, W. H. B. Sauer, A. Bombrun, and D. Swinnen, "Prospects for inhibitors of protein tyrosine phosphatase 1B as antidiabetic drugs," Journal of Medicinal Chemistry, vol. 47, no. 17, pp. 4142-4146, 2004.

[4] D. E. Moller, "New drug targets for type 2 diabetes and the metabolic syndrome," Nature, vol. 414, no. 6865, pp. 821-827, 2001.

[5] C. DeSouza and V. Fonseca, "Therapeutic targets to reduce cardiovascular disease in type 2 diabetes," Nature Reviews Drug Discovery, vol. 8, pp. 361-367, 2009.

[6] N. Cho and Y. Momose, "Peroxisome proliferator-activated receptor $\gamma$ agonists as insulin sensitizers: from the discovery to recent progress," Current Topics in Medicinal Chemistry, vol. 8, pp. 1483-1507, 2008.

[7] B. Panunti, A. A. Jawa, and V. A. Fonseca, "Mechanisms and therapeutic targets in type 2 diabetes mellitus," Drug Discovery Today: Disease Mechanisms, vol. 1, no. 2, pp. 151-157, 2004.

[8] D. K. Arulmozhi and B. Portha, "GLP-1 based therapy for type 2 diabetes," European Journal of Pharmaceutical Sciences, vol. 28, no. 1-2, pp. 96-108, 2006.

[9] J. M. Lehmann, L. B. Moore, T. A. Smith-Oliver, W. O. Wilkison, T. M. Willson, and S. A. Kliewer, "An antidiabetic thiazolidinedione is a high affinity ligand for peroxisome proliferatoractivated receptor $\gamma$ (PPAR $\gamma$ )," Journal of Biological Chemistry, vol. 270, no. 22, pp. 12953-12956, 1995.

[10] C. J. Rosen, "The rosiglitazone story-lessons from an FDA advisory committee meeting," The New England Journal of Medicine, vol. 357, pp. 844-846, 2007.

[11] M. T. Smith, "Mechanisms of troglitazone hepatotoxicity," Chemical Research in Toxicology, vol. 16, no. 6, pp. 679-687, 2003.

[12] M. Chandran, S. A. Phillips, T. Ciaraldi, and R. R. Henry, "Adiponectin: more than just another fat cell hormone?" Diabetes Care, vol. 26, no. 8, pp. 2442-2450, 2003.

[13] A. H. Knoll, "The early evolution of eukaryotes: a geological perspective," Science, vol. 256, no. 5057, pp. 622-627, 1992.

[14] M. E. Greene, B. Blumberg, O. W. McBride et al., "isolation of the human peroxisome proliferator activated receptor gamma cDNA: expression in hematopoietic cells and chromosomal mapping," Gene Expression, vol. 4, no. 4-5, pp. 281-299, 1995.

[15] B. Desvergne and W. Wahli, "Peroxisome proliferator-activated receptors: nuclear control of metabolism," Endocrine Reviews, vol. 20, no. 5, pp. 649-688, 1999.

[16] R. T. Nolte, G. B. Wisely, S. Westin et al., "Ligand binding and co-activator assembly of the peroxisome proliferator-activated receptor- $\gamma$," Nature, vol. 395, no. 6698, pp. 137-143, 1998. 
[17] M. Hendlich, F. Rippmann, and G. Barnickel, "LIGSITE: automatic and efficient detection of potential small molecule-binding sites in proteins," Journal of Molecular Graphics and Modelling, vol. 15, no. 6, pp. 359-363, 1997.

[18] "The PyMOL Molecular Graphics System, Version 1.5.0.1," Schrödinger, LLC.

[19] V. Chandra, P. Huang, Y. Hamuro et al., "Structure of the intact PPAR- $\gamma$-RXR- $\alpha$ nuclear receptor complex on DNA," Nature, vol. 456, no. 7220, pp. 350-356, 2008.

[20] T. Sohda, K. Mizuno, E. Imamiya, H. Tawada, K. Meguro, and Y. Kawamatsu Yamamoto, "Studies on antidiabetic agents. III. 5-arylthiazolidine-2, 4-diones as potent aldose reductase inhibitors," Chemical and Pharmaceutical Bulletin, vol. 30, pp. 36013616, 1982.

[21] C. Pirat, A. Farce, N. Lebegue et al., "Targeting peroxisome proliferator-activated receptors (PPARs): development of modulators," Medicinal Chemistry, vol. 55, no. 9, pp. 4027-4061, 2012.

[22] R. T. Gampe Jr., V. G. Montana, M. H. Lambert et al., "Asymmetry in the PPAR $\gamma / \operatorname{RXR} \alpha$ crystal structure reveals the molecular basis of heterodimerization among nuclear receptors," Molecular Cell, vol. 5, no. 3, pp. 545-555, 2000.

[23] H. E. Xu, M. H. Lambert, V. G. Montana et al., "Molecular recognition of fatty acids by peroxisome proliferator-activated receptors," Molecular Cell, vol. 3, no. 3, pp. 397-403, 1999.

[24] P. Cronet, J. F. W. Petersen, R. Folmer et al., "Structure of the PPAR $\alpha$ and $-\gamma$ ligand binding domain in complex with AZ 242; ligand selectivity and agonist activation in the PPAR family," Structure, vol. 9, no. 8, pp. 699-706, 2001.

[25] H. E. Xu, M. H. Lambert, V. G. Montana et al., "Structural determinants of ligand binding selectivity between the peroxisome proliferator-activated receptors," Proceedings of the National Academy of Sciences of the United States of America, vol. 98, no. 24, pp. 13919-13924, 2001.

[26] H. E. Xu, T. B. Stanley, V. G. Montana et al., "Structural basis for antagonist-mediated recruitment of nuclear co-repressors by PPAR $\alpha, "$ Nature, vol. 415, no. 6873, pp. 813-817, 2002.

[27] P. Sauerberg, I. Pettersson, L. Jeppesen et al., "Novel tricyclic$\alpha$-alkyloxyphenylpropionic acids: dual PPAR $\alpha / \gamma$ agonists with hypolipidemic and antidiabetic activity," Journal of Medicinal Chemistry, vol. 45, no. 4, pp. 789-804, 2002.

[28] S. Ebdrup, I. Pettersson, H. B. Rasmussen et al., "Synthesis and biological and structural characterization of the dual-acting peroxisome proliferator-activated receptor $\alpha / \gamma$ agonist ragaglitazar," Journal of Medicinal Chemistry, vol. 46, no. 8, pp. 13061317, 2003.

[29] T. Östberg, S. Svensson, G. Selén et al., "A new class of peroxisome proliferator-activated receptor agonists with a novel binding epitope shows antidiabetic effects," Journal of Biological Chemistry, vol. 279, no. 39, pp. 41124-41130, 2004.

[30] I. Takada, R. T. Yu, H. E. Xu et al., "Alteration of a single amino acid in peroxisome proliferator-activated receptor- $\alpha$ (PPAR $\alpha)$ generates a PPAR $\delta$ phenotype," Molecular Endocrinology, vol. 14, no. 5, pp. 733-740, 2000.

[31] G. Q. Shi, J. F. Dropinski, B. M. McKeever et al., "Design and synthesis of $\alpha$-aryloxyphenylacetic acid derivatives: a novel class of PPAR $\alpha / \gamma$ dual agonists with potent antihyperglycemic and lipid modulating activity," Journal of Medicinal Chemistry, vol. 48, no. 13, pp. 4457-4468, 2005.

[32] Y. Li, M. Choi, K. Suino et al., "Structural and biochemical basis for selective repression of the orphan nuclear receptor liver receptor homolog 1 by small heterodimer partner," Proceedings of the National Academy of Sciences of the United States of America, vol. 102, no. 27, pp. 9505-9510, 2005.

[33] N. Mahindroo, C. F. Huang, Y. H. Peng et al., "Novel indole-based peroxisome proliferator-activated receptor agonists: design, SAR, structural biology, and biological activities," Journal of Medicinal Chemistry, vol. 48, no. 26, pp. 8194-8208, 2005.

[34] S. A. Fyffe, M. S. Alphey, L. Buetow et al., "Recombinant human PPAR- $\beta / \delta$ ligand-binding domain is locked in an activated conformation by endogenous fatty acids," Journal of Molecular Biology, vol. 356, no. 4, pp. 1005-1013, 2006.

[35] S. A. Fyffe, M. S. Alphey, L. Buetow et al., "Reevaluation of the PPAR- $\beta / \delta$ ligand binding domain model reveals why it exhibits the activated form," Molecular Cell, vol. 21, no. 1, pp. 1-2, 2006.

[36] N. Mahindroo, C. C. Wang, C. C. Liao et al., "Indol-1-yl acetic acids as peroxisome proliferator-activated receptor agonists: design, synthesis, structural biology, and molecular docking studies," Journal of Medicinal Chemistry, vol. 49, no. 3, pp. 12121216, 2006.

[37] E. Burgermeister, A. Schnoebelen, A. Flament et al., "A novel partial agonist of peroxisome proliferator-activated receptor- $\gamma$ $(\operatorname{PPAR} \gamma)$ recruits $\operatorname{PPAR} \gamma$-coactivator- $1 \alpha$, prevents triglyceride accumulation, and potentiates insulin signaling in vitro," Molecular Endocrinology, vol. 20, no. 4, pp. 809-830, 2006.

[38] I. L. Lu, C. F. Huang, Y. H. Peng et al., "Structure-based drug design of a novel family of PPAR $\gamma$ partial agonists: virtual screening, X-ray crystallography, and in vitro/in vivo biological activities," Journal of Medicinal Chemistry, vol. 49, no. 9, pp. 2703-2712, 2006.

[39] B. Kuhn, H. Hilpert, J. Benz et al., "Structure-based design of indole propionic acids as novel PPAR $\alpha / \gamma$ co-agonists," Bioorganic \& Medicinal Chemistry Letters, vol. 16, no. 15, pp. 40164020, 2006.

[40] C. R. Hopkins, S. V. O’Neil, M. C. Laufersweiler et al., "Design and synthesis of novel N-sulfonyl-2-indole carboxamides as potent PPAR- $\gamma$ binding agents with potential application to the treatment of osteoporosis," Bioorganic \& Medicinal Chemistry Letters, vol. 16, no. 21, pp. 5659-5663, 2006.

[41] N. Mahindroo, Y. H. Peng, C. H. Lin et al., "Structural basis for the structure-activity relationships of peroxisome proliferatoractivated receptor agonists," Journal of Medicinal Chemistry, vol. 49, no. 21, pp. 6421-6424, 2006.

[42] G. Pochetti, C. Godio, N. Mitro et al., "Insights into the mechanism of partial agonism: crystal structures of the peroxisome proliferator-activated receptor $\gamma$ ligand-binding domain in the complex with two enantiomeric ligands," Journal of Biological Chemistry, vol. 282, no. 23, pp. 17314-17324, 2007.

[43] R. Epple, M. Azimioara, R. Russo et al., "3,4,5-trisubstituted isoxazoles as novel PPAR $\delta$ agonists. Part 2," Bioorganic \& Medicinal Chemistry Letters, vol. 16, no. 21, pp. 5488-5492, 2006.

[44] H. Oon Han, S. H. Kim, K. H. Kim et al., "Design and synthesis of oxime ethers of $\alpha$-acyl- $\beta$-phenylpropanoic acids as PPAR dual agonists," Bioorganic \& Medicinal Chemistry Letters, vol. 17, pp. 937-941, 2007.

[45] A. L. B. Ambrosio, S. M. G. Dias, I. Polikarpov, R. B. Zurier, S. H. Burstein, and R. C. Garratt, "Ajulemic acid, a synthetic nonpsychoactive cannabinoid acid, bound to the ligand binding domain of the human peroxisome proliferator-activated receptor $\gamma$," Journal of Biological Chemistry, vol. 282, no. 25, pp. 1862518633, 2007.

[46] M. Einstein, T. E. Akiyama, G. A. Castriota et al., "The differential interactions of peroxisome proliferator-activated receptor $\gamma$ 
ligands with Tyr473 is a physical basis for their unique biological activities," Molecular Pharmacology, vol. 73, no. 1, pp. 62-74, 2008.

[47] M. L. Sierra, V. Beneton, A. B. Boullay et al., "Substituted 2-[(4aminomethyl)phenoxy]-2-methylpropionic acid PPAR $\alpha$ agonists. 1. Discovery of a novel series of potent HDLc raising agents," Journal of Medicinal Chemistry, vol. 50, no. 4, pp. 685695, 2007.

[48] R. P. Trump, J. E. Cobb, B. G. Shearer et al., "Co-crystal structure guided array synthesis of PPAR $\gamma$ inverse agonists," Bioorganic \& Medicinal Chemistry Letters, vol. 17, no. 14, pp. 3916-3920, 2007.

[49] J. B. Bruning, M. J. Chalmers, S. Prasad et al., "Partial agonists activate PPAR $\gamma$ using a helix 12 independent mechanism," Structure, vol. 15, no. 10, pp. 1258-1271, 2007.

[50] I. Pettersson, S. Ebdrup, M. Havranek et al., "Design of a partial PPAR $\delta$ agonist," Bioorganic \& Medicinal Chemistry Letters, vol. 17, no. 16, pp. 4625-4629, 2007.

[51] A. Casimiro-Garcia, C. F. Bigge, J. A. Davis et al., "Effects of modifications of the linker in a series of phenylpropanoic acid derivatives: synthesis, evaluation as PPAR $\alpha / \gamma$ dual agonists, and X-ray crystallographic studies," Bioorganic and Medicinal Chemistry, vol. 16, no. 9, pp. 4883-4907, 2008.

[52] T. Itoh, L. Fairall, K. Amin et al., "Structural basis for the activation of PPAR $\gamma$ by oxidized fatty acids," Nature Structural \& Molecular Biology, vol. 15, no. 9, pp. 924-931, 2008.

[53] S. Keil, H. Matter, K. Schonafinger et al., "Sulfonylthiadiazoles with an unusual binding mode as partial dual peroxisome proliferator-activated receptor (PPAR) $\gamma / \delta$ agonists with high potency and in vivo efficacy," ChemMedChem, vol. 6, pp. 633653, 2011.

[54] C. Weidner, J. C. de Groot, A. Prasad et al., "Amorfrutins are potent antidiabetic dietary natural products," Proceedings of the National Academy of Sciences of the United States of America, vol. 109, pp. 7257-7262, 2012.

[55] T. Waku, T. Shiraki, T. Oyama et al., "Structural insight into PPAR $\gamma$ activation through covalent modification with endogenous fatty acids," Journal of Molecular Biology, vol. 385, no. 1, pp. 188-199, 2009.

[56] T. Waku, T. Shiraki, T. Oyama, K. Maebara, R. Nakamori, and K. Morikawa, "The nuclear receptor PPAR $\gamma$ individually responds to serotonin- and fatty acid-metabolites," The EMBO Journal, vol. 29, pp. 3395-3407, 2010.

[57] T. Oyama, K. Toyota, T. Waku et al., "Adaptability and selectivity of human peroxisome proliferator-activated receptor (PPAR) pan agonists revealed from crystal structures," Acta Crystallographica Section D, vol. 65, no. 8, pp. 786-795, 2009.

[58] T. Waku, T. Shiraki, T. Oyama, and K. Morikawa, "Atomic structure of mutant PPAR $\gamma$ LBD complexed with 15d-PGJ2: novel modulation mechanism of $\operatorname{PPAR} \gamma / \operatorname{RXR} \alpha$ function by covalently bound ligands," FEBS Letters, vol. 583, no. 2, pp. 320324, 2009.

[59] M. Ohashi, T. Oyama, I. Nakagome et al., "Design, synthesis, and structural analysis of phenylpropanoic acid-type PPAR $\gamma$ selective agonists: discovery of reversed stereochemistry-activity relationship," Journal of Medicinal Chemistry, vol. 54, no. 1 , pp. 331-341, 2011.

[60] K. Wakabayashi, S. Hayashi, Y. Matsui et al., "Pharmacology and in vitro profiling of a novel peroxisome proliferator-activated receptor $\gamma$ ligand, cerco-A," Biological \& Pharmaceutical Bulletin, vol. 34, no. 7, pp. 1094-1104, 2011.
[61] R. Montanari, F. Saccoccia, E. Scotti et al., "Crystal structure of the peroxisome proliferator-activated receptor $\gamma$ (PPAR $\gamma$ ) ligand binding domain complexed with a novel partial agonist: a new region of the hydrophobic pocket could be exploited for drug design," Journal of Medicinal Chemistry, vol. 51, no. 24, pp. 7768-7776, 2008.

[62] H. Zhang, D. E. Ryono, P. Devasthale et al., "Design, synthesis and structure-activity relationships of azole acids as novel, potent dual PPAR $\alpha / \gamma$ agonists," Bioorganic \& Medicinal Chemistry Letters, vol. 19, pp. 1451-1456, 2009.

[63] Y. Li, A. Kovach, K. Suino-Powell, D. Martynowski, and H. E. $\mathrm{Xu}$, "Structural and biochemical basis for the binding selectivity of peroxisome proliferator-activated receptor $\gamma$ to PGC- $1 \alpha$," Journal of Biological Chemistry, vol. 283, no. 27, pp. 19132-19139, 2008.

[64] Y. Li, J. Zhang, F. J. Schopfer et al., "Molecular recognition of nitrated fatty acids by PPAR $\gamma$," Nature Structural \& Molecular Biology, vol. 15, no. 8, pp. 865-867, 2008.

[65] B. G. Shearer, H. S. Patel, A. N. Billin et al., "Discovery of a novel class of PPAR $\delta$ partial agonists," Bioorganic \& Medicinal Chemistry Letters, vol. 18, no. 18, pp. 5018-5022, 2008.

[66] D. R. Artis, J. J. Lin, C. Zhang et al., "Scaffold-based discovery of indeglitazar, a PPAR pan-active anti-diabetic agent," Proceedings of the National Academy of Sciences of the United States of America, vol. 106, no. 1, pp. 262-267, 2009.

[67] U. Grether, A. Bénardeau, J. Benz et al., "Design and biological evaluation of novel, balanced dual PPAR $\alpha / \gamma$ agonists," ChemMedChem, vol. 4, no. 6, pp. 951-956, 2009.

[68] A. Motani, Z. Wang, J. Weiszmann et al., "INT131: a selective modulator of PPARy," Journal of Molecular Biology, vol. 386, no. 5, pp. 1301-1311, 2009.

[69] A. Bénardeau, J. Benz, A. Binggeli et al., "Aleglitazar, a new, potent, and balanced dual PPAR $\alpha / \gamma$ agonist for the treatment of type II diabetes," Bioorganic \& Medicinal Chemistry Letters, vol. 19, no. 9, pp. 2468-2473, 2009.

[70] C. H. Lin, Y. H. Peng, M. S. Coumar et al., "Design and structural analysis of novel pharmacophores for potent and selective peroxisome proliferator-activated receptor $\gamma$ agonists," Journal of Medicinal Chemistry, vol. 52, no. 8, pp. 2618-2622, 2009.

[71] R. V. Connors, Z. Wang, M. Harrison et al., "Identification of a $\operatorname{PPAR} \delta$ agonist with partial agonistic activity on PPAR $\gamma$," Bioorgan-ic \& Medicinal Chemistry Letters, vol. 19, no. 13, pp. 35503554, 2009.

[72] G. Fracchiolla, A. Laghezza, L. Piemontese et al., "New 2aryloxy-3-phenyl-propanoic acids as peroxisome proliferatoractivated receptors $\alpha / \gamma$ dual agonists with improved potency and reduced adverse effects on skeletal muscle function," Journal of Medicinal Chemistry, vol. 52, no. 20, pp. 6382-6393, 2009.

[73] A. Casimiro-Garcia, C. F. Bigge, J. A. Davis et al., "Synthesis and evaluation of novel $\alpha$-heteroaryl-phenylpropanoic acid derivatives as PPAR $\alpha / \gamma$ dual agonists," Bioorganic and Medicinal Chemistry, vol. 17, no. 20, pp. 7113-7125, 2009.

[74] Y. Li, Z. Wang, N. Furukawa et al., “T2384, a novel antidiabetic agent with unique peroxisome proliferator-activated receptor $\gamma$ binding properties," Journal of Biological Chemistry, vol. 283, no. 14, pp. 9168-9176, 2008.

[75] J. Li, L. J. Kennedy, Y. Shi et al., "Discovery of an oxybenzylglycine based peroxisome proliferator activated receptor $\alpha$ selective agonist 2-((3-((2-(4-chlorophenyl)-5-methyloxazol-4-yl)methoxy)benzyl)(methoxycarbonyl)amino)acetic acid 
(BMS-687453)," Journal of Medicinal Chemistry, vol. 53, no. 7, pp. 2854-2864, 2010.

[76] A. Furukawa, T. Arita, S. Satoh et al., "Discovery of a novel selective PPAR $\gamma$ modulator from (-)-cercosporamide derivatives," Bioorganic \& Medicinal Chemistry Letters, vol. 20, pp. 20952098, 2010.

[77] A. Riu, M. Grimaldi, A. le Maire et al., "Peroxisome proliferatoractivated receptor $\gamma$ is a target for halogenated analogs of bisphenol A," Environmental Health Perspectives, vol. 119, no. 9, pp. 1227-1232, 2011.

[78] C. A. Luckhurst, L. A. Stein, M. Furber et al., "Discovery of isoindoline and tetrahydroisoquinoline derivatives as potent, selective PPAR $\delta$ agonists," Bioorganic \& Medicinal Chemistry Letters, vol. 21, no. 1, pp. 492-496, 2011.

[79] A. Riu, A. le Maire, M. Grimaldi et al., "Characterization of novel ligands of $\operatorname{ER} \alpha, \operatorname{Er} \beta$, and PPAR $\gamma$ : the case of halogenated bisphenol A and their conjugated metabolites," Toxicological Sciences, vol. 122, pp. 372-382, 2011.

[80] K. A. Evans, B. G. Shearer, D. D. Wisnoski et al., "Phenoxyacetic acids as PPAR $\delta$ partial agonists: synthesis, optimization, and in vivo efficacy," Bioorganic \& Medicinal Chemistry Letters, vol. 21, pp. 2345-2350, 2011.

[81] J. Uppenberg, C. Svensson, M. Jaki, G. Bertilsson, L. Jendeberg, and A. Berkenstam, "Crystal structure of the ligand binding domain of the human nuclear receptor PPAR $\gamma$," Journal of Biological Chemistry, vol. 273, no. 47, pp. 31108-31112, 1998.

[82] H. Zhang, X. Xu, L. Chen et al., "Molecular determinants of magnolol targeting both RXR $\alpha$ and PPAR $\gamma$," PloS ONE, vol. 6, Article ID e28253, 2011.

[83] A. Casimiro-Garcia, G. F. Filzen, D. Flynn et al., "Discovery of a series of imidazo $[4,5-b]$ pyridines with dual activity at angiotensin II type 1 receptor and peroxisome proliferator-activated receptor- $\boldsymbol{\gamma}$," Journal of Medicinal Chemistry, vol. 54, no. 12, pp. 4219-4233, 2011.

[84] L. Porcelli, F. Gilardi, A. Laghezza et al., "Synthesis, characterization and biological evaluation of ureidofibrate-like derivatives endowed with peroxisome proliferator-activated receptor activity," Journal of Medicinal Chemistry, vol. 55, pp. 37-54, 2012.

[85] M. Sime, A. C. Allan, P. Chapman et al., "Discovery of GSK1997132B a novel centrally penetrant benzimidazole PPAR $\gamma$ partial agonist," Bioorganic \& Medicinal Chemistry Letters, vol. 21, pp. 5568-5572, 2011.

[86] A. C. Puhl, A. Bernardes, R. L. Silveira et al., "Mode of peroxisome proliferator-activated receptor $\gamma$ activation by luteolin," Molecular Pharmacology, vol. 81, no. 6, pp. 788-799, 2012.

[87] W. Liu, F. Lau, K. Liu et al., "Benzimidazolones: a new class of selective peroxisome proliferator-activated receptor $\gamma(\operatorname{PPAR} \gamma)$ modulators," Journal of Medicinal Chemistry, vol. 54, pp. 85418554, 2011.

[88] A. A. Amato, S. Rajagopalan, J. Z. Lin et al., "GQ-16, a novel peroxisome proliferator-activated receptor $\gamma$ (PPAR $\gamma$ ) ligand, promotes insulin sensitization without weight gain," The Journal of Biological Chemistry, vol. 287, pp. 28169-28179, 2012.

[89] R. R. Malapaka, S. Khoo, J. Zhang et al., "Identification and mechanism of 10-carbon fatty acid as modulating ligand of peroxisome proliferator-activated receptors," The Journal of Biological Chemistry, vol. 287, pp. 183-195, 2012.

[90] A. Furukawa, T. Arita, T. Fukuzaki et al., "Substituents at the naphthalene $\mathrm{C} 3$ position of (-)-cercosporamide derivatives significantly affect the maximal efficacy as PPAR $\gamma$ partial agonists,"
Bioorganic \& Medicinal Chemistry Letters, vol. 22, pp. 1348-1351, 2012.

[91] N. Kuwabara, T. Oyama, D. Tomioka et al., "Peroxisome proliferator-activated receptors (PPARS) have multiple binding points that accommodate ligands in various conformations: phenylpropanoic acid-type PPAR ligands bind to PPAR in different conformations, depending on the subtype," Journal of Medicinal Chemistry, vol. 55, pp. 893-902, 2012.

[92] Y. Amano, T. Yamaguchi, K. Ohno et al., "Structural basis for telmisartan-mediated partial activation of PPAR gamma," Hypertension Research, vol. 35, pp. 715-719, 2012.

[93] J. L. Oberfield, J. L. Collins, C. P. Holmes et al., "A peroxisome proliferator-activated receptor $\gamma$ ligand inhibits adipocyte differentiation," Proceedings of the National Academy of Sciences of the United States of America, vol. 96, no. 11, pp. 6102-6106, 1999.

[94] T. S. Hughes, M. J. Chalmers, S. Novick et al., "Ligand and receptor dynamics contribute to the mechanism of graded PPAR $\gamma$ agonism," Structure, vol. 20, pp. 139-150, 2012.

[95] R. S. Chana, A. J. Lewington, and N. J. Brunskill, "Differential effects of peroxisome proliferator activated receptor- $\gamma(\operatorname{PPAR} \gamma)$ ligands in proximal tubular cells: thiazolidinediones are partial PPAR $\gamma$ agonists," Kidney International, vol. 65, no. 6, pp. 20812090, 2004.

[96] K. Yamagishi, K. Yamamoto, Y. Mochizuki, T. Nakano, S. Yama$\mathrm{da}$, and H. Tokiwa, "Flexible ligand recognition of peroxisome proliferator-activated receptor- $\gamma(\operatorname{PPAR} \gamma)$," Bioorganic \& Medicinal Chemistry Letters, vol. 20, no. 11, pp. 3344-3347, 2010.

[97] C. G. Ji and J. Z. H. Zhang, "Protein polarization is critical to stabilizing AF-2 and helix-2' domains in ligand binding to PPAR- $\gamma$," Journal of the American Chemical Society, vol. 130, no. 50, pp. 17129-17133, 2008.

[98] K. Henriksen, I. Byrjalsen, P. Qvist et al., "Efficacy and safety of the PPAR $\gamma$ partial agonist balaglitazone compared with pioglitazone and placebo: a phase III, randomized, parallel-group study in patients with type 2 diabetes on stable insulin therapy," Diabetes/Metabolism Research and Reviews, vol. 27, no. 4, pp. 392-401, 2011.

[99] P. Misra, R. Chakrabarti, R. K. Vikramadithyan et al., "PAT5A: a partial agonist of peroxisome proliferator-activated receptor $\gamma$ is a potent antidiabetic thiazolidinedione yet weakly adipogenic," Journal of Pharmacology and Experimental Therapeutics, vol. 306, no. 2, pp. 763-771, 2003.

[100] S. Khanna, M. E. Sobhia, and P. V. Bharatam, "Additivity of molecular fields: CoMFA study on dual activators of PPAR $\alpha$ and PPAR $\gamma$," Journal of Medicinal Chemistry, vol. 48, no. 8, pp. 30153025, 2005.

[101] C. Fiévet, J.-C. Fruchart, and B. Staels, "PPAR $\alpha$ and PPAR $\gamma$ dual agonists for the treatment of type 2 diabetes and the metabolic syndrome," Current Opinion in Pharmacology, vol. 6, pp. 606$614,2006$.

[102] I. Ahmed, K. Furlong, J. Flood, V. P. Treat, and B. J. Goldstein, "Dual PPAR $\alpha / \gamma$ agonists: promises and pitfalls in type 2 diabetes," American Journal of Therapeutics, vol. 14, no. 1, pp. 49-62, 2007.

[103] Y. Xu, C. J. Rito, G. J. Etgen et al., "Design and synthesis of $\alpha$-aryloxy- $\alpha$-methylhydrocinnamic acids: a novel class of dual peroxisome proliferator-activated receptor $\alpha / \gamma$ agonists," Journal of Medicinal Chemistry, vol. 47, no. 10, pp. 2422-2425, 2004. 
[104] B. C. Hansen, X. T. Tigno, A. Benardeau, M. Meyer, E. Sebokova, and J. Mizrahi, "Effects of aleglitazar, a balanced dual peroxisome proliferator-activated receptor $\alpha / \gamma$ agonist on glycemic and lipid parameters in a primate model of the metabolic syndrome," Cardiovascular Diabetology, vol. 10, p. 7, 2011.

[105] S. L. Cox, "Tesaglitazar: a promising approach in type 2 diabetes," Drugs of Today, vol. 42, no. 3, pp. 139-146, 2006.

[106] D. Conlon, “Goodbye glitazars?” British Journal of Diabetes \& Vascular Disease, vol. 6, no. 3, pp. 135-137, 2006.

[107] L. S. Higgins and A. M. DePaoli, "Selective peroxisome proliferator-activated receptor $\gamma(\operatorname{PPAR} \gamma)$ modulation as a strategy for safer therapeutic PPAR $\gamma$ activation," The American Journal of Clinical Nutrition, vol. 91, pp. 267S-272S, 2009.

[108] S. Rocchi, F. Picard, J. Vamecq et al., "A unique PPAR $\gamma$ ligand with potent insulin-sensitizing yet weak adipogenic activity," Molecular Cell, vol. 8, no. 4, pp. 737-747, 2001.

[109] T. Allen, F. Zhang, S. A. Moodie et al., "Halofenate is a selective peroxisome proliferator-activated receptorgamma modulator with antidiabetic activity," Diabetes, vol. 55, no. 9, pp. 2523-2533, 2006.

[110] T. Fujimura, C. Kimura, T. Oe et al., "A selective peroxisome proliferator-activated receptor $\gamma$ modulator with distinct fat cell regulation properties," Journal of Pharmacology and Experimental Therapeutics, vol. 318, no. 2, pp. 863-871, 2006.

[111] T. Tagami, H. Yamamoto, K. Moriyama et al., "A selective peroxisome proliferator-activated receptor- $\gamma$ modulator, telmisartan, binds to the receptor in a different fashion from thiazolidinediones," Endocrinology, vol. 150, no. 2, pp. 862-870, 2009.

[112] H. A. Pershadsingh and T. W. Kurtz, "Insulin-sensitizing effects of telmisartan: implications for treating insulin-resistant hypertension and cardiovascular disease," Diabetes Care, vol. 27, no. 4, p. 1015, 2004.

[113] J. Rieusset, F. Touri, L. Michalik et al., "A new selective peroxisome proliferator-activated receptor $\gamma$ antagonist with antiobesity and antidiabetic activity," Molecular Endocrinology, vol. 16, no. 11, pp. 2628-2644, 2002.

[114] H. M. Wright, C. B. Clish, T. Mikami et al., "A synthetic antagonist for the peroxisome proliferator-activated receptor $\gamma$ inhibits adipocyte differentiation," Journal of Biological Chemistry, vol. 275, no. 3, pp. 1873-1877, 2000.

[115] T. M. Willson, J. E. Cobb, D. J. Cowan et al., "The structureactivity relationship between peroxisome proliferator-activated receptor $\gamma$ agonism and the antihyperglycemic activity of thiazolidinediones," Journal of Medicinal Chemistry, vol. 39, no. 3, pp. 665-668, 1996.

[116] K. A. Reddy, B. B. Lohray, V. Bhushan et al., "Novel antidiabetic and hypolipidemic agents. 5. Hydroxyl versus benzyloxy containing chroman derivatives," Journal of Medicinal Chemistry, vol. 42, no. 17, pp. 3265-3278, 1999.

[117] K. Matsumoto, S. Miyake, M. Yano, Y. Ueki, and Y. Tominaga, "Increase of lipoprotein (a) with troglitazone," The Lancet, vol. 350, no. 9093, pp. 1748-1749, 1997.

[118] K. Kawai, Y. Kawasaki-Tokui, T. Odaka et al., "Disposition and metabolism of the new oral antidiabetic drug troglitazone in rats, mice and dogs," Arzneimittel-Forschung, vol. 47, no. 4, pp. 356-368, 1997.

[119] B. B. Lohray, V. B. Lohray, A. C. Bajji et al., “(-)3-[4-[2-(phenoxazin-10-yl)ethoxy]phenyl]-2-ethoxypropanoic acid [(-)DRF 2725]: a dual PPAR agonist with potent antihyperglycemic and lipid modulating activity," Journal of Medicinal Chemistry, vol. 44, no. 16, pp. 2675-2678, 2001.
[120] D. A. Brooks, G. J. Etgen, C. J. Rito et al., "Design and synthesis of 2-methyl-2-4-[2-(5-methyl-2-aryloxazol-4-yl)ethoxy]phenoxypropionic acids: a new class of dual PPAR $\alpha / \gamma$ agonists," Journal of Medicinal Chemistry, vol. 44, no. 13, pp. 20612064, 2001.

[121] T. Sohda, K. Mizuno, and Y. Kawamatsu, "Studies on antidiabetic agents. VI. Asymmetric transformation of ( \pm )-5-[4-(1-methylcyclohexylmethoxy)benzyl]-2,4-thiazolidinedione (ciglitazone) with optically active 1-phenylethylamines," Chemical and Pharmaceutical Bulletin, vol. 32, no. 11, pp. 4460-4465, 1984.

[122] P. V. Bharatam and S. Khanna, "Rapid racemization in thiazolidinediones: a quantum chemical study," Journal of Physical Chemistry A, vol. 108, no. 17, pp. 3784-3788, 2004.

[123] D. Haigh, G. Allen, H. C. Birrell et al., "Non-thiazolidinedione antihyperglycaemic agents. Part 3: the effects of stereochemistry on the potency of $\alpha$-methoxy- $\beta$-phenylpropanoic acids," Bioorganic and Medicinal Chemistry, vol. 7, no. 5, pp. 821-830, 1999.

[124] M. Oguchi, K. Wada, H. Honma et al., "Molecular design, synthesis, and hypoglycemic activity of a series of thiazolidine2,4-diones," Journal of Medicinal Chemistry, vol. 43, no. 16, pp. 3052-3066, 2000.

[125] H. Yanagisawa, M. Takamura, E. Yamada et al., "Novel oximes having 5-benzyl-2,4-thiazolidinedione as antihyperglycemic agents: synthesis and structure-activity relationship," Bioorganic \& Medicinal Chemistry Letters, vol. 10, no. 4, pp. 373-375, 2000.

[126] G. R. Madhavan, R. Chakrabarti, R. K. Vikramadithyan et al., "Synthesis and biological activity of novel pyrimidinone containing thiazolidinedione derivatives," Bioorganic and Medicinal Chemistry, vol. 10, no. 8, pp. 2671-2680, 2002.

[127] B. B. Lohray, V. Bhushan, B. P. Rao et al., "Novel euglycemic and hypolipidemic agents," Journal of Medicinal Chemistry, vol. 41, no. 10, pp. 1619-1630, 1998.

[128] Y. Momose, T. Maekawa, T. Yamano et al., "Novel 5-substituted 2,4-thiazolidinedione and 2,4-oxazolidinedione derivatives as insulin sensitizers with antidiabetic activities," Journal of Medicinal Chemistry, vol. 45, no. 7, pp. 1518-1534, 2002.

[129] R. C. Desai, W. Han, E. J. Metzger et al., "5-Aryl thiazolidine2,4-diones: discovery of PPAR dual $\alpha / \gamma$ agonists as antidiabetic agents," Bioorganic \& Medicinal Chemistry Letters, vol. 13, no. 16, pp. 2795-2798, 2003.

[130] B. Y. Kim, J. B. Ahn, H. W. Lee et al., "Synthesis and antihyperglycemic activity of erythrose, ribose and substituted pyrrolidine containing thiazolidinedione derivatives," Chemical and Pharmaceutical Bulletin, vol. 51, no. 3, pp. 276-285, 2003.

[131] H. W. Lee, Y. K. Bok, B. A. Joong et al., "Molecular design, synthesis, and hypoglycemic and hypolipidemic activities of novel pyrimidine derivatives having thiazolidinedione," European Journal of Medicinal Chemistry, vol. 40, no. 9, pp. 862-874, 2005.

[132] K. Liu, L. Xu, J. P. Berger et al., "Discovery of a novel series of peroxisome proliferator-activated receptor $\alpha / \gamma$ dual agonists for the treatment of type 2 diabetes and dyslipidemia," Journal of Medicinal Chemistry, vol. 48, no. 7, pp. 2262-2265, 2005.

[133] A. Pinelli, C. Godio, A. Laghezza et al., "Synthesis, biological evaluation, and molecular modeling investigation of new chiral fibrates with PPAR $\alpha$ and PPAR $\gamma$ agonist activity," Journal of Medicinal Chemistry, vol. 48, no. 17, pp. 5509-5519, 2005.

[134] N. J. Kim, K. O. Lee, B. W. Koo et al., "Design, synthesis, and structure-activity relationship of carbamate-tethered aryl propanoic acids as novel PPAR $\alpha / \gamma$ dual agonists," Bioorganic \& Medicinal Chemistry Letters, vol. 17, no. 13, pp. 3595-3598, 2007.

[135] K. G. Liu, M. H. Lambert, A. H. Ayscue et al., "Synthesis and biological activity of L-tyrosine-based PPAR $\gamma$ agonists with 
reduced molecular weight," Bioorganic \& Medicinal Chemistry Letters, vol. 11, no. 24, pp. 3111-3113, 2001.

[136] B. R. Henke, S. G. Blanchard, M. F. Brackeen et al., "N-(2benzoylphenyl)-L-tyrosine PPAR $\gamma$ agonists. 1. Discovery of a novel series of potent antihyperglycemic and antihyperlipidemic agents," Journal of Medicinal Chemistry, vol. 41, no. 25, pp. 5020-5036, 1998.

[137] M. Takamura, M. Sakurai, E. Yamada et al., "Synthesis and biological activity of novel $\alpha$-substituted $\beta$-phenylpropionic acids having pyridin-2-ylphenyl moiety as antihyperglycemic agents," Bioorganic and Medicinal Chemistry, vol. 12, no. 9, pp. 24192439, 2004.

[138] Y. Itoh, Y. Kawamata, M. Harada et al., "Free fatty acids regulate insulin secretion from pancreatic $\beta$ cells through GPR40," Nature, vol. 422, pp. 173-176, 2003.

[139] E. Christiansen, C. Urban, N. Merten et al., "Discovery of potent and selective agonists for the free fatty acid receptor 1 (FFA1/ GPR40), a potential target for the treatment of type II diabetes," Journal of Medicinal Chemistry, vol. 51, pp. 7061-7064, 2008.

[140] E. Christiansen, M. E. Due-Hansen, and T. Ulven, "A rapid and efficient Sonogashira protocol and improved synthesis of free fatty acid 1 (FFA1) receptor agonists," Journal of Organic Chemistry, vol. 75, no. 4, pp. 1301-1304, 2010.

[141] S. B. Bharate, K. V. Nemmani, and R. A. Vishwakarma, "Progress in the discovery and development of small-molecule modulators of G-protein-coupled receptor 40 (GPR40/FFA1/ FFAR1): an emerging target for type 2 diabetes," Expert Opinion on Therapeutic Patents, vol. 19, pp. 237-264, 2009.

[142] S. Y. Lu, Y. J. Jiang, J. Lv, T. X. Wu, Q. S. Yu, and W. L. Zhu J, "Molecular docking and molecular dynamics simulation studies of GPR40 receptor-agonist interactions," Journal of Molecular Graphics and Modelling, vol. 28, no. 8, pp. 766-774, 2010.

[143] H. Koyama, D. J. Miller, J. K. Boueres et al., "(2R)-2-ethylchromane-2-carboxylic acids: discovery of novel PPAR $\alpha / \gamma$ dual agonists as antihyperglycemic and hypolipidemic agents," Journal of Medicinal Chemistry, vol. 47, no. 12, pp. 3255-3263, 2004.

[144] C. Parmenon, J. Guillard, D. H. Caignard et al., "4,4-dimethyl1,2,3,4-tetrahydroquinoline-based PPAR $\alpha / \gamma$ agonists. Part. II: synthesis and pharmacological evaluation of oxime and acidic head group structural variations," Bioorganic \& Medicinal Chemistry Letters, vol. 19, no. 10, pp. 2683-2687, 2009.

[145] C. Parmenon, J. Guillard, D. H. Caignard et al., "4,4-Dimethyl1,2,3,4-tetrahydroquinoline-based $\operatorname{PPAR} \alpha / \gamma$ agonists. Part I: synthesis and pharmacological evaluation," Bioorganic \& Medicinal Chemistry Letters, vol. 18, no. 5, pp. 1617-1622, 2008.

[146] M. Ohashi, I. Nakagome, J.-i. Kasuga et al., "Design, synthesis and in vitro evaluation of a series of $\alpha$-substituted phenylpropanoic acid PPAR $\gamma$ agonists to further investigate the stereochemistry-activity relationship," Bioorganic \& Medicinal Chemistry, vol. 20, no. 21, pp. 6375-6383, 2012.

[147] I. M. Kapetanovic, "Computer-aided drug discovery and development (CADDD): in silico-chemico-biological approach," Chemico-Biological Interactions, vol. 171, no. 2, pp. 165-176, 2008.

[148] C. Hansch, D. Hoekman, A. Leo, D. Weininger, and C. D. Selassie, "Chem-bioinformatics: comparative QSAR at the interface between chemistry and biology," Chemical Reviews, vol. 102, no. 3, pp. 783-812, 2002.

[149] C. Hansch, D. Hoekman, and H. Gao, "Comparative QSAR: toward a deeper understanding of chemicobiological interactions," Chemical Reviews, vol. 96, no. 3, pp. 1045-1075, 1996.
[150] S. P. Gupta, "QSAR studies on enzyme inhibitors," Chemical Reviews, vol. 87, no. 5, pp. 1183-1253, 1987.

[151] B. D. Silverman and D. E. Platt, "Comparative molecular moment analysis (coMMA): 3D-QSAR without molecular superposition," Journal of Medicinal Chemistry, vol. 39, no. 11, pp. 2129-2140, 1996.

[152] R. D. Cramer, D. E. Patterson, and J. D. Bunce, "Comparative molecular field analysis (CoMFA). 1. Effect of shape on binding of steroids to carrier proteins," Journal of the American Chemical Society, vol. 110, no. 18, pp. 5959-5967, 1988.

[153] G. Klebe, U. Abraham, and T. Mietzner, "Molecular similarity indices in a comparative analysis (CoMSIA) of drug molecules to correlate and predict their biological activity," Journal of Medicinal Chemistry, vol. 37, no. 24, pp. 4130-4146, 1994.

[154] H. Gohlke and G. Klebe, "Drugscore meets CoMFA: adaptation of fields for molecular comparison (AFMoC) or how to tailor knowledge-based pair-potentials to a particular protein," Journal of Medicinal Chemistry, vol. 45, no. 19, pp. 4153-4170, 2002.

[155] V. Lather, V. Kairys, and M. X. Fernandes, "Quantitative structure-activity relationship models with receptor-dependent descriptors for predicting peroxisome proliferator-activated receptor activities of thiazolidinedione and oxazolidinedione derivatives," Chemical Biology and Drug Design, vol. 73, no. 4, pp. 428-441, 2009.

[156] L. Rathi, S. K. Kashaw, A. Dixit, G. Pandey, and A. K. Saxena, "Pharmacophore identification and 3D-QSAR studies in $N$ (2-benzoyl phenyl)-L-tyrosines as PPAR $\gamma$ agonists," Bioorganic and Medicinal Chemistry, vol. 12, no. 1, pp. 63-69, 2004.

[157] P. J. Brown, T. A. Smith-Oliver, P. S. Charifson et al., "Identification of peroxisome proliferator-activated receptor ligands from a biased chemical library," Chemistry and Biology, vol. 4, no. 12, pp. 909-918, 1997.

[158] M. Scarsi, M. Podvinec, A. Roth et al., "Sulfonylureas and glinides exhibit peroxisome proliferator-activated receptor $\gamma$ activity: a combined virtual screening and biological assay approach," Molecular Pharmacology, vol. 71, no. 2, pp. 398-406, 2007.

[159] P. Markt, D. Schuster, J. Kirchmair, C. Laggner, and T. Langer, "Pharmacophore modeling and parallel screening for PPAR ligands," Journal of Computer-Aided Molecular Design, vol. 21, no. 10-11, pp. 575-590, 2007.

[160] C. Giaginis, S. Theocharis, and A. Tsantili-Kakoulidou, "A consideration of PPAR- $\gamma$ ligands with respect to lipophilicity: current trends and perspectives," Expert Opinion on Investigational Drugs, vol. 16, no. 4, pp. 413-417, 2007.

[161] N. K. Salam, T. H. Huang, B. P. Kota, M. S. Kim, Y. Li, and D. E. Hibbs, "Novel PPAR-gamma agonists identified from a natural product library: a virtual screening, induced-fit docking and biological assay study," Chemical Biology \& Drug Design, vol. 71, no. 1, pp. 57-70, 2008.

[162] Y. Tanrikulu, O. Rau, O. Schwarz et al., "Structure-based pharmacophore screening for natural-product-derived PPAR $\gamma$ agonists," ChemBioChem, vol. 10, no. 1, pp. 75-78, 2009.

[163] Y. Tanrikulu, M. Nietert, U. Scheffer et al., "Scaffold hopping by "fuzzy" pharmacophores and its application to RNA targets," ChemBioChem, vol. 8, no. 16, pp. 1932-1936, 2007.

[164] B. O. Al-Najjar, H. A. Wahab, T. S. Tengku, A. C. Shu-Chien, N. A. Ahmad, and M. O. Taha, "Discovery of new nanomolar peroxisome proliferator-activated receptor $\gamma$ activators via elaborate ligand-based modeling," European Journal of Medicinal Chemistry, vol. 46, no. 6, pp. 2513-2529, 2011. 
[165] D. Barnum, J. Greene, A. Smellie, and P. Sprague, "Identification of common functional configurations among molecules," Journal of Chemical Information and Computer Sciences, vol. 36, no. 3, pp. 563-571, 1996.

[166] S. Sundriyal, B. Viswanad, P. Ramarao, A. K. Chakraborti, and P. V. Bharatam, "New PPAR $\gamma$ ligands based on barbituric acid: virtual screening, synthesis and receptor binding studies," Bioorganic \& Medicinal Chemistry Letters, vol. 18, no. 18, pp. 4959-4962, 2008.

[167] H. Zheng, S. Li, L. Ma et al., "A novel agonist of PPAR- $\gamma$ based on barbituric acid alleviates the development of non-alcoholic fatty liver disease by regulating adipocytokine expression and preventing insulin resistance," European Journal of Pharmacology, vol. 659, no. 2-3, pp. 244-251, 2011.

[168] S. Sundriyal, B. Viswanad, E. Bharathy, P. Ramarao, A. K. Chakraborti, and P. V. Bharatam, "New PPAR $\gamma$ ligands based on 2-hydroxy-1,4-naphthoquinone: computer-aided design, synthesis, and receptor-binding studies," Bioorganic \& Medicinal Chemistry Letters, vol. 18, pp. 3192-3195, 2008.

[169] S. Sundriyal and P. V. Bharatam, "Important pharmacophoric features of pan PPAR agonists: common chemical feature analysis and virtual screening," European Journal of Medicinal Chemistry, vol. 44, no. 9, pp. 3488-3495, 2009.

[170] S. Sundriyal and P. V. Bharatam, 'Sum of activities' as dependent parameter: a new CoMFA-based approach for the design of pan PPAR agonists," European Journal of Medicinal Chemistry, vol. 44, no. 1, pp. 42-53, 2009.

[171] J. Choi, Y. Park, H. S. Lee, Y. Yang, and S. Yoon, "1,3-diphenyl$1 \mathrm{H}$-pyrazole derivatives as a new series of potent PPAR $\gamma$ partial agonists," Bioorganic and Medicinal Chemistry, vol. 18, no. 23, pp. 8315-8323, 2010.

[172] Z. L. Wei, P. A. Petukhov, F. Bizik et al., "Isoxazolyl-serine-based agonists of peroxisome proliferator-activated receptor: design, synthesis, and effects on cardiomyocyte differentiation," Journal of the American Chemical Society, vol. 126, no. 51, pp. 1671416715, 2004.

[173] T. Kaya, S. C. Mohr, D. J. Waxman, and S. Vajda, "Computational screening of phthalate monoesters for binding to PPAR $\gamma$," Chemical Research in Toxicology, vol. 19, no. 8, pp. 999-1009, 2006.

[174] V. G. Maltarollo and K. M. Honorio, "Molecular properties of fatty acids related to PPAR binding and metabolic diseases," Medicinal Chemistry Research, pp. 1-8, 2012.

[175] Y. Ma, S.-Q. Wang, W.-R. Xu, R.-L. Wang, and K.-C. Chou, "Design novel dual agonists for treating type-2 diabetes by targeting peroxisome proliferator-activated receptors with core hopping approach," PloS ONE, vol. 7, no. 6, Article ID e38546, 2012.

[176] L. Michalik, V. Zoete, G. Krey et al., "Combined simulation and mutagenesis analyses reveal the involvement of key residues for peroxisome proliferator-activated receptor $\alpha$ helix 12 dynamic behavior," Journal of Biological Chemistry, vol. 282, no. 13, pp. 9666-9677, 2007.

[177] J. H. Choi, A. S. Banks, J. L. Estall et al., "Anti-diabetic drugs inhibit obesity-linked phosphorylation of PPAR $\gamma 3$ by Cdk5," Nature, vol. 466, no. 7305, pp. 451-456, 2010.

[178] J. H. Choi, A. S. Banks, T. M. Kamenecka et al., "Antidiabetic actions of a non-agonist PPAR $\gamma$ ligand blocking Cdk5-mediated phosphorylation," Nature, vol. 477, pp. 477-481, 2011.

[179] J. Jyrkkarinne, J. Kablbeck, J. Pulkkinen et al., "Molecular dynamics simulations for human CAR inverse agonists," Journal of Chemical Information and Modeling, vol. 52, pp. 457-464, 2012.

[180] D. Genest, N. Garnier, A. Arrault, C. Marot, L. Morin-Allory, and M. Genest, "Ligand-escape pathways from the ligandbinding domain of PPAR $\gamma$ receptor as probed by molecular dynamics simulations," European Biophysics Journal, vol. 37, no. 4, pp. 369-379, 2008.

[181] V. Zoete, A. Grosdidier, and O. Michielin, "Peroxisome proliferator-activated receptor structures: ligand specificity, molecular switch and interactions with regulators," Biochimica et Biophysica Acta, vol. 1771, no. 8, pp. 915-925, 2007.

[182] G. Pochetti, N. Mitro, A. Lavecchia et al., "Structural insight into peroxisome proliferator-activated receptor $\gamma$ binding of two ureidofibrate-like enantiomers by molecular dynamics, cofactor interaction analysis, and site-directed mutagenesis," Journal of Medicinal Chemistry, vol. 53, no. 11, pp. 4354-4366, 2010.

[183] A. Rogue, C. Spire, M. Brun, N. Claude, and A. Guillouzo, "Gene expression changes induced by PPAR gamma agonists in animal and human liver," PPAR Research, vol. 2010, Article ID 325183, 16 pages, 2010.

[184] A. Rogue, M. P. Renaud, N. Claude, A. Guillouzo, and C. Spire, "Comparative gene expression profiles induced by PPAR $\gamma$ and PPAR $\alpha / \gamma$ agonists in rat hepatocytes," Toxicology and Applied Pharmacology, vol. 254, no. 1, pp. 18-31, 2011. 


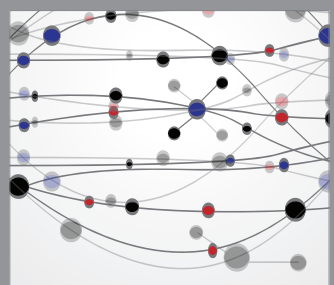

The Scientific World Journal
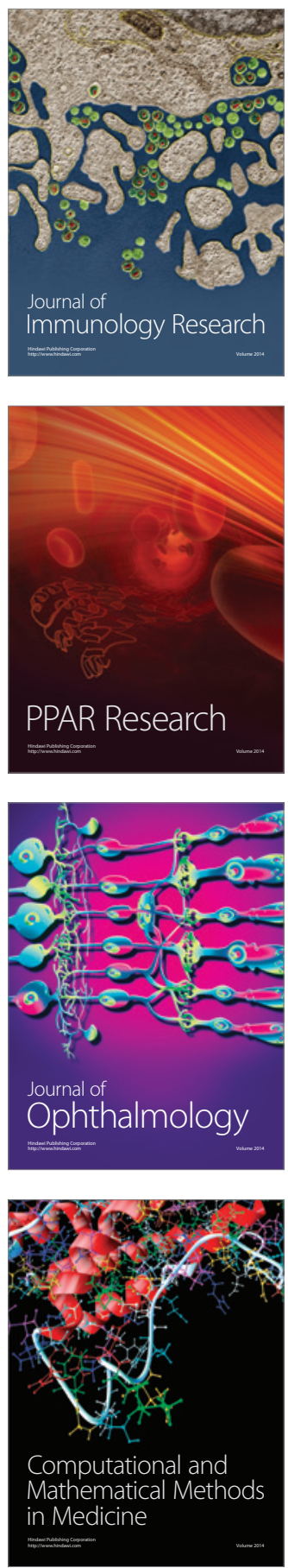

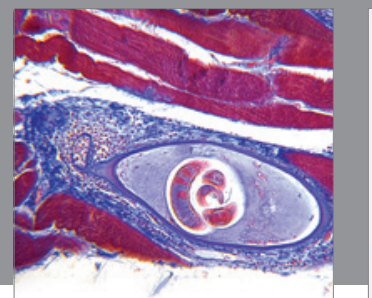

Gastroenterology

Research and Practice
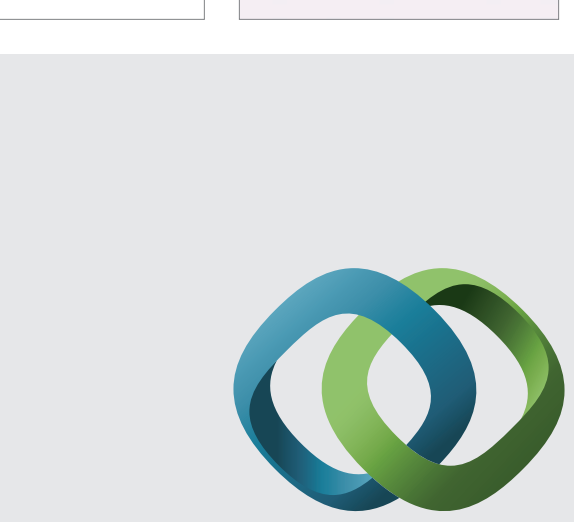

\section{Hindawi}

Submit your manuscripts at

http://www.hindawi.com
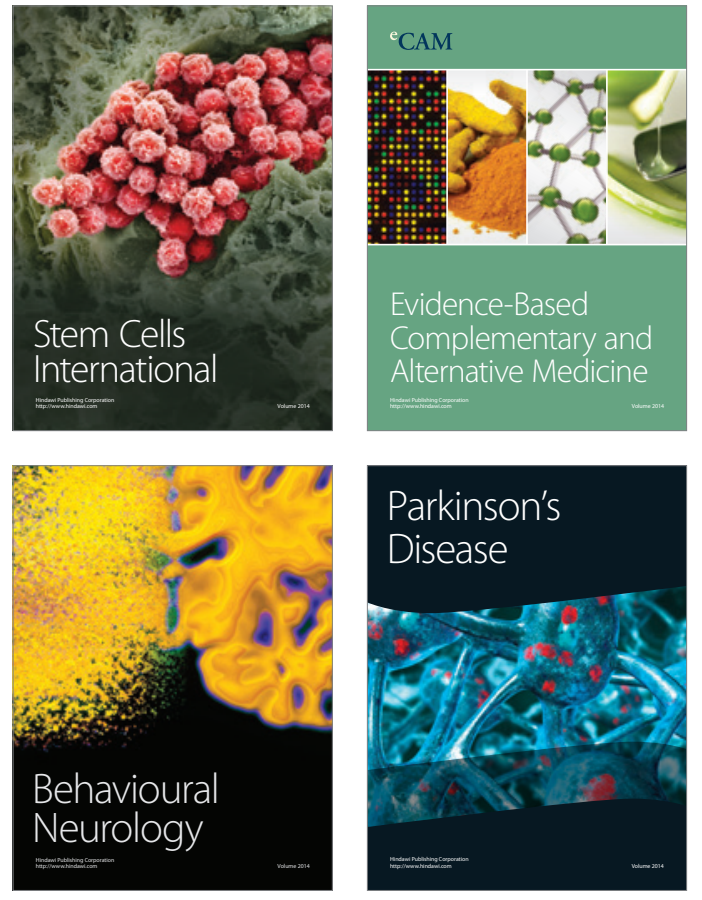
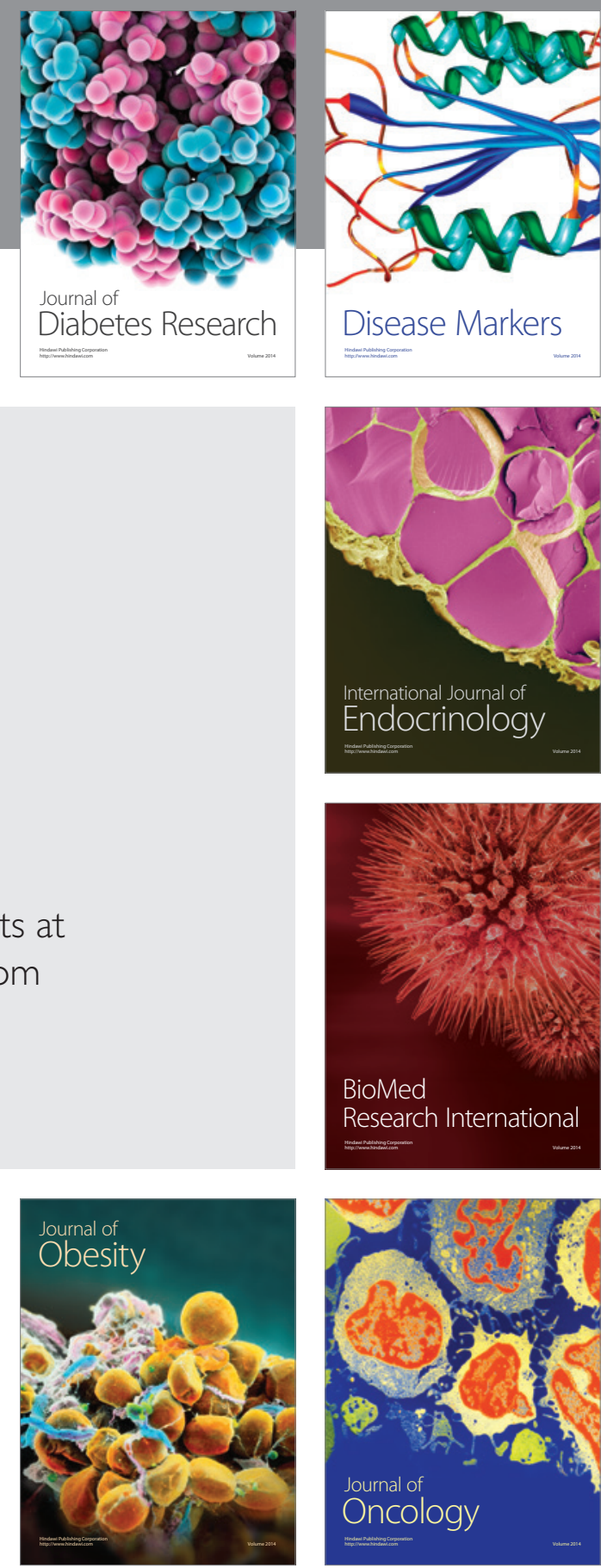

Disease Markers
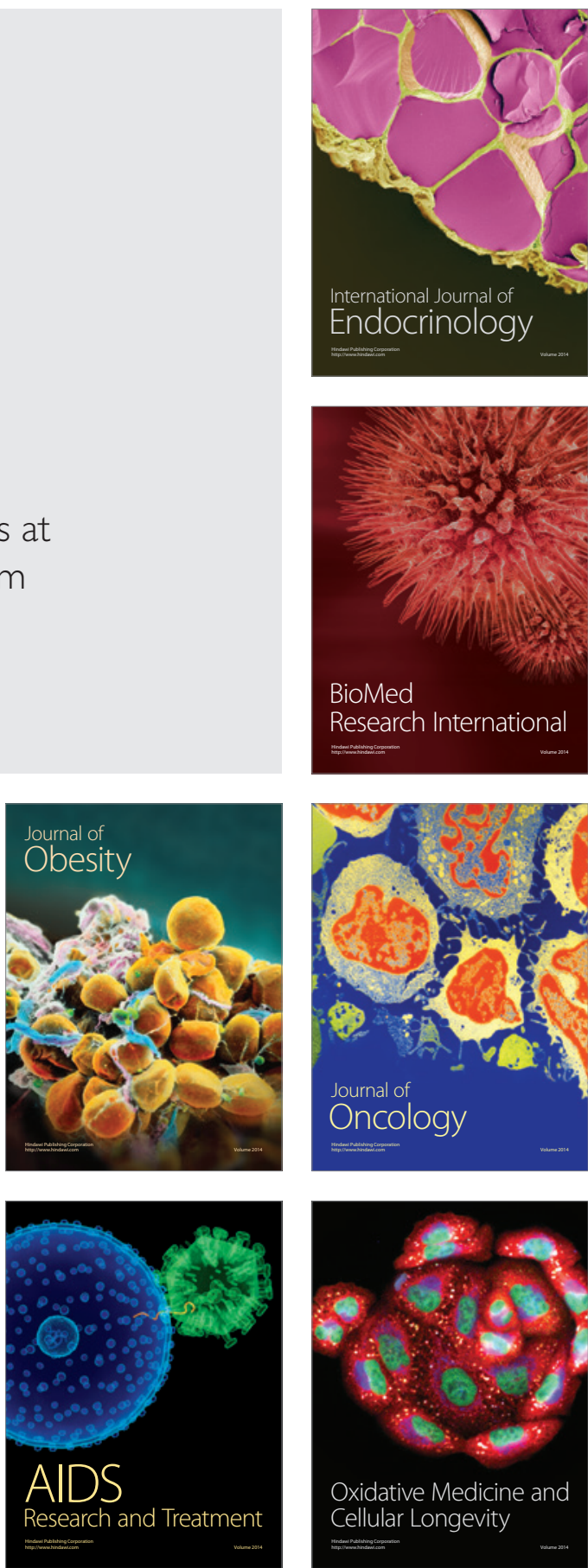